A Qualitative Exploration of the Views and Experiences of Family Court Magistrates Making Decisions in Care Proceedings involving Parents with Learning Disabilities

by

\title{
Laura Kollinsky
}

\begin{abstract}
Volume 1
Submitted for the degree of Doctor of Psychology

(Clinical Psychology)
\end{abstract}

\author{
Department of Psychology \\ Faculty of Arts and Human Sciences \\ University of Surrey
}

October 2010

(C) Laura Kollinsky 2010 
All rights reserved

INFORMATION TO ALL USERS

The quality of this reproduction is dependent upon the quality of the copy submitted.

In the unlikely event that the author did not send a complete manuscript and there are missing pages, these will be noted. Also, if material had to be removed, a note will indicate the deletion.

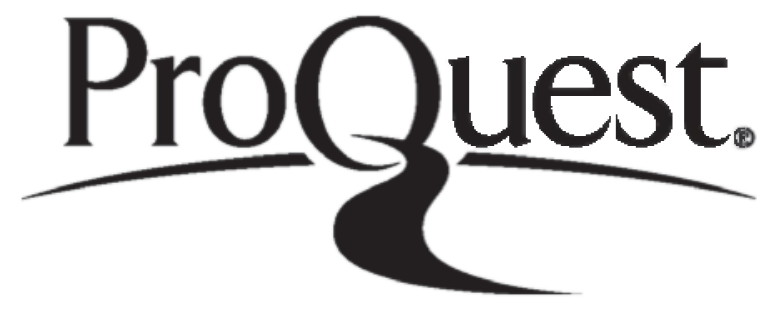

ProQuest 27610192

Published by ProQuest LLC (2019). Copyright of the Dissertation is held by the Author.

All rights reserved.

This work is protected against unauthorized copying under Title 17, United States Code Microform Edition (C) ProQuest LLC.

ProQuest LLC.

789 East Eisenhower Parkway

P.O. Box 1346

Ann Arbor, Ml 48106 - 1346 


\section{Contents}

\section{Academic Dossier}

Adult Mental Health Essay

5

What is the evidence base for formulation as a core clinical skill?

Professional Issues Essay

What are the differences and similarities in the process and content of supervision and consultation practices in clinical teams? How might we evaluate the effectiveness of supervision and consultation in our NHS work?

Problem Based Learning Reflective Account 1

The relationship to change

Problem Based Learning Reflective Account 2

Working with people in later life, their families and the

Professional network

Problem Based Learning Reflective Account 3

How do we know if IAPT is working?

Summary of Personal and Professional Learning Discussion

Group Process Account 1

Summary of Personal and Professional Learning Discussion

Group Process Account 2 


\section{Clinical Dossier}

Overview of three years' placement experience

Psycho-education and Cognitive Behavioural Therapy with a man

in his early 30 s with a diagnosis of schizophrenia and presenting with anxiety

Summary of Case Report 2 - Adult Mental Health

Cognitive Behavioural Therapy with a man in his early 20 s

presenting with depression

Summary of Case Report 3 - Child - Psychometric

Psychological assessment of an eight year old boy presenting with attention problems

Summary of Case Report 4-Older People

81

An integrative approach to working with a 68 year old woman

experiencing low mood; within a systemic framework

Summary of Oral Presentation of Clinical Activity - Learning Disabilities 83 Developing skills and a greater understanding of working collaboratively 
Research Dossier

Service Related Research Project including evidence of feedback

to the service

Promoting recovery and facilitating social inclusion: The views of staff members of adult mental health services in one locality

Abstract of Qualitative Research Project

'At the moment we're just sharing space not sharing the

experience': Investigating division in a shared learning environment

Major Research Project

A qualitative exploration of the views and experiences of family court magistrates making decisions in care proceedings involving parents with learning disabilities 


\section{'What is the evidence \\ base for formulation as \\ a core clinical skill?'}

\section{Adult Mental Health Essay \\ December 2007}

Year 1 


\section{Introduction}

I will set out to briefly outline how formulation developed as a core clinical skill, what it is and its function. I will then look at the evidence base for formulation as a core clinical skill. I will be focusing on the evidence which relates to issues of reliability of formulation and its usefulness. I will also consider the clients' view of the impact of formulation on therapy and what else would be helpful to look at when trying to answer the question of the usefulness of formulation i.e., the development of the therapeutic relationship and the resulting understanding of one's difficulties.

Whilst reviewing the evidence base for formulation as a core clinical skill, one could at first assume that the noted gaps in the evidence base (Bieling \& Kuyken, 2003) would lead one to question how the process of formulation has come to receive such a powerful status in the world of clinical psychology. I intend to show that although there are notable gaps in the research looking at the usefulness of formulation, there is a lot to learn from the research that can be applied in practice. I will also explain why I believe these gaps are apparent and the difficulties I see would be encountered when attempting to assess the usefulness of formulation.

As a first year trainee clinical psychologist it has become clear what a huge role formulation has in guiding therapy and developing interventions. Formulation has been stated as a key skill that clinical psychologists acquire through training and experience, and a skill which is considered as being unique to the profession. The Division of Clinical Psychology's (DCP) document The Core Purpose and Philosophy of the Profession (2001) states that 'the core skills of a clinical psychologist are: assessment, formulation, intervention and evaluation.' The skill of formulation is referred to as being unique to clinical psychologists due to the information which they draw on. It states that 'The ability to access, review, critically evaluate, analyse and synthesise psychological data and knowledge from a psychological perspective is one that is unique to psychologists, both pure and applied' (DCP, 2001, p.3). 
As an essential skill that I am aiming to develop I thought it would be an appropriate learning opportunity to explore why this is deemed to be a unique, core skill and whether or not there is evidence to support this claim.

\section{What is formulation and how did it develop?}

Formulation is defined by the DCP $(2001, \mathrm{p} .3)$ as 'the summation and integration of the knowledge that is acquired by the assessment process (which may involve a number of different procedures)'. It states that formulation draws on psychological theory and information available to produce a structure for 'describing a problem, how it developed and is being maintained'. The training of clinical psychologists is referred to highlighting that training in the link between theory and practice and the ability to draw on a variety of psychological models and theories means that a number of different hypotheses may be developed in the formulation. This is noted to be the foundation of intervention.

Sim et al., (2005) explain that definitions of formulation differ between practitioners of specific models of therapy and between those of different models, but that the formulation usually follows the specific theoretical approach while attempting to integrate different perspectives. Although various definitions of formulation have been proposed they are said to 'essentially cover the same scope (i.e. the descriptive, prescriptive and predictive aspects of the case)' (Sim et al., 2005, p.290).

When considering how the term formulation developed, Crellin (1998, p.18) draws attention to the appearance of the term formulation in clinical psychology texts in the 1950s when the profession was trying to develop a diagnostic role and become independent from psychiatry. Crellin's research into the history of psychology indicates that 'a major reason for the past and current emphasis on the technique of clinical formulation in clinical psychology training is that this skill formed the basis for the profession's distinctiveness and autonomy within the NHS, and ultimately came almost to define the profession' (Crellin, 1998, p.18).

Tarrier (2006) refers to an influential paper published by Kanfer and Saslow in 1965 which represented the need for a shift from psychiatric diagnosis to a 
psychological alternative of behavioural analysis. The main view represented in the paper was that psychiatric diagnosis was limited by issues of 'precision, consistency, reliability and validity' (Kanfer \& Saslow, 1965 cited in Tarrier, 2006). The authors argued that a reduction to a classification when individual's circumstances and conditions vary so much could help or hinder treatment. They proposed that information about the individual should be collected relating to various aspects of their life and behaviour and analysed in order to make treatment more appropriate. Kanfer and Saslow (1965) were noted to refer to this process as 'formulation' (Tarrier, 2006).

Formulation appears to have developed as it was able to incorporate many of the things that psychiatric diagnosis was accused of lacking such as links between aetiology, prognosis and treatment, and the inclusion of personal, social, cultural contexts and the clients viewpoint (Johnstone, 2006). These issues are particularly important when considering the difference and diversity of clients. As it is possible to formulate the same case from a number of different models, we must keep in mind that there may be a big difference in the way that people experience things. For example, Peters et al., (1999) discuss the influence of culture on psychosis arguing that Western definitions of psychosis do not necessarily apply to other cultures. It is therefore important to consider the context of people's situations and how they conceptualize their own problems. Formulation allows this to be done.

One important point that has been emphasised in our training is that a formulation should not be considered as truth, but rather a possible explanation that includes major components of an individual and their world.

\section{What is an evidence base?}

In simple terms an evidence base, is what the evidence suggests in relation to a given topic or question. In this case I have interpreted the question to be asking what the evidence shows in support of formulation as a meaningful and useful skill and that which contradicts this or discredits its importance. 
Two main categories of evidence have been referred to when looking at formulation which are 'top-down' and 'bottom-up' by Bieling and Kuyken (2003). The 'top-down' category involves questioning if the theories that formulations draw on are supported by empirical research. The 'bottom-up' category mainly involves investigating the outcome of formulations in order to consider its usefulness. This includes considering if the process of formulating is reliable and valid and if the formulation improves the outcome of therapy and reduces symptoms of psychological distress.

Research that has considered the views of clients on the impact of formulation and also evidence that relates to the indirect effect that formulation could have on therapy such as agreement between client and therapist on the 'correctness' of the formulation and how comprehensible the formulation can make one's difficulties also form part of the evidence base.

Literature searches have been noted to produce relatively little research into the area of the evidence base for formulation (Kuyken et al., 2005). The majority of research has involved psychodynamic models of formulation; however, little appears to be known about cognitive-behavioural formulations (Persons et al., 1995 ) or systemic formulations. I have chosen to focus on research into cognitive and cognitive behavioural formulation as I am using this approach in my first year adult mental health placement. I will therefore be looking at this area of research in order to enquire what the evidence suggests and why there has been such little research completed. I will not compare the findings with those done on other psychological models as the theories on which the formulations are based differ.

\section{What the evidence base suggests}

Top-down' evidence for formulation

As noted earlier 'top-down' evidence involves questioning if the theories that formulations draw on are supported by empirical research. This is a huge topic to cover as it would involve looking at the evidence base for the effectiveness of the application of the various psychological models and the evidence related to the theories upon which they are based (of which there are many). The effectiveness of Cognitive Therapy has been demonstrated in research. For example, Bieling 
and Kuyken (2003) refer to studies by Clark and Beck (1999), Rapee (1991) and Cottraux and Blackburn (2001) that suggest that cognitive therapies are efficacious and effective interventions for depression, anxiety and personality disorders.

Kuyken et al., (2005, p.1188) state that 'the outstanding challenge is to provide a scientific basis to the formulation methods that cognitive therapists use in understanding their clients' presenting problems and in planning interventions'. In relation to this I feel that the essay question would be more appropriately answered by considering the evidence that relates to the usefulness of formulation and its impact on therapy.

\section{'Bottom-up' evidence for formulation}

\section{Reliability}

The first type of evidence that I will look at in this category concerns whether therapists can reliably formulate, i.e., can they agree on aspects of formulation. As formulations aim to draw on appropriate theories to make inferences about an individual case, one could expect therapists drawing on the same theories to produce similar formulations (Kuyken, 2006). In the studies I have examined, therapists have been provided with the same information on individual cases gained from the assessment period via audio tapes and transcripts. They have been asked to identify descriptive elements of the individual case such as the presenting problems and inferential elements such as the core beliefs and dysfunctional thoughts. The therapists have received training in using the specific formulation techniques being examined in the studies.

Persons and Bertagnolli (1999) and Persons et al., (1995) have completed two studies which investigate the issue of reliability. Persons and Bertagnolli (1999) state that one major goal of therapy is usually to solve evident problems and alleviate symptoms of psychological distress. They also note that in cognitive behavioural therapy (CBT) this is done by changing cognitions and behaviour, and that 'therefore, reliable methods for assessing patients' overt problems and underlying schemas are needed'. In relation to this statement both studies looked at inter-rater reliability of cognitive-behavioural case formulations of 
depression, which included the ability to identify overt problems and assess core beliefs (schemas). Both studies found that therapists were good at identifying patient's overt problems. The findings from these studies suggest that therapists are less able to agree with one another when identifying client's core beliefs about themselves, others and the world. Inter-rater agreement was noted to be poor when single judges of core beliefs were considered. When ratings of core beliefs were averaged over five judges the inter-rater agreement was noted to be good.

One thing that I have noticed about the research that I have examined above is that the therapists who were examined were only given one day of training in the particular formulation approach that they were asked to apply. This may affect the reliability of the formulations due to lack of experience using the particular approach. Another possible explanation that has been suggested for the low reliability, when identifying core beliefs in cognitive or cognitive behaviour therapy, is that the theories that the formulations are based on may not be elaborative enough to facilitate this. Persons et al., $(1995$, p.30) note that 'although the cognitive theory specifies that distorted schema underlie depression and anxiety, it does not provide much detail about these schemas'. This is noted to be in contrast to psychodynamic approaches in which much more specific inferential aspects relating to psychological distress are outlined in theories which may account for the higher inter-rater reliability in research that has been done in this area (Persons et al., 1995).

A further limitation of the studies acknowledged by Persons et al., (1995) and Persons and Bertagnolli (1999) is that only limited sources of information were provided about each client that the formulations were based on. This was done by providing an audiotape of a session and a transcript. This meant that the participants missed out on things like visual cues and body language that may be useful when assessing someone and developing a formulation. I agree with Persons and Bertagnolli (1999) who explain that their method of testing would not allow their therapist participants to process the information in the same way as which it would be done in a therapy session, i.e., 'when material must be processed in the sequence in which it is received from the patient' (Persons \& 
Bertagnolli, 1999, p.281). The limitations of the study suggest that the findings may not be transferrable to clinical settings as the processes used do not reflect an accurate assessment period with a client. Other limitations that would affect generalizations to other populations include the fact that the studies only focussed on two cases and these were reported to be 'relatively straightforward' (Persons \& Bertagnolli, 1999, p.281).

A more recent study has been completed by Kuyken et al.,(2005) who assessed the ability of practitioners to produce reliable cognitive formulations across a much larger group of professionals $(n=115)$. A broad range of psychological practitioners were selected and they had various amounts of experience. This group was selected in order to improve the applicability of the research and 'maximize ecological validity' (Kuyken et al., 2005, p.1191). In contrast to the above research (e.g., Persons et al., 1995) Kuyken et al., (2005) found agreement between practitioners was good for not only the descriptive elements but also when identifying core beliefs and compensatory strategies. However, they found that reliability decreased when asked to make inferences for less prominent information such as dysfunctional assumptions. An important finding in this study and some of those examined above is that level of experience and training has been reported to have a positive effect on the reliability of formulations (e.g., Persons \& Bertagnolli, 1999).

The study by Kuyken et al., (2005) acknowledged the limitations of the studies by Persons and Bertagnolli (1999) and Persons et al., (1995) and appeared to take steps in their methodology to resolve them. The case of the client presented in the study was selected as it was viewed to be reasonably complex and had presented issues around formulation that could be considered as typical of clients seen in practice. A range of materials were presented to the participants that were considered by the authors to be essential for formulation. These were a detailed intake assessment, observation of the client during the assessment, standardised psychological assessments and a multi-axial diagnosis. The material presented also included video clips of techniques used by the therapist to identify the deeper cognitions of client (Kuyken et al., 2005). The findings from the study would suggest that the differences in methodology helped to make the 
formulations more reliable and the findings would also therefore be more transferrable to clinical practice. Although the methodology has been adapted to be more representative of clinical practice, this study still only involved looking at one client's case, so caution should be taken when generalising the findings.

As well as methodological issues, there appear to be difficulties with the formulation process that may impact on the reliability of formulations. Kuyken $(2006, p .16)$ states that there is a great amount of research suggesting that people rely on 'heuristic principles when making decisions under conditions of uncertainty'. Although there is little evidence looking at the direct affect of heuristics on formulation it has been suggested that they are likely to affect the formulation process (Kuyken et al., 2005). The heuristic categories that are noted to impact on decision-making include the representativeness bias, the availability bias and the anchoring and adjustment bias. The representativeness bias may mean seeing the presenting issues as representative of another set of issues. The availability bias may mean that evidence that comes to mind more easily is more likely to be used and regarded as most important. The anchoring and adjustment bias may mean that future judgements are likely to be based upon an idea in the initial hypothesis (Kuyken, 2006). If heuristics are influencing clinical psychologists when they are formulating then one could question if the process of formulating can be seen as reliable. I would therefore question the usefulness of studies that look at the reliability of formulations.

Another limitation of the research on reliability is that the formulations the therapists develop are compared to formulations that had been developed by experts (Persons \& Bertagnolli, 1999). There appears to be an assumption that there is a 'correct' or as the authors have described 'benchmark' formulation that should be compared to. The studies do not consider the clients view in relation to reliability. I think that it is important to consider the views of the clients on formulation, because if the formulations are not helpful to the client then the proposed intervention may be unsuccessful, leading to poor outcomes (Johnstone, 2006). There is also the potential for damage to the therapeutic relationship due to unhelpful formulations and this is particularly important to be aware of as Moloney (2006) points out that there are various 'non-specific' factors 
that may account for most of the benefits of psychological treatments; the quality of the therapeutic relationship is one of these.

Although reliability has been argued to be an important aspect of scientifically based cognitive formulations (Bieling \& Kuyken, 2003), we cannot assume that agreement about the content of formulations means that they are necessarily useful. It has been noted for example, that two formulations of the same case could have very little in common, making them unreliable, but they could enable and impact on successful interventions. This has been summarised by Kuyken et al., (2005, p.1191) who state that 'it may be more important for a formulation to be a coherent and justifiable account of a person's presenting problems than for it to be replicable in similar form by other cognitive therapists'. I will therefore now go onto explore issues of validity

\section{$\underline{\text { Validity }}$}

There does not appear to be any research that directly examines the validity of cognitive or cognitive behavioural formulation, i.e. if the key aspects of formulation meaningfully relate to the individual's presenting problems (Bieling \& Kuyken, 2003). Although there has not been any direct research in this area, if validity examines if the key aspects of formulation are meaningfully related to the presenting problems then one might assume that the quality of formulations and the outcome of therapy can reflect validity. I will therefore look at these areas of research.

\section{Quality of formulations}

The only piece of research that appears to have looked at the quality of cognitive formulations is that done by Kuyken et al., (2005) (methodology outlined above). They examined to what extent therapists' formulations could be 'good enough' to be applied to cognitive therapy in 'best practice' i.e. whether the elements within the formulation interact with the presenting problems in the hypothesised way and if the formulation is helpful in the intervention planning. The quality of the participants formulations were assessed using the Quality of Cognitive Case Formulation Rating Scale (Fothergill \& Kuyken, 2002, cited in Kuyken et al., 2005). The quality of formulations were scaled from 'good', to 'good enough', to 'poor' 
and 'very poor'. A 'good enough" formulation was noted to relate a large amount of information that was considered to be relevant to the case, such as childhood information, core beliefs and dysfunctional assumptions to the 'prototypical problematic situations' (Kuyken et al., 2005, p.1194). A 'very poor' formulation was noted to include a lot of irrelevant information and minimal amounts of integration between the elements.

The study found that under half of participants' formulations were reported to be at least 'good enough', however; the better quality formulations were produced by participants with a higher number of years of post-qualification experience and accreditation such as the British Association for Behavioural Cognitive Psychotherapies (BABCP). This would indicate evidence to support the view that formulation is a core clinical skill, as the quality of formulation improves as one moves from pre-qualified to qualified status and it is a skill that continues to develop with experience. These findings have implications for practice in that consulting with colleagues with greater experience and training may provide a valuable insight when developing formulations.

This research has noted that a good quality formulation is helpful in the intervention planning. One could assume that if formulation impacts on the intervention planning, then the outcome of therapy should also be considered.

\section{Outcome of therapy}

The desired outcome of the input from a clinical psychologist will vary between individuals from; facilitating change, to solutions to problems, to the provision of psychological knowledge through teaching (Generic Professional Practice Guidelines, 2007). Positive outcomes of therapy should not just be looking at improving symptoms and making people 'better'. Symptoms may not reduce or disappear but a greater understanding of one's difficulties can sometimes be the outcome that was realistically desired. I agree with Crellin (1998) who explains that the task that we engage in may sometimes be more about helping the individual to arrive at a meaningful explanation which makes sense of things that have happened over time rather than solving problems or removing symptoms. She notes that in this case it would be logical that the client would be satisfied 
with the formulation rather than the therapist. I have therefore chosen to examine the small amount of research that has been done on the client's perspective.

Chadwick et al., (2003) have completed one of the few pieces of research considering the clients views of the effect of formulation in CBT on the therapeutic relationship, beliefs and symptoms among people experiencing delusions (Johnstone, 2006). The research is done in relation to two empirical claims made about the impact of formulation i.e., that formulation enhances therapeutic alliance and eases distress (Chadwick et al., 2003). Hospital anxiety and depression scales (HADS) were used to measure symptoms in four sessions; two prior to formulation and in two sessions when the formulation was presented. They found that there was not a significant impact of case formulation on the reduction of symptoms of anxiety or depression. They state that 'these data (therefore) do not support the hypothesis that case formulation impacts beneficially on distress, operationalised as symptoms of anxiety or depression'.

Although there was not a significant reduction in symptoms, I do not think that this suggests that formulation does not impact on the outcome of therapy. The data collected measures the reduction of symptoms after four sessions of therapy in which only the assessment and formulation procedures have taken place. The role of formulation is to produce hypotheses that can be tested in therapy and guide intervention, not to directly reduce symptoms of psychological distress. The authors' note that formulation may have impacted on symptoms after a longer period of time, i.e., at a later stage in therapy but this was not examined. From what I have learnt and read about formulation I would not expect the formulation itself to have an immediate effect on symptoms of psychological distress but that it would lead to an appropriate intervention that could do so.

It is understandable that people would view a reduction in symptoms as a desired outcome of therapy; however, the recovery model suggests that clients want more than a reduction in symptoms. If people are to recover they want to retain or rebuild a new sense of self, meaning and purpose in life. Recovery has been described as: 
... a deeply, personal unique process of changing one's attitudes, values, feelings, goals, skills and/or roles. It is a way of living a satisfying, hopeful, and contributing life, even with limitations caused by illness. Recovery involves the new development of meaning and purpose in one's life as one grows beyond the catastrophic events of mental illness (Anthony, 1993 cited in Pepper \& Perkins, 2003, p.46).

With this in mind I think it is necessary to consider other areas that could indicate evidence in support of the usefulness of formulation, such as providing feelings of hope and a greater understanding. Semi-structured interviews completed by the clients in the research by Chadwick et al., (2003) looked at the relevance and helpfulness of formulation. Their findings highlighted a number of positive effects that formulation had for them. These included 'having an enhanced understanding of their own problems', seeing a way forward and feeling more optimistic about therapy. Positive feelings included feeling reassured and encouraged. Some clients explained that the formulation suggested that the therapist had understood them. For 9 out of the 11 clients interviewed they said that the formulation 'had increased hope and understanding' (Chadwick et al., 2003, p.679).

Chadwick et al., (2003) also found that there were negative effects of formulation which included a lack of realisation that their problems dated back to childhood and feeling that there were so many factors involved that they did not know how their patterns could be stopped. Negative feelings included feeling upset and worried. It should be noted that four out of the six individuals who reported negative effects of formulation, also reported positive aspects of formulation.

Chadwick et al., (2003) found that although ratings of the therapeutic alliance were positive, formulation did not positively affect the client's view of the therapeutic alliance. It did, however, positively affect the therapist's ratings of the therapeutic alliance. The authors suggest that this may account in part for some of the faith that therapists have in the effectiveness of formulation. They also note that further replications of their finding could suggest that formulation may 
lead to a 'point of unrecognized therapist-client distance for those clients with negative emotional reactions' (Chadwick et al., 2003, p.675). It is important to be aware of this in relation to the suggestions of the impact of the therapeutic relationship on the benefits of psychological interventions (Moloney, 2006).

I think that this aspect of research into the impact of formulation is something that should be looked at more in the future especially as the recovery model has demonstrated that reductions in symptoms are not the only thing that clients want to achieve from therapy.

\section{Conclusion}

This essay set out to examine the evidence base for formulation as a useful skill that impacts on the intervention and outcome of therapy. The small evidence base, overall, suggests that therapists are good at identifying client's presenting problems and that given adequate material therapists are also good at identifying more inferential aspects of formulations such as core beliefs. The evidence also suggests that experience and training affects the ability to identify the main elements of formulation and has a positive effect on quality. This evidence alone would not confirm that formulation is a useful clinical skill; however, I think the limitations of the research mean that the findings at this stage have little meaning.

The majority of research that has been done on the cognitive/cognitive behavioural model has used various types of formulation approach and so I do not think it is appropriate to compare findings across the studies in a meaningful way. Further studies need to be done using a consistent formulation approach în orciei to make the findings meaningful and helpful. Although the findings from the studies could be interpreted to undermine the usefulness of formulation, I have taken the position that as formulation is meant to be a starting point, that the ability to identify presenting problems may be good enough in terms of reliability.

The findings have emphasised the importance of continuing professional development throughout my career and the benefits that additional training and 
workshops can have on my practice. The benefits of supervision and consulting with one's colleagues have also been highlighted.

Although the research by Chadwick $e$ al., (2003) was limited due to the small number of participants and particular focus on psychosis and the findings were inconclusive, this research was of particular interest to me and I feel that this area needs to be developed. Formulation is designed to guide intervention and one would hope that the outcome was positive i.e. helpful to the client in the way that they desired. I have learnt that formulation can affect clients in different ways and that various feelings can be evoked. Although the evidence does not suggest that negative feelings result in negative outcomes of therapy, it is important to be aware that these feelings may arise when sharing a formulation with a client and to make sure that sufficient time is given to the process of receiving feedback from the client. Johnstone (2006) notes that collaboration can reduce the risk of negative responses from the client when sharing formulation and the feedback received can also be used in the 'ongoing process of reformulation' (Johnstone, 2006, p.213).

This experience has shown me how difficult the area of formulation is to examine. The diversity of the therapist appears to affect the process of formulation and it seems that it is difficult to account for this in research. I think it is the diversity of the views of the therapists that makes clinical psychology unique. A formulation is not intending to say that other things are not going on, and it is not saying that the hypothesis is true or fact. I do not think that research should be aiming to show that therapists can develop the same conclusions about a client as it is a starting point, and that is what it is meant to be' (Butler, 2006, p.11). I also think that it is difficult to isolate formulation from the other core clinical skills of assessment, intervention and evaluation (DCP, 2001) as formulation is an ongoing process. Although we are scientist practitioners we know that formulations are only hypotheses and that as we reflect in and upon action these hypotheses may change. 


\section{References}

Anthony, W. A. (1993). Recovery from mental illness: The guiding vision of the mental health service system in the 1990's. Psychosocial Rehabilitation Journal, 16(4), 11-23.

Bieling, P.J. \& Kuyken, W. (2003). Is Cognitive Case Formulation Science or Science Fiction? Clinical Psychology: science and practice, 10(1), 52-69

British Psychological Society (2007). Generic Professional Practice Guidelines. Leicester: U.K.

Butler, G. (2006). The value of formulation: A question for debate. Clinical Psychology Forum, 160, 9-12.

Clark, D.A. \& Beck, A.T. (with Alford, B.A). (1999). Scientific formulations of cognitive theory and therapy of depression. Chichester: Wiley.

Cottraux, J. \& Blackburn, I. (2001). Cognitive therapy. In W.J.Livesley (Ed)., Handbook of personality disorders: Theory, research, and treatment (pp.377-399). New York: Guilford Press.

Chadwick, P., Williams, C. \& Mackenzie, J. (2003) Impact of case formulation in cognitive behaviour therapy for psychosis. Behaviour Research and Therapy, 41, 671-680.

Crellin, C. (1998) Origins and social contexts of the term "formulation" in psychological case-reports. Clinical Psychology Forum, 112, 18-28.

Division of Clinical Psychology (2001). The Core Purpose and Philosophy of the Profession. Leicester: British Psychological Society.

Fothergill, C.D. \& Kuyken, W. (2002). The Quality of Cognitive Case Formulation Rating Scale. Unpublished manuscript. 
Johnstone, L (2006). Controversies and debates about formulation. In L. Johnstone \& R. Dallos. (Eds.) Formulation in Psychology and Psychotherapy: Making sense of peoples problems. (pp.208-235) Hove: Routledge.

Kanfer, F.H. \& Saslow, G. (1965). Behavioural analysis: An alternative to diagnostic classification. Archives of General Psychiatry, 12, 529-38.

Kuyken, W., Fothergill, C.D., Meyrem, M. \& Chadwick, P. (2005). The reliability and quality of cognitive case formulation. Behaviour, Research and Therapy, 43, 11871201.

Kuyken, W. (2006). Evidence-based case formulation: is the emperor clothed? In N. Tarrier (Eds.) Case Formulation in Cognitive Behaviour Therapy. The Treatment of Challenging and Complex Cases. (pp.12-35). Hove: Routledge.

Moloney, P. (2006). The trouble with psychotherapy. Clinical Psychology Forum, $162,29-33$.

Persons, J.B., Mooney, K.A. \& Padesky, C.A. (1995). Interrater reliability of cognitive behavioural case formulations. Cognitive Therapy and Research, 19, 2134.

Persons, J.B. \& Bertagnolli, A. (1999). Inter-rater reliability of cognitivebehavioural case formulation for depression: A replication. Cognitive Therapy and Research, 23, 271-284.

Pepper, J. \& Perkins, R. (2003). Social Inclusion and Recovery: A Model for Mental Health Practice. Edinburgh: Bailliere Tindall.

Peters, E., Day, S., McKenna, J. \& Orbach, G. (1999). Delusional ideation in religious and psychotic populations. British Journal of Clinical Psychology, 38, 8396. 
Rapee, R.M. (1991). Generalized anxiety disorder: A review of clinical features and theoretical concepts. Clinical Psychology Review, 11,419-440.

Sim, K., Gwee, K.P., \& Bateman, A. (1995). Case formulation in psychotherapy: Revitalizing its usefulness as a clinical tool. Academic Psychiatry, 29(3), 289-292.

Tarrier, N. (2006). An introduction to case formulation and its challenges. In N. Tarrier (Eds.) Case formulation in cognitive behaviour therapy. The treatment of challenging and complex cases. (pp.12-35). Hove: Routledge. 


\section{'What are the differences and}

similarities in the process and content of supervision and consultation practices in clinical teams? How might we evaluate the effectiveness of supervision and consultation in our NHS work?'

Professional Issues Essay

\section{January 2009}

Year 2 


\section{Introduction}

As a trainee clinical psychologist I have become increasingly aware of the proposed changes to the profession of clinical psychologists and the desire for us to move away from solely focusing on providing therapy. This was made particularly clear after reading the document by the British Psychological Society (BPS) (2007) entitled New Ways of Working for Applied Psychologists in Health and Social Care: Working psychologically in teams. Over the course of training it has become clear through personal and professional experience what a central role supervision has and will continue to have throughout my career as a clinical psychologist, not only as a supervisee, but also becoming a supervisor myself. Less emphasis during my overall training experience has been placed on consultation; however, it is clear from professional documentation that there is a need for us to incorporate this element of work into our practice. With consultancy and supervision deemed as core competencies within the profession (BPS, 2006) it seems crucial to develop a greater understanding of the practices and the issues in mind. Therefore, this essay was chosen with the hope that it will increase my understanding of supervision and consultation and how they can be applied effectively in my practice.

Clinical psychology has historically been viewed as an expensive resource in the NHS and with the growing demand for psychological therapies from service users and the Department of Health (DOH), the government have made attempts to provide cost effective alternatives including 'guided self-help' and 'stepped care models' (Lake, 2008a). Other professional groups are now doing the work that was traditionally done by clinical psychologists at a cheaper price and this is putting pressure on clinical psychologists to justify their value to services (/bid). Where specialist skills such as those of clinical psychologists are scarce i.e., where the psychologist is absent from the team, or there are long waiting lists for treatment, there is a need to develop alternative means of delivering services to a greater number of service users. This has been reflected by the $\mathrm{DOH}(1990)$, who has called for 'clinical psychology to put its knowledge and skills at the disposal of others' (Cheseldine et al., 2005). Supervision and consultation may be two practices which help us to do this and as Pilgrim (2008, p.12) acknowledges, 'it might be an important strategy for survival'. 
This essay will endeavour to provide the reader with an overview of what supervision and consultation are, providing definitions and information on the practices and how they developed. Some of the differences and similarities in the process and content involved in both supervision and consultation will be discussed. The essay will then discuss how we might be able to evaluate the effectiveness of supervision and consultation in our NHS work, including effectiveness which relates to the impact on the service user, the practice of the supervisee/consultee and supervisor/consultant and the impact on service delivery.

\section{What is supervision?}

Whilst extensively researching the literature regarding supervision within clinical psychology, I gradually became aware of the vast amount of information and literature that has been made available on the subject. Although I was aware of the differing formats of supervision i.e., one-to-one, group and peer supervision, 1 was not aware of the various models of supervision including those developed specifically for supervision and those based on psychotherapy processes e.g., the Integrated Developmental Model (IDM) (Stoltenberg \& Delworth, 1987). This model proposes that supervisees progress in terms of three structures: selfawareness, motivation and autonomy and that developmental levels may differ across particular types of professional activity (Stoltenberg \& Delworth, 1987).

I was also surprised to learn about the various definitions of supervision and how these have developed over time. The scope of this essay does not allow me to go into detail about the variety of supervision, so for the purpose of this essay when I refer to supervision, this is based on one-to-one supervision between two members of the clinical psychology profession. I will indicate when I am referring to the supervision of a qualified or trainee clinical psychologist. Another reason for choosing to refer to supervision in this way, is that the Division of Clinical Psychology (DCP) $(2003$, p.3) note that there is no one model or style of supervision that will apply to all clinical psychologists in all settings and at all times in their career' and that a 'supervisor must be a Chartered Clinical Psychologist'. 
Supervision started to develop in 1925 when psychoanalyst trainees typically engaged in their own therapy. During their therapeutic time, trainees would often discuss their own clients with their analyst and it was when their 'analysts became tired of hearing about their patients' patients" that the concept of supervision was born (Fleming \& Steen, 2004). Although supervision has always been a requirement for trainee clinical psychologists (/bid), it has only become an essential requirement for members of the BPS to receive continued supervision throughout their career, in the last few years (DCP, 2003). The latest policy on continued supervision states that 'All Clinical Psychologists, at all stages of their career and in all work contexts, will engage in regular supervision of their work' (DCP, 2006, p.3).

As mentioned above, there are a large number of definitions of supervision, however, for the purpose of this essay I will be referring to a definition of clinical supervision developed by Milne (2007, p.439):

The formal provision, by approved supervisors, of a relationship-based education and training that is work-focused and which manages, supports, develops and evaluates the work of colleague/s (precision).

Milne (2007) proposes that there are a number of methods used by supervisors, including corrective feedback in relation to the supervisee's performance, teaching, and also collaborative goal-setting. The evaluative component was reported to make supervision different from other activities such as mentoring and coaching. Milne $(2007$, p.439) also outlined a number of objectives of supervision and these included "normative" (e.g., quality control), "restorative" (e.g. encourage emotional processing) and "formative" (e.g. maintaining and facilitating supervisees' competence, capability and general effectiveness)'.

This definition links in with the Division of Clinical Psychology Professional Practice Guidelines which refer to the purposes of supervision as being 'to maintain the quality of performance, and to extend a psychologist's range of skills' (DCP, 1995, p.6). 


\section{What is consultation?}

As when researching the literature regarding supervision, I again became aware of the large quantity of information and literature regarding consultation, although there was a noticeable difference in the quantity relating to clinical psychology and consultation. In contrast to the awareness I had about the differing formats of supervision, this was not the case for consultation and as a result I went into the research process with little knowledge or understanding about the subject. This was also accentuated by my lack of experience of consultation. As with supervision there are differing formats of consultation, including with individuals, groups and organizations (Brunning \& Huffington, 1990) and there are also various models and approaches. With this in mind and having to recognise that the scope of this essay does not allow me to go into detail about the variety, this essay will only refer to formal consultation sessions available within a team, where the clinical psychologist is the consultant and the consultee is a health professional from their team. My reason for narrowing down how I will refer to consultation is to enable me to relate my discussions to debates about the changing roles of clinical psychologists within the NHS.

Consultation is a term that has been documented as far back as 1548 when it was referred to as 'the act of consulting or taking counsel together; deliberation or conference' (Oxford English Dictionary, 1971, p.885, cited in Golding et al., 2006). Occupational psychologists were reported to be the first to use this approach in the field of psychology (Argyris, 1970, cited in Golding et al., 2006), however, it appears that clinical psychologists adopted this approach much later. It was in 1989 that it was first suggested that clinical psychologists should reduce their therapeutic role and increase their role as consultants and this occurred when Derek Mowbray conducted a review in the profession (Pilgrim, 2008). He proposed that clinical psychologists possessed a unique skill which was the ability to construct unique formulations in context and that the employment of clinical psychologists was not cost-effective due to the predominance of therapy rather than consultancy and training of others (/bid).

Despite these calls for action in the profession, Pilgrim (2008) suggests that there has been no sign since the 1990 s of consultation being routinely incorporated into 
clinicians work or on the training courses for those coming into the profession in order to provide them with the necessary skills and understanding for consultancy. This appears to be reflected in the lack of presence of policies or guidelines on consultation within the BPS, although recent documentation has reported peer consultation as an important role for psychologists in 'achieving improved outcomes from teamworking' (BPS, 2007). Recent documentation has also highlighted the importance for psychologists to retain their unique identity and contribution to teams in which they can offer an 'authoritative and constructive counter-balance to the "medical model"' (Ibid, p.3). By retaining this position, psychologists can have a positive effect on service users as the focus of services can be altered towards a recovery approach which suggests that service users want more than just a reduction of symptoms (Repper \& Perkins, 2003).

In contrast to the vast number of definitions about supervision, fewer could be found about consultation. However, for the purpose of this essay I will refer to consultation as 'helping others to use psychological frameworks to develop their own skills and to think and reflect about specific clients' (Preedy, 2008, p.25) 'with the aim of delivering services more effectively' (Dent \& Golding, 2006).

The next part of this essay will go on to highlight the differences and similarities in the content and process of supervision and consultation.

The differences between the process and content of supervision and consultation

The key differences between the process and content of supervision and consultation will be based upon the definitions outlined earlier in this essay. It has been reported that supervision and consultation can be seen as distinct processes with a number of differences between them (Cheseldine et al., 2005). Milne (2007) reports that supervision should be provided by an approved supervisor, who has undertaken relevant training in supervision i.e. 'supervisors need to possess expertise in key areas of professional competence for clinical psychologists, and have had appropriate preparation for their role of supervisor' (DCP, 2005, p.10). Training in consultation is not an essential requirement for 
clinical psychologists and as such clinical psychologists do not need approval to undertake this practice.

Another difference is that in supervision, the supervisor is regarded as an expert in the same area as the supervisee, however, in consultation, the consultant gives advice from their own area of expertise and this may be different from that of the consultee (Cheseldine et al., 2005). The arrangements for supervision and consultation practices also vary. A requirement of clinical psychologists is that supervision occurs regularly and the minimum standard is set at one supervisory session per month (DCP, 2006). In contrast, there is no requirement that clinical psychologists provide consultation or receive consultation and ultimately the consultant is sought out when they are needed. This suggests that there are power differences between supervision and consultation, as supervisees are obliged to undertake supervision and cannot opt out (Milne, 2006), whereas consultees can opt in or out of consultation as they choose.

In supervision and consultation, one of the key differences relates to accountability and responsibility. In the supervision of a trainee clinical psychologist the supervisor becomes accountable for the work that takes place between the supervisee and the client (DCP, 2005). To some extent, the supervisor also becomes accountable for the work of qualified clinical psychologists that they are supervising, 'as once the information is shared, so is responsibility' (Ibid). This creates a power differential between the supervisor and the supervisee, as the supervisor is placed in a position of authority. If the supervisee is a trainee clinical psychologist there is the expectation that they will comply with the recommendations of their supervisor. Supervisory arrangements are made to meet regularly and this can assist in re-evaluating the progress of work that is being done and to ensure that the supervisee is being compliant.

In consultation sessions, advice is often given with suggestions for interventions and further actions. However, if the consultant does not have an organisational remit for the management of those seeking advice, then there is a limit to how directive the advice given can be (Cheseldine et al., 2005). This means that ultimately the consultee has the responsibility to make particular decisions. This 
places the consultant as a colleague rather than in a position of authority and as re-evaluation sessions are not always possible, consultation 'relies on professional integrity and interprofessional confidence' (Cheseldine et el., 2005, p.142).

Supervision also entails an evaluative component. The supervisors of trainee clinical psychologists are required to evaluate the trainee using specific tools that have been selected by the training programmes that allocate the trainee (Milne, 2006). Power dynamics may therefore vary to those in consultation, as the supervisor is placed in a position where they can pass or fail a trainee clinical psychologist. Supervisors are also required to provide corrective feedback (Milne, 2007) and this helps to ensure quality control so that clinicians are competent in the service that they are providing. An evaluative element can also be found in the supervision of qualified clinical psychologists as they are often supervised by their line manager who will have a responsibility for ensuring the quality of services that are provided (DCP, 2006). This evaluative element is not present in consultation and instead involves a relationship among equals (Gonsalvez \& McLeod, 2008). The lack of corrective feedback in consultation can influence the style of the sessions and at times make it more directive than in supervision. This can also affect the presence of anxiety in sessions, as in contrast to supervision, the consultee will not need to fear admitting doubts or mistakes.

Supervision is also defined as 'relationship-based' (Milne, 2007, p.439) and it is noted that the frequency and duration of supervision should allow for all aspects of work to be discussed and also for a beneficial relationship to develop (DCP, 2006). The requirement to meet regularly assists with the development of a relationship and allows the relationship to meet the needs of those involved over time. Without a policy in place for consultation, sessions are likely to occur on a less regular basis and as a result there is less opportunity for a relationship to develop between the consultant and consultee.

Another difference between supervision and consultation relates to the diversity of the professionals involved. Although differing perspectives are shared in supervision, both supervisor and supervisee are from the same profession. By facilitating sessions between clinical psychologists and other professional groups, 
this can broaden perspectives on the work that is being done and allow for reflection on more than one mode of working (Dent \& Golding, 2006). It should, however, be acknowledged, that the diversity of the professionals involved could also present problems in consultation i.e., in forming relationships between parties when there may be tension due to power differentials relating to where the clinical psychologists is positioned in the team, or where there is no shared understanding of presenting problems.

\section{The similarities between the process and content of supervision and consultation}

Although there are a number of differences between the process and content of consultation and supervision, they can also be seen as similar processes with a number of similarities between them. At a very general level, both practices involve the facilitation of personal adaptation through learning and promoting problem-solving (Milne, 2006) and this is achieved by adopting similar techniques in both practices such as the provision of a reflexive space and adopting an open and enquiring approach. Support for this comes from Kolb's (1984) experiential learning cycle which proposes that mere exposure to events will not guarantee learning from the experience. It is proposed that for change in thinking to occur, periods of action need to be processed during a specified period of reflection (Kolb, 1984). In both practices clinical psychologists are able to facilitate this period of reflection and help people to think about their work rather than just providing expert knowledge or the answers to questions. In these settings both supervisor and consultant are also able to model a certain approach to work (DCP, 2005) i.e., an open, enquiring, genuineness and this can aid learning and the development of skills for both the supervisee and the consultee. These approaches may also help to improve the quality of the relationships within supervision and consultation and have been mentioned as critical components in the supervisory relationship (/bid). This indicates how both practices can be regarded as means of continuing professional development as they facilitate the development of professional skills and service development (Cheseldine et al., 2005). 
Adopting a questioning approach can help to identify gaps in the consultee's/supervisee's knowledge about the service users that they are working with and these can then be used to identify problems that can be solved together and to develop ideas about interventions that could take place in future work. The space can also be used to explore different viewpoints, ideas and ways of understanding what is happening in the work and also feelings that people are experiencing due to the work. An emphasis around developing a greater understanding of service users' distress can lead to a shift in the nature and focus of work that is being done by professionals and can also lead to a cultural change (Lake, 2008b). Providing time to consider the impact of the work on the professional facilitates the supportive process of supervision and consultation and can contribute to personal development and the alleviation of anxieties.

Supervision and consultation both share a number of similar aims. These include to share knowledge and information, i.e., to educate, to improve competence and to develop skills that the consultee/supervisee can draw on in order to become more independent from the supervisor/consultant.

The process and content of supervision and consultation may both be based around particular psychological approaches including cognitive, psychodynamic and systemic and this will be determined by the clinical psychologist leading the sessions. Although the specific model may vary across practices, the application of a model can help to structure sessions, foster the development of a shared language between those involved and to make the process of reflecting on work clear and intuitive (Lake, 2008b). Also in both practices, although the psychological expertise is brought to the sessions by the person facilitating the sessions, how the expertise is used is a collaborative process (Dent \& Golding, 2006).

In both supervision and consultation sessions, written records are kept about the content of the session and clients that are discussed. Notes are also made on the actions that are suggested for the supervisee or consultee to complete (Cheseldine et al., 2005). Consent should also be gained from the client by the supervisee and the consultee before discussing their case in either practices 
(Cheseldine et al., 2005, DCP, 2005). The development of mutually agreed contracts about the process and content of sessions also occurs in both practices, although in supervision it is more likely to be a written contract which is reviewed regularly i.e., annually, whereas in consultation it is likely to be an agreed statement (Lake et al., 2008).

\section{How might we evaluate the effectiveness of supervision and consultation in our} NHS work?

Historically there has been the assumption that supervision is effective, however, research studies have produced mixed results and have been heavily criticised due to methodological issues (Ellis et al., 1996). One thing that may account for this is that supervision is an interpersonal exchange, highlighting the subjective and ever changing nature of this topic and the complexity that would be involved when attempting to research this area. As a result much of the literature includes personal views and anecdotal accounts of supervision. Even if we were to try to ignore the criticisms of the evidence that exists, a number of things make it difficult for the research to be relevant to supervision specifically within clinical psychology in the UK including; many findings are from the US and may not be relevant to the UK, research involving counsellors and psychotherapists may not be relevant to clinical psychology, much of the research involves trainees and may therefore not be generalisable to qualified professionals and would not relate to the developmental aspects of supervision over time (DCP, 2005).

Less literature can be found on the effectiveness of consultation, which may be related to the importance of this practice being raised at a later date to that of supervision i.e., only in the last few years (Pilgrim, 2008). However, the research that has been done has received less criticism in relation to methodological issues and this may be related to the lack of the relationship-based element which is not assumed or expected to develop or change over time. With this in mind, it is not the aim of this essay to report on the effectiveness of supervision and consultation per se, but rather to focus on how it can be evaluated in our NHS work. 
There is a need for us to evaluate the effectiveness of supervision and consultation as there is growing demand for evidence based practice in our NHS work and we are also expected to possess skills in these areas as they are regarded as core competencies of the profession (DCP, 2006). If we are to evaluate the effectiveness of supervision and consultation it is necessary to review this in relation to the aims and objectives of these practices. The DCP (2005) note that these can be broken down into components: 'best practice in relation to clients; best practice in relation to other professional and service delivery; best practice in relation to professional development; best practice in relation to personal development; best practice in relation to organisational objectives' (p.5).

Ideally it would be helpful to have large-scale funded projects to investigate differing aspects of supervision and consultation; however, we know that this is not usually an achievable or realistic option. We can however, apply our skills in research in smaller-scale research projects within the services that we work. Research is a crucial part of our training to be clinical psychologists and we are regularly reminded at the university and during placements, of the importance that the role of research can play in our work as reflective scientist-practitioners. As clinical psychologists receive training in research, this means that we are well placed to carry out research as part of our role. We are fortunate to have experienced firsthand, the value of research in services by completing a service related research project during the training course and can therefore promote the potential benefits to the services in which we go on to work e.g., through my own experience I was able to find out what professionals were doing well in a service that I worked in and then I provided positive feedback to them.

Both supervision and consultation share similar aims of increasing the competence of supervisee/consultee and improving service delivery. This would suggest that these practices could have a positive impact on service users, if the practices were effective. If we want to evaluate the effectiveness of supervision and consultation in relation to clients then it is important to include service users and relatives/carers in the evaluation process. User and carer participation in the design and delivery of services is also recommended in the National Institute for 
Clinical Excellence (NICE) guidelines (BPS, 2007). Although it would be difficult to evaluate if there is a direct link between supervision/consultation and service user outcomes, we can investigate other elements including satisfaction with services. We should try to ensure that feedback is gained from those using our services as this can help us to form an evidence base from which practitioners and commissioners can identify and address issues that are most important (BPS, 2007), which could then be managed through supervision and/or consultation. This can be done in a number of ways including through the use of complaints and satisfaction questionnaires. This would provide us with an insight into the effectiveness of supervision and consultation as they both aim to improve service delivery. Audits and service evaluations are also valuable in measuring the standard of services that are provided and allow the views and opinions of staff and service users to be incorporated into the research.

It may be more feasible to evaluate the effectiveness of consultation via these methods as it would be unethical for a clinical psychologist to work without receiving supervision, but there is no requirement for professionals to receive consultation. This would mean that measures could be developed to assess a relationship between the development of a consultation system within a team and service user outcomes. In order to evaluate supervision ethically, information could be gained by investigating if there are any links between service user outcomes and the hours spent on supervision.

Beinhart (2004) reported key features that promote effective relationships for peer consultation and supervision, with mutual trust and respect being at the core. The importance of establishing rapport, clarifying roles, exploring hopes and expectations and setting clear boundaries was also noted (BPS, 2007). It is important for us as practitioners to make theory practice links and this can be applied when evaluating the effectiveness of supervision and consultation. One way of doing this would be to incorporate into questionnaires items that will evaluate the views and experiences of those involved in supervision and consultation on the key features reported to be important by Beinhart (2004). 
Another way, in which we might evaluate the effectiveness of consultation and supervision in our NHS work, would be for all those involved to be evaluated. Although trainee clinical psychologists are evaluated in a number of areas relating to clinical competence, the supervisors themselves are less often evaluated. This is also true for consultants working in clinical teams. The literature suggests that there are instruments available to evaluate supervisors such as a checklist by Borders and Leddick (1987) which includes items such as 'helps me clarify my objectives in working with clients' (Hawkins \& Shohet, 2004). Alternatively structured evaluation questionnaires could be developed and used within a service to ask consultees and supervisees about their experiences of consultation or supervision. Ratings could be then be collated by an independent agency, in order to preserve anonymity, when several ratings on one supervisor or consultant have been provided. Although this is not standard practice, this has been deemed feasible (Gonsalvez \& McLeod, 2008) and is something that could be adopted relatively easily. Feedback could also be sought verbally in these practices.

There are also a number of ways that the effectiveness of supervision and consultation could be evaluated in relation to service delivery. One way of doing this could be to investigate if there are any effects of supervision/consultation on waiting lists or inappropriate referrals within teams to determine if the aim of quality control is being met across the practices. In research by Prior et al., (2003) they found that levels of competence increased as a result of consultation and that this then had a positive effect in terms of managing referral rates (Cheseldine et al., 2005). It has been suggested that supervision may reduce burnout and enhance well-functioning (Rupert \& Morgan, 2005, cited in Gonsalvez \& McLeod, 2008). If this is accurate then it may be worth investigating the levels of staff absence and stress within the NHS through the use of questionnaires or as part of professional reviews to determine how supported staff feel and if they thought that consultation/supervision played any part in this. 


\section{Personal reflections and Conclusion}

When deciding which essay to write I chose the one which I thought would be most relevant to my professional development. During this process I have been struck and challenged by the numerous issues involved with supervision and consultation and the complexity of these practices. This has also been reflected in the extent of the literature that can be found when researching these topics. As a result I have become aware that many more issues could have been discussed in this essay, but that the breadth of the question did not allow for this to be covered within the word count. I have endeavoured to highlight to the reader where the similarities and differences lie between the practices of supervision and consultation and how the effectiveness of these might be evaluated in our NHS work.

It is clear that a great deal of research has been conducted on the effectiveness of supervision and that studies are starting to appear in relation to consultation. However, debates continue about the methodologies that have been used and there does not seem to be an easy way to evaluate effectiveness. The fact remains that supervision and consultation are expensive practices to facilitate within the NHS and that research should continue in order to highlight their value and importance to service managers and organizations and to promote these as being skills that set clinical psychologists apart from solely being psychological therapists. It is essential that if we do evaluate the effectiveness of these practices that our findings are shared with all those with an interest in these practices. Despite the challenges of this essay, I have gained a greater understanding of the importance of supervision and consultation and the roles that these practices will play in my future career. 


\section{References}

Argyris, C. (1970). Intervention, theory and method. Massachusetts: AddisonWesley.

Beinhart, H. (2004). Models of supervision and the supervisory relationship and their evidence base. In I. Fleming \& L. Steen (Eds.) Supervision and clinical psychology. Theory, practice and perspectives. Hove: Brunner-Routledge

Borders, L.D. \& Leddick, G.R. (1987). Handbook of counselling supervision. Alexandria, VA: ACES.

British Psychological Society (2007). New ways of working for applied psychologists in health and social care: Working psychologically in teams. Leicester: Author.

British Psychological Society, Committee for scrutiny of individual clinical qualifications (2006). Core competencies - clinical psychology - a guide. Leicester: Author.

Brunning, H. \& Huffington, C. (1990). Jumping off the fence: Developing the consultancy model. Clinical Psychology Forum, 29, 31-33.

Cheseldine, S., Manders, D. \& McGowan, C. (2005). The role of consultation clinics in services for children and young people with learning disabilities and/or autism. Child and Adolescent Mental Health, 10 (3), 140-142.

Dent, H.R. \& Golding, K.S. (2006). Engaging the network: Consultation for looked after and adopted children. In K.S. Golding, H.R. Dent, R. Nissim and L. Stott (Eds.) Thinking psychologically about children who are looked after and adopted: Space for reflection (pp.164-194). Chicester: John Wiley \& Sons Ltd.

Department of Health (1990). Manpower planning advisory group. London: HMSO. 
Division of Clinical Psychology (2006). Continued supervision policy document. Leicester: British Psychological Society.

Division of Clinical Psychology (2005). Discussion paper: DCP policy on continued supervision (revised version). Leicester: British Psychological Society.

Division of Clinical Psychology (2003). Policy guidelines on supervision in the practice of clinical psychology. Leicester: British Psychological Society.

Division of Clinical Psychology (1995). Professional practice guidelines. Leicester: British Psychological Society.

Ellis, M., Ladany, N., Krengel, M. \& Schult, D. (1996). Clinical supervision research from 1981 to 1993: A methodological critique. Journal of Counselling Psychology, 43(1), 35-50.

Fleming, I., \& Steen, L. (2004). Supervision and clinical psychology. Theory, practice and perspectives. Hove: Brunner-Routledge.

Golding, K.S., Dent, H.R., Nissim, R. \& Stott, L. (2006). Thinking psychologically about children who are looked after and adopted: Space for reflection. Chicester: John Wiley \& Sons Ltd.

Gonsalvez, C.J. \& McLeod, H.J. (2008). Toward the science-informed practice of clinical supervision: The Australian context. Australian Psychologist, 43(2), 79-87.

Hawkins, P. \& Shohet, R. (2004). Supervision in the helping professions ( $\left.2^{\text {nd }} \mathrm{edn}\right)$. Berkshire: Open University Press.

Kolb, D.A. (1984). Experiential learning: Experience as the source of learning and development. New Jersey: Prentice-Hall.

Lake, N. (2008a). Developing skills in consultation 1: The current context. Clinical Psychology Forum, 186, 13-17. 
Lake, N. (2008b). Developing skills in consultation 2: A team formulation approach. Clinical Psychology Forum, 186, 18-24.

Lake, N., Solts, B., \& Preedy, K. (2008). Developing skills in consultation 4: Supporting the development of consultation skills - a trainer's and a manager's perspective. Clinical Psychology Forum, 186, 29-33.

Milne, D. (2006). Developing clinical supervision research through reasoned analogies with therapy. Clinical Psychology and Psychotherapy, 13, 215-222.

Milne, D. (2007). An empirical definition of clinical supervision. British Journal of Clinical Psychology, 46, 437-447.

Oxford English Dictionary (1971) Compact Edition.

Pilgrim, D. (2008). Developing skills in consultation: Editorial. Clinical Psychology Forum, 186, 11-12.

Prior, H., Stirling, H., Shepherd, K., \& Stirrat, J. (2003). Advantages of a staged consultation supervisory model for health visitors, from child clinical psychology. Clinical Psychology, 26, 32-35.

Preedy, K. (2008). Developing skills in consultation 3: Personal reflections on consultation as a newly qualified psychologist. Clinical Psychology Forum, 186, 2528.

Repper, J. \& Perkins, R. (2003). Social inclusion and recovery: A model for mental health practice. Edinburgh, Bailliere Tindall.

Rupert, P.A., \& Morgan, D.J. (2005). Work setting and burnout among professional psychologists. Professional Psychology: Research and Practice, 36, 544-550. 
Stoltenberg, C.D., \& Delworth, U. (1987). Supervising counselors and therapists: A developmental approach. San Francisco: Jossey-Bass. 


\title{
'The relationship to change'
}

\author{
Problem based learning
}

reflective account 1

March 2008

Year 1 


\section{The original 'Problem'}

A problem based learning ( $\mathrm{PBL}$ ) task was introduced to us on the first day of the course. We were given a title 'The relationship to change' and told to prepare a presentation in our groups to present in six weeks time to the other case discussion groups (CDG) and members of staff from the course team. I was in a group with 6 other trainee clinical psychologists from the cohort and a group facilitator who is a qualified clinical psychologist and university tutor. There was a male in the group which I hoped would bring a balanced opinion to discussions with the five other females. The group also consisted of the oldest and youngest member of the cohort. I was aware of the variety of experiences that people may have gained before coming onto the course and being reminded of the varying ages of my colleagues helped me to remain appreciative of the different perspectives they could bring to the group experience. I was also aware of the similarities between me and some of the female members of the group such as age, class and ethnicity, but I was also mindful not to make assumptions about them. This awareness of diversity has made me more mindful when working with service users, colleagues and carers.

\section{The group process and implications for practice}

When the first group meeting took place I remember feeling a mixture of emotions including excitement, anxiety and relief that I had survived the first day. I had made an agreement with myself to speak up in group settings as this is something that $\mathrm{I}$ had regretted not doing enough in my undergraduate degree. I was aware of feeling nervous about this as the members of my group presented as being confident. I was soon put at ease however to hear that other members were experiencing similar feelings and it was a nice opportunity to share this in a space that did not seem as daunting as in front of the whole cohort. This space was made safe for me as ground rules such as listening and respecting each other were established quite naturally. This first session seemed to reflect Tuckman's (1965) initial stage of 'forming' in which group members may be polite when getting to know each other.

I found the task of the PBL daunting and confusing which I think was due to the lack of guidance from the facilitator. I assumed that the facilitator was not doing 
their job properly and I felt disappointed as I had high expectations about the level of guidance we would be receiving. However, after reading the information on PBL exercises I felt able to appreciate the reasons behind this i.e., that the problem case would produce 'triggers' which we could use to define our own learning objectives and increase our knowledge and understanding (Wood, 2003). I was impressed by the quick organisation of the group in the first session in which we assigned the roles of scribe and chair facilitating the involvement of all group members in the sessions that were to follow. I was reluctant to put myself forward as the chair as I was concerned that I did not have the skills to do this, however, I realised that I could learn from the other group members and develop the skills through the experience. I therefore put myself forward at a later stage in the process where I hoped I would feel more confident. I was relieved to have a chair at an early stage in the process as it helped give some structure to the session and take away some of the responsibility that I was feeling to come up with useful ideas. As a facilitator of a mood management group I have become aware of the need to prepare sessions that are structured and include activities that will encourage members to demonstrate their individual skills and approaches to tasks. Learning from others is a benefit that I appreciated in the PBL setting and is one that members of the mood management group have also expressed. This is also something that I have incorporated in individual therapy to facilitate learning.

We set ourselves the task of researching models of change for homework. I was motivated to engage in my own private study, however, this seemed to create an 'information overload' as I was unsure how much study to do and what information would be relevant and useful. This has been reported as a disadvantage of PBL exercises (Wood, 2003); however, it taught me the importance of being clear about what your own expectations are and what others are expecting of you. This lesson has been particularly useful in my clinical practice when completing work for my supervisors and setting homework for service users.

My anxiety about the homework fluctuated leading up to the next group meeting. The facilitator had suggested that we 'check-in' on how each member was feeling 
about things and knowing that this would be part of the process came as a great relief as it felt like a way to encourage me to share my anxieties. I was relieved to hear that other members had similar experiences related to the private study and even more relieved that some had not done much at all as I had felt the need to demonstrate my commitment to the group and to reflect my desire to be a good trainee clinical psychologist. It was helpful to have learnt this lesson as a group early on as with hindsight it helped to make our homework tasks much more productive and relevant to the PBL exercise.

Our group experienced a change in session five when planning the content of the presentation. Some members of the group appeared to have taken on the role of organising other members. This is not something I disliked at first as it was somewhat an easy option to sit back and let others take control, however, during this session 1 found it hard to cope with. They were giving inconsistent direction to the group members. This left me feeling confused and picked upon when I found it hard to grasp what they were expecting of me. Due to my perceived inability to understand what they were asking me to do I felt vulnerable and isolated. With the support of the facilitator I was able to express how I was feeling about these inconsistencies and although it appeared to resolve things at the time it appeared to form a split in the group meaning that two smaller groups developed. I felt responsible for this and shared my thoughts with the smaller group that I had seemed to become a part of. We discussed how to deal with this problem and decided it was important to raise it in the next group session. We were able to resolve this problem by discussing it in the next group session. This experience of conflict within the group seemed to reflect Tuckman's (1965) 'storming' stage of group development in which members know each other well enough to start working through disagreements about goals and practices.

I learnt a great deal from this session and I am able to see that I try to give clear and concise messages when working with service users. I also take steps to facilitate feedback at the end of each session in order to focus on aspects that were helpful or unhelpful. I have learnt the importance of adapting the information I provide to suit the individual's needs. 


\section{The presentation}

We decided to structure our presentation around our relationship to change as a group throughout the PBL exercise and how this was developing each week in the build up to the presentation. The transition theories (Adams et al., 1976) appealed to the group as the stages featured in the cycle seemed to reflect not only how we were feeling as members of a group, but also in our personal journeys in becoming trainee clinical psychologists. It's applicability to other settings also seemed appealing as it allowed us to look back at our reactions to previous life events and consider how this could be mapped onto service user's experiences in a clinical setting. I was personally quite excited to discover this model as at the time I had moved into the uncertainty phase (see Figure 1) where I was losing confidence and was relieved that I would hopefully move into a period of recovery and discover new confidence.

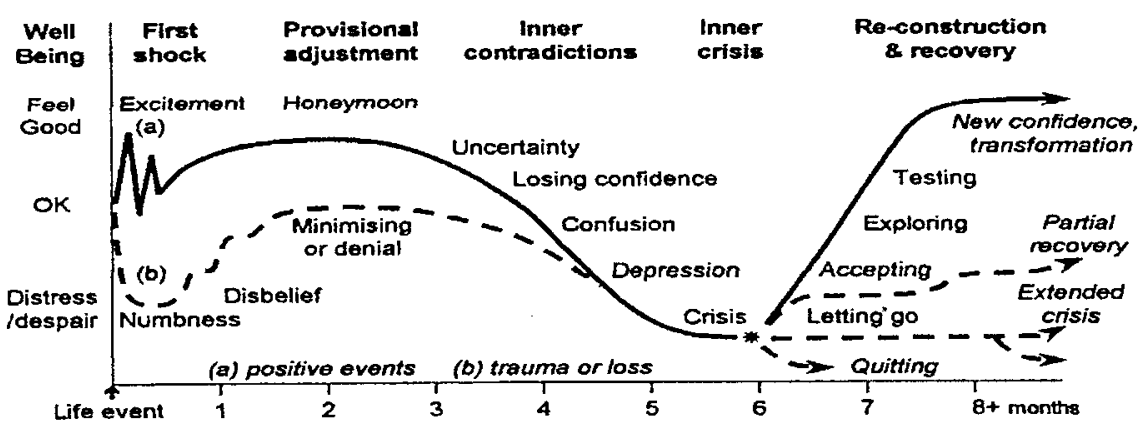

Figure 1: Phases \& features of the Transition Cycle, adapted from Adams et al., 1976

I have been aware in my clinical practice that for some service users introducing theory to help understand their difficulties has been reassuring and validating. This has also been noticeable in a group setting in which members felt relieved to learn that they were experiencing relatively common responses to life events. I am also aware that for some the use of theory can be daunting and confusing and effective communication is necessary to determine the impact.

Lavender (2003) identifies 'four processes in reflective practice: reflection in action, reflection on action, reflection about impact on others and reflection about self (awareness and development)'. I think a main strength of reflecting each week on the changes that were taking place within the group was that we 
were able to incorporate the above aspects of reflecting into the group process. I think that by reflecting regularly throughout the process we were able to emphasize what was making our group work successfully and overcome any difficulties that were highlighted. I have had similar experiences when reflecting on my work with service users. A weakness of this approach was that planning the content of the presentation was left until late on in the process, which added to an already stressful and anxiety provoking situation.

My initial reaction after our presentation was one of relief which was quickly followed by disappointment. I believe our presentation had met our objectives and was interesting. I was aware that I become anxious when presenting and made efforts to try to overcome this, such as practicing in advance and preparing cue cards. However, the feedback said 'some presenters had good eye contact and others did not engage with the audience'. I felt that I was not able to engage well with the audience due to the anxiety and thought that I had let the other members of my group down. With hindsight I am able to look at the feedback with a more open mind and acknowledge that this was the only area which 'required revision'. I have realised how easy it is to focus on the negatives and dismiss the positives, but also how constructive feedback can be as it has made me aware of some of my learning needs, which I now feel ready to accept. Reflecting back on the presentation I am pleased to think that I have made progress and taken steps to arrange events in which I have practiced public speaking to increase my confidence and decrease my anxiety. I think that this experience has made me more aware of the challenges that service users may face when they start psychological work. I hope that these lessons have made me more empathic as a trainee clinical psychologist, especially as this has been noted as an important characteristic in the development of a good therapeutic alliance (Ackerman \& Hilsenroth, 2001).

\section{Summary}

Reflecting back on the PBL task has made me more aware of my personal and professional development and how the lessons I learnt have transferred into my practice. The process has made me more mindful of the impact that reflection can have in various aspects of my life and encouraged me to engage with it in a 
more natural way. I have learnt that I need to be aware of how frustrating 'not knowing' can be and instead embrace the opportunity to understand new ideas and concepts, no matter how abstract they may be. 


\section{References}

Ackerman, S. \& Hilsenroth, M. (2001). A Review of Therapist Characteristics and Techniques Negatively Impacting the Therapeutic Alliance. Psychotherapy, 38, 171-185.

Adams, J.D., Hayes, J. \& Hopson, B. (Eds). Transition: Understanding \& managing personal change. Martin Robertson: London

Lavender, T. (2003). Redressing the balance: the place, history and the future of reflective practice in clinical training. Clinical Psychology, 27, 11-15.

Tuckman, B.W. (1965). Developmental sequence in small groups. Psychological Bulletin. 63(6), 384-399.

Wood, D.F. (2003). ABC of learning and teaching in medicine: Problem based learning. Clinical Review. British Medical Journal, 326, 328-330. 


\title{
'Working with people in later
}

\section{life, their families and the}

\author{
professional network'
}

\section{Problem based learning \\ reflective account 2}

March 2009

Year 2 


\section{The problem based learning exercise}

A problem based learning ( $\mathrm{PBL}$ ) exercise was introduced to us during a session at university with colleagues from the third year of the training course. We were given information about a 69 year old man, Mr Nikolas, who had been referred to the psychology department for assessment of his short term memory problems, and his needs for care. This included information on the man's family and history and details about his presenting problems and current situation. The exercise presented us with three questions; 'what is the problem?', 'who has the problem?' and 'what might happen?' We were told to work together in groups to develop a presentation that would be given to half of the other groups involved in the exercise six weeks after our first meeting. The groups were allocated by the course team and included members of both year groups.

The group comprised of me and three other members of my Personal and Professional Learning Discussion Groups (PPG); one male and two females, and three colleagues from the third year of the training course; one male and two females. The group seemed quite balanced in relation to gender, age and the experience that people had in working with people in later life. I was aware that this was in contrast to the various groups that I had worked in in the past during the training course which had often included an all female group of people of a similar age to me. I was also aware that our group was not ethnically diverse las we were all white British) and as a result I made efforts to try to consider and incorporate other perspectives into our discussions. Despite this, I was hopeful that working with a more diverse group would be a valuable learning opportunity for my personal and professional development. Another difference to the previous PBL exercise was that we were not allocated a facilitator for the exercise and instead we were required to work independently.

\section{The group process}

We seemed to come together as a group quickly during our first meeting and this was displayed by the apparent ease in which people shared their ideas for the presentation and thoughts about the exercise. However, during future group meetings I became aware of how one member of the group was more dominant than others. Although in the past I have welcomed having a leader in groups I 
realised during this exercise that not all leaders may be good leaders. I quickly became irritated by this group member's tendency to take over and how this contributed to quieter voices being squashed or ignored. My irritation was heightened by the group member's other tendency to delegate work and roles to members of the group and then not meet their own requirements; failing to do the work that they had been set and not turning up to some of the group meetings. This experience has helped me to recognise the powerful role that leaders can have especially in relation to the dynamics that can form in a group and the importance of paying attention to both process and content when working with colleagues and service users. I discovered that I was not the only one to be annoyed by this group member as a colleague from my PPG shared similar feelings with me in a discussion outside of our group meetings. We talked about how we could manage this situation and as a result we made a more conscious effort to draw attention to some of the quieter voices in our group and tried to be persistent in getting our own voices heard. Despite this challenge, we continued to work productively throughout the process and as a group we created opportunities for all voices to be incorporated into group meetings by allocating work and roles evenly between all group members.

During the group meetings for the exercise and the period of reflection since the presentation, I noticed that there was a change in the role that I adopted in comparison to the PBL exercise in the first year of the training course. I was aware that I did not want to 'opt-out' of speaking in our group meetings and that I was more keen than usual to share my ideas with the group. On reflection there may be a number of reasons that may account for this change. The process of the PBL exercise was familiar on this occasion and this familiarity eased my anxieties about not knowing what was expected of me. My confidence in my abilities and myself has also developed since the first PBL exercise and this has become especially noticeable in relation to my tendency to compare myself to my colleagues. I have become aware through this process that I worry much less about not being good enough to be a trainee clinical psychologist and this has been supported by my experiences of success with academic work at university and positive feedback received from supervisors and service users on placements. 
Feedback has been highlighted as one of the most powerful influences on learning (Hattie \& Timperley, 2007).

\section{The presentation}

We decided to make 'age' the main focus of our presentation as during our discussions we became aware that it was the age of Mr Nikolas that was determining the type of assessment that we would offer him and the formulations that we had developed. We realised that if Mr Nikolas was 20 years younger, i.e., 49 years old, that we would not have considered administering a neuropsychological assessment until other problems had been assessed for; such as depression, as we were aware that people with a diagnosis of depression can frequently report memory problems (Hertel, 1994). We went on to develop two formulations based on the age of Mr Nikolas being 69 years old and 49 years old. This difference in age immediately altered our perspectives of Mr Nikolas from being a vulnerable old man who was likely to have dementia, to a man who had been affected by his divorce and was experiencing difficulties adjusting to life on his own. In turn this altered our perspectives on the role of a clinical psychologist in such situations and the possible interventions that could result i.e., neuropsychological assessment and subsequent recommendations versus psychological assessment and a therapeutic intervention. The formulation also differed according to age, as the formulation for the 69 year old Mr Nikolas focused on the problems lying with him as an individual, whereas the formulation for the 49 year old Mr Nikolas focused on the problems lying within the systems around him.

After spending time sharing our thoughts together as a group we decided to incorporate role plays into our presentation. I was pleased about this initially as I remembered feeling disappointed after the first year PBL exercise as we had taken a didactic approach to our presentation and this seemed to prevent us from engaging with our audience. I was hopeful that this approach would produce a more enjoyable presentation for the audience to watch and for me to be involved in. Feeling pleased about taking this approach was quite quickly replaced with anxiety at the realisation that I would be required to act in front of my colleagues and course team, which is something that I would have actively tried to avoid this 
time last year. I enjoyed participating in the role play in the presentation much more than I had expected to and I believe that this was due to experiencing less anxiety than on previous presentations that I have done. I think that exposure to presentations and case discussions over the course of my training experience has helped me learn to manage my anxieties and has provided me with the opportunity to encounter positive experiences of presenting, such as sharing my views and opinions with others and receiving constructive feedback from those I have presented to. I believe that this has been helped by the systems that have been put in place by the university in which feedback forms are given to individuals after their presentations at the university and feedback is also given from placement supervisors on placement paperwork. This experience has helped to strengthen my understanding of the importance of exposure to anxiety provoking situations in order to challenge beliefs and realise that one's negative predictions do not always come true, as is recommended in cognitive behavioural treatments for anxiety disorders (Leahy \& Holland, 2000).

During the questions section at the end of our presentation I was aware that my colleagues from the year above answered all the questions. Although at the time I recognised that my anxiety may hold me back in such a situation and encourage me to 'opt out' of answering questions, I was keen to try to face my fears and try something new. Unfortunately, my colleagues from the year above always started answering questions before I had time to formulate my response and as a result I did not feel able to contribute in this part of the process. Although this proved frustrating at the time, and admittedly there was more that I could have done to become part of this process, this experience helped me to recognise the need to provide people with the space to contribute their thoughts and opinions especially in a group setting and I was able to see how important the role of a facilitator could be in this process.

\section{Reflections on the exercise and implications for clinical work}

During my reflections on the $\mathrm{PBL}$ exercise and presentation I have become aware of a number of influences that the experience has had on me and my practice on placement. In relation to $\mathrm{my}$ current placement working with children and families, I have noticed a change in the level of importance that I now place on 
both the content and process of sessions with service users and their families/carers. I have realised that as a first year trainee clinical psychologist that I was often more concerned about the content of my sessions and at times paid less attention than may have been necessary to the process of sessions. I believe that this may have been affected by usually working alone with service users. This has been one of the major differences to my adult mental health placement and through regular sessions with children and their families I have learnt that it is essential to pay attention, not only to what is being said, but also to who is saying what and how things are being said. This exercise has also taught me about the importance of facilitating the space for quieter voices to be heard, particularly when the child may be young and not have the necessary skills or confidence to assert themselves.

This exercise will also have important implications for future placements, in particular my older adults' placement next year. This experience has developed my awareness of the many issues that may arise when working with this client group, including issues of risk, potential abuse and the challenges of adjusting to the ageing process and changes that occur in the systems around the individuals. I will be especially mindful of the impact that age may have on the perspectives I bring to working with individuals in later life and as a result I will take care not to make assumptions and to continue to develop thorough formulations.

I think that this exercise has been a very positive experience and it has taught me a lot about my personal and professional development. I valued working with colleagues from the year above and appreciated working with different and more experienced individuals (in terms of their training experience). It has also helped to reinforce to me the benefits of reflection i.e., that mere exposure to events does not guarantee learning, but that for a change in thinking to occur that action needs to be processed by a period of reflection (Kolb, 1984). 


\section{References}

Hattie, J. \& Timperley, H. (2007). The power of feedback. Review of Educational Research, 77 (1), 81-112.

Hertel, P. T. (1994). Depression and memory: Are impairments remedial through attentional control? Current Directions in Psychological Science, 3(6), 190-193.

Kolb, D. A. (1984). Experiential learning: Experience as the source of learning and development. New Jersey: Prentice Hall.

Leahy, R. L. \& Holland, S. J. (2000). Treatment plans and interventions for depression and anxiety disorders. New York: The Guildford Press. 


\title{
'How do we know if IAPT is
}

\author{
working?'
}

Problem based learning

reflective account 3

February 2010

Year 3 


\section{The problem based learning exercise}

A problem based learning ( $\mathrm{PBL}$ ) exercise was introduced to us with colleagues from the second year of the training course. We were given some information about the Improving Access to Psychological Therapies (IAPT) programme and asked to prepare a consultation report on how the effectiveness of IAPT can be assessed. This information included; the principle aims of IAPT, the benefits for people receiving services from the demonstration sites where it had been piloted and details of planned future funding and what this funding could allow. The exercise presented us with 'the problem': how do we know if IAPT is working? We were told to work together in groups to develop a presentation that would be given to half of the other groups involved in the exercise six weeks after our first meeting. The groups were allocated by the course team and included members of both year groups.

The group comprised of me and three other members of my Personal and Professional Learning Discussion Group (PPG): one male and two females, and three colleagues from the second year of the training course; three females. The group seemed quite balanced in relation to age and the knowledge that people had regarding IAPT, however, I was aware there was an imbalance regarding gender, which is something that I have been mindful of as a member of our PPG since starting the course, in which there are six females and one male. I was also aware that our group was not particularly ethnically diverse (as five of us were white British) and as a result I made efforts to try to consider and incorporate other perspectives into our discussions. I was hopeful that working with colleagues from the year below who I had not worked with before would be a valuable learning opportunity for my personal and professional development.

\section{The group process}

When our group gathered for the first time I noticed how enthusiastic the second year trainees appeared and $I$ appreciated this as in previous group tasks the beginning phases have often been the slowest and their enthusiasm seemed to provide our group with the energy to produce some good ideas for how we could structure the presentation. Despite this, I was aware that the enthusiasm was somewhat in contrast to how the group members from my year presented, which 
I believe was a reflection of the pressures that we were under at the time as many of us were going through ethics procedures for our major research projects (MRP) and we had just completed a demanding assignment. This contrast in levels of enthusiasm became most apparent when planning the work that we would need to do for the exercise outside of our meetings. Although we were all in agreement that there was a lot of literature to read on IAPT I noticed that as final year trainees we seemed keen to choose a focus or specific area for the presentation as a first step to ensure that when selecting literature to read and review that it would be relevant to the exercise and a sensible use of our time (especially when considering our workload around that time). I noticed that my drive to work efficiently contributed to me taking a more assertive role within this group and I found myself being more of a leader than I am used to. This was not something that I had done consciously or been aware of at the time and it was only after the first session, when my colleague from my PPG pointed out that I had been much more assertive than usual, that I recognised a change in my role. With this new role I helped to lead discussions as well as divide tasks between group members equally and keep us focused on our vision for the presentation. This was a change in my role that I welcomed as more recently on the course we have been learning about the importance of leadership skills as clinical psychologists and is something that has been emphasised in the New ways of working document; Organising, managing and leading psychological services (British Psychological Society (BPS), 2007). I believe the PBL experience has helped me to develop my leadership skills and that these will be transferrable to my clinical practice.

Selecting relevant reading material has also been something that I have realised the importance of more recently, especially on my older adults' placement as it is a new area to me and I am constantly being reminded of how much there is to learn due to the different issues that have arisen when working with this client group compared to others. This has meant that there have often been times when I have needed to do extra reading in preparation for clinical work and working within time pressures has been essential. I believe that these experiences are representative of the time pressures that I am likely to face when 
I am qualified and I do not have the study time to indulge in all the reading that I would like to. This is something that I will need to remain mindful of in the future.

During our initial meetings it became difficult for us to find times to meet as a group as colleagues from my year had different timetables to those in the year below. Although I recognised how common this problem can be when arranging meetings in groups; meeting together proved more difficult than expected. In order to work around this we decided to schedule in meetings where both year groups had a gap in the timetable and then meet with those who were available. Over the course of our group meetings I noticed how there was one member who was only present for one of our meetings throughout the whole PBL process. Although initially I remember thinking that this was an understandable experience when in a group, as it is difficult to plan around other people's plans and unexpected sicknesses etc; as time went on I felt quite frustrated with the absent group member and wondered if they were really prioritising the PBL exercise. I expressed my frustration within the group and realised that other people were feeling this way too. We realised that we were feeling held back as we were unable to get everyone's perspectives and that this was becoming stressful due to the deadline that we were working to. In order to cope with this frustration we agreed that it was important to delegate responsibilities to all group members, even if they were not present during meetings and this was possible through contact via emails. I also suggested that we take minutes during meetings which could be circulated to all group members to further inform communication between us and this appeared to be relatively successful and enabled us to include all group members even if they could not be physically present. Since this experience I have become more aware of the importance of communicating with those who are absent whether it be when running groups or sessions with clients and they are unable to attend or when working with colleagues in teams.

\section{The presentation}

During our initial group meeting each of us shared our views and experiences of the IAPT programme. Although very few of us had experience of working within an IAPT programme it became apparent that the majority of us had relatively negative views about IAPT and we appeared sceptical of its effectiveness. I 
noticed how during our discussion as a group we seemed keen to express our criticisms and as a result we lost focus on the exercise. A change in our approach took place when we heard from a member of the group who is doing her MRP about IAPT and had prior experience of working within an IAPT service. Up until this point I had assumed that the negative perspective of IAPT was somewhat unanimous within our group, however, our colleague was able to introduce a different perspective to our discussion and get us thinking in a more balanced way. When this happened it made me aware of my vulnerability to adopt a stereotypical view and make assumptions and reminded me of the importance of considering other perspectives and taking a more neutral and curious stance. This is something that I have also been paying attention to on my current placement, which I noticed most recently during a service development meeting. Here it was explained that the service was being encouraged to offer only one specific type of therapy to clients as a result of its 'impressive evidence base'. During this meeting I found myself trying to consider and introduce the perspectives of others' for whom this type of therapy may not be effective for or may not be their treatment of choice. The consultant psychologist praised me for my contributions and this helped me to realise the importance of being neutral and curious not only when working directly with clients but also when working at a service level. Our recent teachings in systemic week have also reinforced the importance of adopting a neutral position as 'problems are believed to arise when the therapist loses neutrality' (Hayes, 1991, p.35).

As a group we reflected on the different perspectives of IAPT that had arisen out of our discussions and decided to try to represent the various individuals who may be involved with IAPT and how we would know if it was working; as effectiveness could mean different things to each of them. We did this by allocating roles within our group (including commissioners, service users, psychologists and GPs) and then reviewing literature evaluating the demonstration sites and IAPT pathfinder sites whilst trying to take on the perspective of the roles that we had been allocated. We approached the presentation by creating two role plays about setting up an IAPT service; with the first role play focusing on the ways IAPT currently evaluates its effectiveness and the second role play summarising the strengths and weaknesses of these evaluations and some ideas for possible 
improvements in terms of evaluation of effectiveness. Despite the difficulties we faced coming together as a group, I enjoyed both planning and carrying out the presentation. Although the scripted role play may have made it difficult for us to engage fully with each other and the audience, it seemed to be a successful way in which we could represent the various views that we felt needed to be considered when evaluating the effectiveness of IAPT.

\section{Final reflections on the exercise and implications for clinical work}

Whilst reflecting on the final PBL exercise I have realised that I have learnt more from these experiences than I expected to. Although during each PBL exercise I have initially been rather confused by the vagueness of instructions, I have come to value the freedom that these exercises have provided to us as trainee clinical psychologists in terms of allowing us to be creative when sharing our varying perspectives and expressing these to our colleagues. During this exercise I was initially disappointed that we had not been given a 'problem' involving a case study but instead had been asked to work with a research based 'problem', assuming that with the MRP in progress that I had enough research to be grappling with. However, this was an important process in helping me think more carefully about the realities of incorporating research into my clinical work when I am a qualified psychologist and how important this will be in terms of service evaluation and development, especially as evaluation is a core competency required of clinical psychologists (BPS, 2006). It has also helped me to become more mindful of my approach to tasks outside of individual work and the need to take a more curious and neutral stance, but yet at times take on a leadership role when trying to determine what different perspectives people may hold and how they can be heard. 


\section{References}

British Psychological Society, Committee for scrutiny of individual clinical qualifications (2006). Core competencies - Clinical psychology - A guide. Leicester.

British Psychological Society (2007). New ways of working for applied psychologists in health and social care: Organising, managing and leading psychological services. Leicester.

Hayes, H. (1991). A re-introduction to family therapy: clarification of three schools. Australian and New Zealand Journal of Family Therapy, 12, 27-43. 


\title{
Summary of Personal and
}

\author{
Professional Learning
}

Discussion Group Account 1

September 2008

Year 1

NB: Although the name of the groups has been changed by the course team from a 'Case Discussion Group (CDG)' to a 'Personal and Professional Learning Discussion Group (PPLDG)', this summary refers to it as a Case Discussion Group (CDG). 
Our CDG adopted quite a structured approach during the first year of training; assigning the role of chair and scribe to different group members for each meeting. Although this worked quite well initially when we were taking part in the problem based learning task, this approach caused some difficulties within the group in later parts of the year as some group members found it difficult to make contributions to the sessions as the structure did not always allow them to do so freely. The facilitator of the group was particularly helpful and supportive regarding this issue and helped the group overcome these difficulties.

We used the group as a place to share personal and professional issues and as a result it seemed to be a very supportive environment in which group members reflected upon their experiences openly and honestly. Over the year the group continued to be a place in which people sought and offered support and we appeared to grow in confidence in our tendency to use the space effectively, which was commented on by the facilitator. I also found the group helpful in developing my own confidence personally and professionally. It provided a space in which I could talk about my anxieties related to the training experience and the input from others was helpful in normalising some of my feelings. My awareness also increased about the importance of feeling safe in a group setting and the importance of focusing on both process and content particularly in clinical settings. 


\title{
Summary of Personal and
}

\author{
Professional Learning
}

\section{Discussion Group Account 2}

\author{
July 2009
}

\section{Year 2}

NB: Although the name of the groups has been changed by the course team from a 'Case Discussion Group (CDG)' to a 'Personal and Professional Learning Discussion Group (PPLDG)', this summary refers to it as a Case Discussion Group (CDG). 
This Case Discussion Group (CDG) process account endeavoured to provide the reader with an insight into the 'work' of the group that was done during the second year of training; providing information on the approach that the group adopted and how this changed over the year. The account included reflections on the individual contributions I made to the group and how this evolved over time; including my views and experiences of conflict within the group and the benefits of holding different positions in debates. With this I also tried to consider the perspectives of the other group members. The account discussed the group processes which occurred over the course of the year and the factors and members which were influential in this process. A theme which arose in the account related to the stage of training I was at and how this had been reflected in the way I had worked and used the CDG. This had also been mirrored in my clinical practice in which I had been working more autonomously and independently. I had also made links between the experiences within the group and how this had affected my personal and professional development; in particular how discussions about current issues within the NHS had influenced the development of my professional identity. I had also reflected on the approaching final year of training and the changes I intended to make in contributing to the CDG. 


\section{Overview of three years'}

\section{placement experience}




\section{Adult Mental Health}

Clients

Adults between the ages of $18-69$ years old referred to the Community Mental Health Team (CMHT) and Primary Care Trust (PCT)

\section{Therapy Model}

Cognitive Behavioural Therapy (CBT) and Family Intervention for Psychosis

\section{Settings}

Clients' homes, CMHT offices, local in-patient unit, primary care offices in health centre, community day centre, hostel

\section{Modes and types of work (interventions)}

- $\quad$ CBT work with individuals with diagnoses including panic disorder, social anxiety, depression, low self-esteem, bipolar disorder, cyclothymia

- Following one week's formal training on family intervention for psychosis work, worked jointly with the Occupational Therapist from the CMHT with a client and his parents

- Co-facilitated mood management group with Community Mental Health Nurse

- Co-facilitated anxiety management group with Community Mental Health Nurse

\section{Assessments}

- Neuropsychological assessments with two individuals with memory difficulties

- Psychology assessments with individuals referred for psychological therapies covering a range of issues including anger, depression, anxiety, low self-esteem, a history of sexual abuse and hearing voices

- Assessments to determine the suitability of clients for groups

- Pre and post assessments with group members

- Use of a range of standardised assessment measures

- Formal and informal risk assessments 
Teaching/Training/Presentations

- Presentation and dissemination of Service Related Research Project (SRRP) results detailed below

- Presentation of a case at a psychotherapy case discussion group

\section{Service Development Work}

SRRP completed to evaluate staff views from three CMHTs, the assertive outreach team (AORT) and the drug and alcohol team, on the facilitation of recovery and social inclusion for clients in the locality. Results disseminated widely to a large audience which involved staff members who participated in the study, staff from other services who did not participate and members of the recovery special interest group.

\section{Children and Adolescents}

Clients

Children and adolescents between the ages of 8-17 years old referred to the Child and Adolescent Mental Health Service (CAMHS)

Therapy Model

Cognitive Behavioural Therapy and Systemic/Narrative Therapy

Settings

CAMHS offices and schools

\section{Modes and types of work (interventions)}

- Individual work with issues including depression, anxiety, obsessive compulsive disorder, panic disorder and confusion about a diagnosis of Asperger's Syndrome

- Work with families and children with issues including spider phobia, sleep problems, separation anxiety and attention difficulties

\section{Assessments}

- Assessments with new referrals to the team with individuals and families regarding issues including anxiety, depression, emotional and behavioural 
difficulties at school, separation anxiety, obsessive compulsive disorder and spider phobia

- Cognitive and educational attainment assessments

- School observation to inform assessment completed by a colleague within the team

- Use of a range of standardised assessment measures

- Formal and informal risk assessments

\section{Teaching/Training/Presentations}

Toileting problems teaching run jointly with the Psychiatrist from the team. Provided for local health visitors, nursery nurses and school nurses

\section{Learning Disabilities}

Clients

Adults with a diagnosis of a learning disability between the ages of 18-57 years old referred to the Community Teams for People with Learning Disabilities (CTPLD) and assessment and treatment unit.

\section{Therapy Model}

Integrative

\section{Settings}

CTPLD offices (across two localities), day services, clients' homes, residential homes, assessment and treatment unit

Modes and types of work (interventions)

- Individual work with issues including anxiety, anger, panic disorder, lack of assertiveness, a history of sexual abuse and symptoms of schizoaffective disorder

- Work with staff teams and families with issues including challenging behaviour, disclosure of sexual abuse, panic disorder and anger

- Relaxation group for clients at the assessment and treatment unit 


\section{Assessments}

- Assessments with new referrals to the team, which included gathering information from individuals, families, staff teams and other professionals

- Cognitive assessments with individuals with memory problems

- Assessment of cognitive and social functioning to determine presence of learning disability

- Functional assessment of challenging behaviour

- Asperger's Syndrome assessment

- Observations of clients to contribute to assessments

- Pre and post assessments with group members

- Use of a range of standardised assessment measures

- Formal and informal risk assessments

\section{Teaching/Training/Presentations}

Counselling Skills training with all staff working at the assessment and treatment unit

Service Development Work

Contributed to audit work done on files at the assessment and treatment unit as part of the accreditation by the Royal College of Psychiatry

\section{Older People}

\section{Clients}

Adults aged between 65-93 years old referred to the Community Mental Health Team (CMHT) for Older People (aged 65 and over)

Therapy Model

Cognitive Behavioural Therapy

\section{Settings}

CTPLD offices, clients' homes, residential home, day hospital 


\section{Modes and types of work (interventions)}

- Individual work with issues including depression, obsessive compulsive disorder, panic disorder and difficulties adjusting to symptoms of dementia

- Work with families and staff members with issues including anxiety, depression and obsessive compulsive disorder

- Co-facilitated Cognitive Stimulation Therapy (CST) group with Assistant Psychologist and Occupational Therapist for clients with a diagnosis of dementia, accompanied by a friend or family member

\section{Assessments}

- Psychology assessments with individuals referred for psychological therapies covering a range of issues including depression, anxiety and panic disorder

- Neuropsychological assessments with individuals with memory problems

- Assessments to determine the suitability of clients for group

- Pre and post assessments with group members

- Use of a range of standardised assessment measures

- Formal and informal risk assessments

\section{Teaching/Training/Presentations}

Active listening skills training with all staff of the older people home treatment team

Additional

Consultation work with residential staff team members working with a lady with depression and anxiety following a stroke and the death of her husband

\section{Specialist Placement - Paediatric Psychology Service}

\section{Clients}

Children and adolescents aged between 4-17 years old referred to the Paediatric Psychology Service 
Therapy Model

Cognitive Behavioural Therapy and Systemic Therapy

\section{Settings}

Paediatric psychology offices in the hospital, medical wards and schools

Modes and types of work (interventions)

- Individual work with issues including depression, social anxiety and difficulties adjusting to a diagnosis of irritable bowel disease

- Work with families and children with issues including difficulties adjusting to conditions such as achondroplasia and cancer, obesity, daytime wetting and trauma following a dog attack

\section{Assessments}

- Psychology assessments with individuals referred for psychological therapies covering issues including depression, anxiety, social anxiety, obesity, behavioural difficulties and difficulties adjusting to conditions

- Use of a range of standardised assessment measures

- Informal risk assessments

\section{Teaching/Training/Presentations}

Presentation of client at weekly psychology meeting

Presentation of major research project at weekly psychology meeting 


\section{'Psycho-education and}

\section{Cognitive Behavioural Therapy}

with a man in his early 30s with

a diagnosis of schizophrenia

and presenting with anxiety'

\section{Summary of Case Report 1 -}

\section{Adult Mental Health}

\section{April 2008}

Year 1 
Jeremy Smith was a man in his early 30 s referred by the Community Mental Health Team (CMHT) psychiatrist for a psychological assessment due to anxiety when travelling in a car. The anxiety was reported to be linked to 'insight senses' and voices associated with a diagnosis of schizophrenia. During my initial meetings with Jeremy we reviewed his presenting difficulties and developed a formulation regarding the anxiety and identified some goals for therapy. Jeremy's difficulties appeared to be well explained by a cognitive model of panic as it allowed us to incorporate Jeremy's misinterpretation of anxiety about travelling in a car as a sign that he would have a psychotic relapse.

At the time of writing the report, 12 individual sessions had been completed with Jeremy. During these sessions the work focused on psycho-education regarding the diagnosis of schizophrenia as Jeremy had a number of questions about the condition. A relapse prevention plan was also developed in order to enable Jeremy to feel more in control in terms of identifying early warning signs that he may be experiencing a relapse. Cognitive therapy was also incorporated into sessions to help Jeremy review the misinterpretation of the symptoms of anxiety that he was experiencing. Strategies such as positive self-talk and exposure to car journeys were also adopted in order to help Jeremy overcome his avoidance of travelling by car. At the time of the report Jeremy's understanding of his condition had increased and his anxiety had reduced on short and long car journeys. 


\section{'Cognitive Behavioural Therapy}

with a man in his early 20s

presenting with depression'

Summary of Case Report 2 -

Adult Mental Health

September 2008

Year 1 
David was a man in his early 20 s referred by the Senior Health Officer to the Community Mental Health Team (CMHT) for a psychological assessment due to feeling depressed. David he reported having difficulties in his relationships with family and friends and anxiety that people would judge him negatively. David had also experienced previous difficulties with an eating disorder and self-harm. During initial meetings with David we spent time developing the therapeutic relationship, a formulation of his low mood and anxiety and identified some goals for therapy. David's difficulties appeared to be well explained by a cognitive model of low self-esteem as it allowed us to incorporate David's negative sense of self, feelings of inadequacy and worthlessness and his subsequent avoidance of others.

At the time of writing the report, 13 individual sessions had been completed with David. During these sessions the work focused on monitoring and adapting David's activities in order to overcome his avoidance of others and increase his pleasure and sense of achievement. Cognitive work was also used in order to help David re-interpret some of his earlier life experiences and alter some of his negative beliefs about himself. Sessions also incorporated a focus on some unresolved issues David had with his grandmother who had passed away and teased him as a child about his weight. At the time of the report David's anxiety had reduced regarding being judged negatively by others and he was feeling more able to go out alone. 


\title{
'Psychological assessment of an eight year old boy
}

presenting with attention

\author{
problems'
}

\section{Summary of Case Report 3 -}

Child: Psychometric case report April 2009

Year 2 
Joshua King was an eight year old boy who was referred to the Child and Adolescent Mental Health Service (CAMHS) by his GP for assessment due to his parents' concerns about his short attention span, behavioural problems, impulsivity and recent changes in behaviour. His school teacher reported extra concerns about Joshua's weak social skills and overly physical contact with his peers. He was also underachieving academically in all areas at school, with particular weaknesses in reading, writing and spelling. Joshua and his mother were seen for an initial assessment and information was also gathered from a school report and previous speech and language therapy report.

After gathering this information, initial investigations involved screening Joshua for ADHD and this was done through the use of the parent and teacher Conner's forms. These revealed that Joshua did not have ADHD and as a result an extended assessment was deemed necessary to further explore his difficulties. The Test of Everyday Attention for Children (TEA-Ch), the Wechsler Intelligence Scale for Children, fourth edition (WISC-IV) and theory of mind tests were administered over four sessions with Joshua and a school observation was completed. The results of the assessment were interpreted and the summary, conclusions and recommendations were fed back to Joshua's parents and school teachers. 


\title{
'An integrative approach to
}

\section{working with a 68 year old}

\section{woman experiencing low}

\section{mood; within a systemic}

\author{
framework'
}

Summary of Case Report 4-

Older People

April 2010

Year 3 
Mrs Mary Jones was a 68 year old woman who was referred to the Older People's Community Mental Health Team (CMHT) by her GP for assessment due to decline in her mood. She was reported as 'presenting with severe depression post stroke'. Mary was seen for an initial assessment by the team Consultant Psychiatrist who made a referral to psychology. Information was gathered from Mary during an initial meeting in which she reported experiencing worries about swallowing and feeling depressed about the death of her husband and how difficult her life had become following a stroke she had in 2007. Information was also gathered from staff members working at the care home that Mary lived in and her son Keith, who were heavily involved with Mary and her care. Previous reports were also consulted as Mary had been involved with other services in the past.

After gathering this information, it was agreed that a mixture of individual and indirect intervention with staff at the home and Keith would be most appropriate. Three individual sessions took place with Mary and two sessions jointly with her and Keith. This incorporated solution-focused techniques in order to develop some solutions that all parts of the system could adopt in order to help manage the problems. The work also involved a consultation session with staff members at the care home in order to share the psychological formulation and help them develop a greater understanding of Mary's experiences and their skills in managing the problems. 


\title{
'Developing skills and a greater understanding of working
}

\author{
collaboratively'
}

Summary of Oral Presentation

of Clinical Activity - Learning

Disabilities

September 2009

Year 2 
Tony was a 57 year old man with a diagnosis of a learning disability, Klinefelter's syndrome and type I diabetes. He was admitted to an assessment and treatment unit (ATU) for people with learning disabilities following a period in which he expressed suicidal thoughts and attempted to harm himself as a result of 'anxious attacks' that he had been experiencing. He had also been finding it difficult to comply with his diabetes treatment and consequently this had been poorly controlled. During Tony's admission at the ATU concern was expressed that the poor management of his diabetes may have affected his cognitive functioning. Subsequently, he was referred for a re-assessment of his cognitive functioning to determine if there had been any decline since a previous assessment. Whilst feeding back the results of the assessment (which indicated no change in functioning) to Tony he became upset and disclosed to me that he had been sexually assaulted as a child. Tony said that he wanted to talk to someone about the assault as the memories had been distressing him. The Safeguarding Adults Procedures were followed and discussions took place with my supervisor when it was agreed that I would meet with Tony to give him a space to talk about his experiences. However, on meeting with Tony he explained that he no longer wanted to talk about these experiences.

For the oral presentation of clinical activity I chose to focus on how I worked with a disclosure of sexual assault and my subsequent involvement with Tony. This included what I learnt from the experience and how I developed personally and professionally as a result. In brief, the experience reinforced to me the value of working collaboratively with people and the positive impact that providing choice and working flexibly can have on well-being and self-esteem. This was apparent whilst talking to Tony about our involvement together when he explained that it had been good to know that people are there to listen to him when he needs them. The experience also demonstrated to me how I have changed over the course of clinical training; moving from focusing on content within sessions at the beginning of training, to moving on to incorporate a focus on the process, in particular the development of the therapeutic relationship; thus becoming a reflective-scientist practitioner. 


\title{
'Promoting recovery and
}

\section{facilitating social inclusion: The}

views of staff members of adult

\section{mental health services in one}

\author{
locality'
}

\section{Service Related Research}

\author{
July 2008
}

Year 1 


\section{Abstract}

\section{Objectives}

This research was interested in staff perceptions of the extent to which they think recovery-oriented practices are being implemented in adult mental health services in their locality and the barriers that may prevent this from happening. Their views would be used to guide the development of the training programmes on recovery for staff which are currently being developed within the Trust.

\section{Method}

The Recovery Self Assessment (RSA) questionnaire adapted for UK use and openended questions (developed in consultation with the recovery steering group and service users) were sent out to all staff members (sample size of 64 staff) of the three local Community Mental Health Teams (CMHTs), Assertive Outreach Team (AORT) and the drug team. There was a response rate of $59 \%$ for the open-ended questions and $48 \%$ for the questionnaire.

\section{$\underline{\text { Results }}$}

Results indicate that staff have mixed knowledge about what recovery is, however, in their responses many staff demonstrated that they are working within a recovery-oriented framework. The results also showed that staff have clear views about what the barriers are to working within a more recoveryoriented framework.

\section{Discussion}

The results have important implications both in guiding the development of future training that is offered and enabling staff to work in a more recovery-oriented framework. 


\section{Acknowledgements}

This project was supported by the recovery lead of the Trust, the recovery steering group and both my field and university research tutors. I would like to thank a local service user for his input in developing and adapting the measures used in this project. I would also like to thank the participants for taking the time to complete and return the questionnaires and the staff at the CMHTs, AORT and Drug Team who facilitated this process. 


\section{Introduction}

It is understandable that people would view a reduction in symptoms as a desired outcome of therapy; however, the recovery model suggests that clients want more than a reduction in symptoms. If people are to recover, they want to retain or rebuild a new sense of self, meaning and purpose in life (Repper \& Perkins, 2003).

There has been a change in mental health services in the way people think about others' experiences of mental distress, the principles that guide services and the way people are offered care (Ridgway \& Press, 2004). The move towards recovery has become a central feature of mental health services in the USA and New Zealand and this also seems to be the case in the UK. Government Policies in the UK have included the need for a move towards recovery in Modernising Mental Health Services; The National Service Framework for Mental Health and in a chapter on mental health in the NHS (National Health Service) Plan. These policies provide a framework for implementing service approaches that are "highly individualised and orientated toward recovery' (Ridgway \& Press, 2004, p.3).

This move appears to have taken place in the UK in order to put service users at the centre of everything mental health professionals do. Due to the importance of the focus that has been put onto recovery, there is reported to be 'an urgent need to find ways of enabling services to approach the development of recovery facilitating services' (Ridgway \& Press, 2004, p.4).

At a Trust level, South West London \& St. George's (SWL\&SG) Mental Health NHS Trust has a vision that recognises how challenging it can be to retain or recover a meaningful, satisfying and valued life. In May 2007 the trust developed a strategy for Recovery and Social Inclusion. It notes that changes will need to take place at all levels of the organisation in order for the strategy to be implemented, and that staff members of the Trust will be required to think about what they do and how they do it to make sure that everything possible is being done to 'foster hope and facilitate the recovery and social inclusion of the people we serve' (SWL\&SG Strategy for promoting recovery and facilitating social inclusion, 2007, p.2). 


\section{Aims}

This brief review of some of the literature suggests that there is a need for promoting recovery and social inclusion and it is backed by policy at both Trust wide and government levels.

This research project examined staff perceptions of the degree to which they believe recovery-oriented practices are being implemented within mental health services in the locality. The findings will be used by the Trust recovery lead and steering group to guide the development of training on recovery that is being offered to staff.

\section{Research questions}

\section{Answered using a questionnaire:}

1) What do staff think are the recovery-oriented strengths and areas for improvement of the activities, values and practices of adult mental health services in the locality?

Answered using responses to open-ended questions:

2) What do staff think the term 'recovery' means?

3) What do staff think they are doing that is recovery-oriented?

4) What do staff think the barriers are to working within a more recoveryoriented framework? 


\section{Method}

\section{Participants}

Of a sample size of 64 NHS Trust staff, 38 participated in the study (response rate of $59 \%$ ). All participants completed and returned the open-ended questions and 31 of these participants completed and returned the questionnaire. Four of these 31 had missing data as they failed to complete the second side of the questionnaire. All demographic information was collected separately so there was no way to identify those who had missing data.

Of the 38 participants; there were 13 nurses, 9 psychiatrists, 7 social workers, 4 psychologists, 3 occupational therapists, 1 team manager and 1 criminal justice worker. In terms of ethnicity, $34 \%$ of participants reported that they were White British, $13 \%$ were Other British, 13\% were White Other and $40 \%$ were Other. The ages of staff ranged from 25 - 61 years old. Of the participants; 18 were male and 20 were female.

\section{Measures}

An extensive literature search was conducted to identify relevant measures and contact was made with the clinical audit assistant for the locality. At a meeting between three Clinical Psychologists from the recovery and social inclusion service improvement group, two trainee clinical psychologists also doing an SRRP on recovery and a service user, the available measures were reviewed and the decision was made to use the Recovery Self-Assessment (RSA) developed by O'Connell et al. (2005). Permission to use the measure free of charge was given by the authors of the measure.

The RSA is a 36 item self-completion tool that includes closed questions which are rated using a 5 point Likert scale ranging from 'Strongly Disagree' to 'Strongly Agree'. The option of 'not applicable' is also included for each item. The provider version of the measure was used.

The items on the RSA are said to reflect objective practices that are associated with five domains of recovery ( $O^{\prime}$ Connell et al., 2005), these are: 
- 'Life goals' - refers to the development and pursuit of individually defined goals such as employment and education.

- 'Involvement' - refers to service users being involved in the development/provision of services, staff training and meetings.

- 'Diversity of Treatment Options' - refers to services providing peer support, a variety of treatment options and support with becoming involved in non-mental health activities.

- 'Choice' - refers to service users having access to their records, staff not trying to influence choice and respecting the choice of service users.

- 'Individually-tailored services' - refers to services being tailored to individual needs, cultures and interests and building links with the community.

\section{Procedure}

The measure was chosen and, in consultation with the recovery steering group, it was adapted to include more appropriate language for a UK rather than a US service (see Appendix 1: adapted questionnaire). The measure was then shared with the recovery steering group and local service user groups to gain further feedback on the suitability of the measure. No further changes were made. Additionally, six open-ended questions were developed to gain a better idea of staff understanding of the term 'recovery', what they think they are doing that is recovery-oriented and what barriers are in the way of this. This was to highlight misunderstanding and gaps in knowledge that future training sessions might address (see Appendix 2: open-ended questions).

The measures were circulated to all staff members (excluding administrative staff) of the three CMHTs, AORT and the Drug team. A letter was sent to all team managers explaining the purpose of the research and instructions for administering the measures. The managers were requested to circulate the measures to all team members, preferably at their team meeting in order to increase response rates. A separate demographics sheet was also provided to ensure that responses remained anonymous (see Appendix 3 for letter, instructions and demographics sheet). One team manager invited me to their team meeting to talk to them about the project and the staff completed the 
measures while I waited which was helpful in increasing the response rate. Reminder emails were sent to team managers and personal contact was made with staff members to request that the measures be completed and returned.

\section{Results}

Analysis

Staff responses to the questionnaire i.e., ratings using the 5-point Likert scale, were analysed using descriptive statistics and the open-ended questions were analysed using content analysis.

\section{Research question 1}

What do staff think are the recovery-oriented strengths and areas for improvement of the activities, values and practices of adult mental health services in the locality?

Staff were asked to rate items on a questionnaire indicating the degree to which they thought the items reflected the recovery-oriented activities, values and practices of their locality. Staff responses to the questionnaire were analysed to highlight staff perceptions of the highest and lowest rated recovery-oriented activities, values and practices within the Trust. As the questionnaire had a Likert scale, which is ordinal, it was considered most informative to use the mode to rank the items in order from highest to lowest. Items were grouped within their recovery-oriented domains (see Appendix 4 for table of results). The highest rated items are said to reflect recovery-oriented strengths of the Trust, and the lowest rated items are said to reflect areas for improvement. The highest rated item was item 13 on the questionnaire from the 'choice' domain. The lowest rated items were items 2,4 and 9 from the 'individually-tailored services' domain and item 7 from the 'choice' domain.

The results were also analysed to determine staff perceptions of recoveryoriented domains of strength and areas for improvement. Table 1 illustrates the number of items in each of the domains gaining the different modal responses on the Likert scale. The results suggest that most staff regard recovery-oriented 
domains of 'involvement' and 'diversity of treatment options' as neither a strength nor area for improvement. The responses were more mixed for items related to 'choice' with this domain including both the highest and lowest rated items, although more ratings reflected areas of strength than areas for improvement. A greater number of positive responses were also found in the life goals' domain, indicating that this is perceived to be an area of strength by staff. The greatest number of negative responses fell into the 'individually-tailored services' domain, with three of the lowest rated items in this category, which suggests that staff perceive this to be an area for improvement within the Trust.

Table 1: The number of items in each recovery-oriented domain gaining each modal response on the Likert scale

\begin{tabular}{|c|c|c|c|c|c|}
\hline & Number 0 & items gain & $g$ the modal $r$ & esponse & \\
\hline $\begin{array}{l}\text { Recovery- } \\
\text { oriented } \\
\text { domains }\end{array}$ & $\begin{array}{l}5 \\
\text { strongly } \\
\text { agree }\end{array}$ & 4-agree & $\begin{array}{l}3 \text { - neither } \\
\text { agree nor } \\
\text { disagree }\end{array}$ & $\begin{array}{ll}2 & - \\
\text { disagree }\end{array}$ & $\begin{array}{l}1 \\
\text { strongly } \\
\text { disagree }\end{array}$ \\
\hline $\begin{array}{l}\text { Life goals (11 } \\
\text { items) }\end{array}$ & 0 & 6 & 5 & 0 & 0 \\
\hline $\begin{array}{l}\text { Involvement } \\
\text { (8 items) }\end{array}$ & 0 & 1 & 7 & 0 & 0 \\
\hline $\begin{array}{l}\text { Diversity of } \\
\text { treatment } \\
\text { options } \quad \text { (6 } \\
\text { items) }\end{array}$ & 0 & 0 & 6 & 0 & 0 \\
\hline $\begin{array}{l}\text { Choice } \quad(6 \\
\text { items) }\end{array}$ & 1 & 2 & 2 & 1 & 0 \\
\hline $\begin{array}{l}\text { Individually- } \\
\text { tailored } \\
\text { services } \quad \text { (5 } \\
\text { items) }\end{array}$ & 0 & 2 & 0 & 3 & 0 \\
\hline
\end{tabular}




\section{Summative content analysis (Hsieh \& Shannon, 2005)}

Written responses to the open-ended questions were analysed using summative content analysis. This approach involves 'identifying and quantifying certain words or content in text with the purpose of understanding the contextual use of the words or content' (Hsieh \& Shannon, 2005, p.1283). The responses to all six questions were analysed individually, however, this report only focuses on responses to three questions because these were most appropriate to the project's aim of developing training on recovery. Responses to all questions are presented in Appendix 5 with some illustrative quotes.

\section{Research question 2}

What do staff think the term 'recovery' means?

The analysis identified two main categories; autonomy and control of symptoms. 26 participants (68\%) were identified as thinking that the term 'recovery' relates to 'autonomy' which included statements such as; 'living a meaningful life' and 'regaining control'.

15 participants (39\%) were identified as thinking that 'recovery' relates to a more symptom-focused approach of 'control of symptoms'. This included statements such as; a 'reduction of symptoms' and 'prevention of relapse'.

\section{Research question 3}

What do staff think they are doing that is recovery-oriented?

The analysis identified three main categories; promoting autonomy, support to clients and families and interventions. 22 participants (58\%) identified recoveryoriented activities and practices which fell into the 'promoting autonomy' category. This included statements such as; 'promoting independence' and 'goal setting'. 
19 participants $(50 \%)$ identified activities and practices which fell into the 'support to clients and families' category and this included statements such as; 'providing support to find employment' and 'offering peer support'.

14 participants (37\%) identified activities and practices which fell into the 'intervention' category and this included statements such as; 'treating symptoms' and 'therapeutic work'.

\section{Research question 4}

What do staff think the barriers are to working within a more recovery-oriented framework?

The analysis identified three main categories; resources, attitudes and structure. 22 participants $(58 \%)$ identified barriers related to 'resources'. This included statements such as; 'time restraints' and 'lack of training'.

17 participants (45\%) identified barriers related to 'attitudes' and this included statements such as; 'attitudes of staff' and 'attitudes of the community'.

6 participants (16\%) identified barriers related to 'structure' and this included statements such as; 'lack of coordination between agencies' and 'the target driven focus of the NHS'.

See Appendix 5 for illustrative quotes for research questions 2-4. 


\section{Discussion}

The results presented suggest that staff have a good understanding of the term 'recovery' and the most common category 'autonomy' fits with the definition given in the locality strategy (see Appendix 6). The results also indicate that some staff may have more to learn about recovery with the need for focus to move away from symptoms (Repper \& Perkins, 2003). Responses demonstrated that staff are currently doing many things to work within a recovery-oriented framework. Staff also have clear views of what the barriers are to working in a recovery-oriented framework. Lack of resources, such as time and training, was noted to be the most prominent barrier. Another common barrier included attitudes; specifically the attitude of those working within a medical framework, attitudes of people in the community and conflicting philosophies of other agencies that staff in the NHS work with. Staff made suggestions for what would help them to work more successfully in a recovery-oriented framework, including more training on recovery, supervision offered by people trained in the recovery approach and joint training with staff from other agencies outside of the NHS (see Appendix 5 for more information).

Most positive rated items were related to 'life goals' and a strength of the locality is that staff think they are diverse in terms of their culture, ethnicity, lifestyle and interests. However, despite this, the lowest rated items were in the 'individuallytailored services' and included the suggestion that specific services are not being offered to service users with different cultures, life experiences, interests and needs. This information will have implications for the development of the training on recovery, as it will allow trainers to teach and motivate staff to use their diversity to provide more individually tailored services to the service users.

It is also encouraging to see that 'involvement' was not the lowest rated recoveryoriented domain. The literature suggests that 'involvement' is one of the most difficult barriers for service users in recovery, as they find it difficult to be involved and accepted as equal members when working with Trust staff $\left(O^{\prime}\right.$ Connell et al., 2005). 


\section{Limitations of research and areas for future research}

Although the findings have been said to reflect staff perceptions of adult mental health services in the locality, this project was not open to all staff members and teams working within the locality for example, ward staff, the home treatment teams or early intervention services. As such, there is a risk that valuable information may be missed that could further influence the development of training on recovery, which may be of particular relevance to these teams in which service users may be experiencing more severe symptoms and may be harder to reach in the community. The same principles also apply to the participants who received the measures but did not return them. With this in mind, the aim of this project was to form a pilot study in adult mental health services in this locality, so future research is likely to examine the views of other staff members in the locality to ensure that training is developed appropriately to meet the varying needs of staff members. Future research could also evaluate the impact of any training programmes that are developed as a result of these findings.

This research only examined staff members' views on recovery. The specific experience and expertise of service users and carers (Perkins, 2005) is said to be a valuable resource for mental health professionals. Future research should, therefore, examine the views of service users and carers in order to ensure that staff are trained to facilitate recovery and social inclusion in ways that are meaningful to those who are receiving the service.

\section{Dissemination of findings}

A meeting has been scheduled for the $17^{\text {th }}$ July 2008 to meet with the recovery lead and steering group for the locality, to consider how the findings might influence future training.

A summary of the development and findings of this project (including the analysis of the open-ended questions not reported on here), was presented at a recent workshop on recovery at the Trust Academic Forum for mental health professionals in June 2008 (See Appendix 7 for acknowledgement of presentation). This presentation included the implications for mental health 
professionals working in the area and recommendations for the development of future training programmes and how to overcome barriers to working in a recovery-oriented framework. A written summary of this project will also be disseminated to all staff members of the teams who participated. Dissemination of the findings has already provided an opportunity for staff to receive some positive feedback about the strength of their knowledge about the term 'recovery' and what they are doing to work within a recovery-oriented framework.

\section{$\underline{\text { Reflections/conclusions }}$}

The high percentage of participants reporting that barriers to working within a more recovery-oriented framework relate to resources supports the need for change in the structure and attitude of the NHS. The recovery steering group are continuously taking steps to try to facilitate these changes, however, demands for more time, smaller caseloads and extra finances are not directly under their control. This is consistent with other studies which suggest that as knowledge of recovery continues to grow, it becomes clear that 'fundamental changes in the service delivery system are needed to support wellness and recovery from psychiatric disabilities' (Sullivan, 1997, cited in O'Connell et al., 2005). This experience, at an early stage of my training, has taught me the importance of trying to facilitate recovery and social inclusion for clients and the barriers that 1 may be faced with when trying to achieve this. 


\section{References}

Hsieh, H-F. \& Shannon, S.E. (2005). Three approaches to qualitative content analysis. Qualitative Health Research, 15(9), 1277-1288. Sage publications.

O'Connell, M., Tondora, J., Croog, G., Evans, A. \& Davidson, L. (2005). From rhetoric to routine: Assessing perceptions of recovery-oriented practices in a state mental health and addiction system. Psychiatric Rehabilitation Journal, 28(4), 378-386.

Perkins, R. (2005). Putting users at the heart of services: A framework for involving people with mental health problems and their relatives, friends and carers. Director of quality assurance and user/carer experience - South West London \& St.George's Mental Health NHS Trust. Retrieved June 2008 from http://www.swlstg-tr.nhs.uk/service_users/get_involved.asp

Repper, J. \& Perkins, R. (2003). Social Inclusion and Recovery: A Model for Mental Health Practice. Edinburgh, Bailliere Tindall.

Ridgway, P. \& Press, A. (2004). Assessing the recovery - commitment of your mental health service: A user's guide for the developing recovery enhancing environments measure (DREEM). Being edited for use in England by Piers Allorr and Peter Higginson.

South West London and St George's Mental Health NHS Trust. (2007). Making life better! An introduction for trust staff to the South West London and St George's Mental Health NHS Trust strategy for promoting recovery and facilitating social inclusion.

Sullivan, W.P. (1997). Strengths, niches, and recovery from serious mental illness. In D. Saleebey (Eds.) The strengths perspective in social work practice $\left(2^{\text {nd }}\right.$ edn). New York: Longman. 


\section{Service Related Research Project Appendices}




\section{APPENDIX 1: RECOVERY SELF ASSESSMENT (RSA)}

\section{QUESTIONNAIRE (ADAPTED TO INCLUDE UK LANGUAGE)}

\section{PROVIDER VERSION}

Please note the changes included replacing the words:

- 'agency' for 'Trust'

- 'person in recovery' and 'agency participant' for 'service user'

- 'exiting or completing the agency' for 'being discharged from the Trust' 
Appendix 1: Recovery Self-Assessment (adapted to include UK language)

Please indicate the degree to which you feel the following items reflect the activilies, values, and practices of your agency.

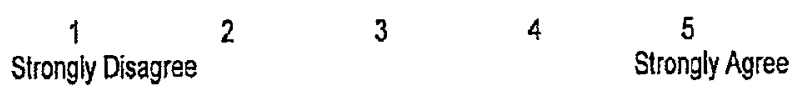

1 Helping people who use our services to build connections with their

$\begin{array}{llllll}1 & 2 & 3 & 4 & 5 & \text { N/A }\end{array}$ neighbourhoods and communities is one of the primary activities in which siaff at this Trust are involved.

2 This Trust offers specific services and programs for individuals with different cullures, life experiences, inierests and needs.

3 Service Users have access to all their treatment records.

4 This Trust provides education to communily employers about employing people with menlal illness and/or addictions.

5 Every effort is made to involve signiticant others (spouses, friends, family members) and other natural supports (i.e., clergy, neighbours, landlords) in the planning of a person's services, if so desired.

6 Service Users can choose and change, if desired, the therapist; psychiatrist, or other service provider with whom they work.

$\begin{array}{llllll}1 & 2 & 3 & 4 & 5 & \text { NA }\end{array}$ $\begin{array}{llllll}1 & 2 & 3 & 4 & 5 & \mathrm{~N} / \mathrm{A}\end{array}$

$\begin{array}{llllll}1 & 2 & 3 & 4 & 5 & \text { N/A }\end{array}$

$\begin{array}{llllll}1 & 2 & 3 & 4 & 5 & \text { N/A }\end{array}$ $\begin{array}{llllll}1 & 2 & 3 & 4 & 5 & \text { N/A }\end{array}$

7 Most services are provided in a person's nalural environment (i.e., $\quad 1^{\cdot} 2 \quad 3 \quad 4 \quad 5 \quad$ N/A home, community, workplace).

8 Service Users are given the opportunity to discuss their sexual and $\quad \begin{array}{lllllll}1 & 2 & 3 & 4 & 5 & \text { N/A }\end{array}$ spiritual needs and interests.

9 All staff at this Trust regularly attend trainings on cultural competency. $\quad \begin{array}{lllllll}1 & 2 & 3 & 4 & 5 & \text { N/A }\end{array}$

10 Staff at this Trust listen to and follow the choices and preferences of $\begin{array}{lllllll}1 & 2 & 3 & 4 & 5 & \text { N/A }\end{array}$ Service Users.

11 Progress made lowards goals (as defined by the Service User) is $\begin{array}{lllllll}1 & 2 & 3 & 4 & 5 & \text { N/A }\end{array}$ monitored on a regular basis.

$\begin{array}{llllllll}12 & T h i s \\ \text { Trust provides structured educational activities to the community } & 1 & 2 & 3 & 4 & 5 & \text { N/A }\end{array}$ about mental illness and addictions.

13 Trust staff do not use threats, bribes, or other forms of coercion to $\quad \begin{array}{lllllll}1 & 2 & 3 & 4 & 5 & \text { N/A }\end{array}$ influence a service user's behaviour or choices.

$\begin{array}{llllllll}14 & \text { Staff and Service Users are encouraged to take risks and try new } & 1 & 2 & 3 & 4 & 5 & \text { N/A }\end{array}$ things.

$\begin{array}{llllllll}15 & \text { Service Users are involved with facilitaling staff training and education } & 1 & 2 & 3 & 4 & 5 & \text { N/A }\end{array}$ programs at this Trust.

$\begin{array}{llllllll}16 & \text { Staff are knowledgeable about special interest groups and activities in } & 1 & 2 & 3 & 4 & 5 & \text { N/A }\end{array}$ the community.

17 Groups, meetings and other activities can be scheduled in the evenings or on weekends so as not to conflict with olher recoveryoriented activities such as employment or school.

18 This Trust actively aftempts to link Service Users with other Service Users who can serve as role models or mentors by making referrals to self-help, peer support, or service user advocacy groups or programs.

$\begin{array}{llllll}1 & 2 & 3 & 4 & 5 & \text { NIA }\end{array}$

$\begin{array}{llllll}1 & 2 & 3 & 4 & 5 & \mathrm{~N} / \mathrm{A}\end{array}$ 
19 This Trust provides a variety of treatment options (i.e., individual, $\begin{array}{lllllll}1 & 2 & 3 & 4 & 5 & \text { NIA }\end{array}$ group, peer support, holislic healing, alternalive treatments, medical) from which Service Users may choose.

$\begin{array}{llllllll}20 & \text { The achievement of goals by Service Users and staff are formally } & 1 & 2 & 3 & 4 & 5 & \text { N/A }\end{array}$ acknowledged and celebrated by the Trust.

21 Service Users are roulinely involved in the evaluation of the Trust's $\quad \begin{array}{lllllll}1 & 2 & 3 & 4 & 5 & \text { N/A }\end{array}$ programs, services, and sevice providers.

22 Staff use a language of recovery (i.e., hope, high expectations, $\quad \begin{array}{llllll}1 & 2 & 3 & 4 & 5 & \text { NiA }\end{array}$ respect) in everyday conversations.

23 Staff play a primary role in helping Service Users become involved in $\begin{array}{lllllll}1 & 2 & 3 & 4 & 5 & \text { N/A }\end{array}$ non-mental healthladdiction related activities, such as church groups, special interest groups and adult education.

24 Procedures are in place to facilitate referrals to other programs and $\begin{array}{lllllll}1 & 2 & 3 & 4 & 5 & \text { N/A }\end{array}$ services if the Trust cannot meet a person's needs.

25 Staff actively assist Service Users with the development of career and $\begin{array}{lllllll}1 & 2 & 3 & 4 & 5 & \text { N/A }\end{array}$ life goals that go beyond symptom management and stabilization.

26 Trust staff are diverse in terms of culture, ethnicity, lffestyle and $\quad \begin{array}{llllllll}1 & 2 & 3 & 4 & 5 & \text { N/A }\end{array}$ interesis.

$\begin{array}{llllllll}27 & \text { Service Users are regular members of Trust advisory boards and } & 1 & 2 & 3 & 4 & 5 & \text { N/A }\end{array}$ management meetings.

$\begin{array}{llllllll}28 & \text { At this Trust, Service Users who are doing well get as much attention } & 1 & 2 & 3 & 4 & 5 & \text { N/A }\end{array}$ as those who are having difficulties.

$\begin{array}{llllllll}29 & \text { Staff routinely assist individuals in the pursuit of educational and/or } & 1 & 2 & 3 & 4 & 5 & \text { N/A }\end{array}$ employment goals.

$\begin{array}{llllllll}30 & \text { Sevice Users work along side Trust stafi on the development and } & 1 & 2 & 3 & 4 & 5 & \text { NA }\end{array}$ provision of new programs and services.

$\begin{array}{llllllll}31 & \text { Trust staff actively help people become involved with acivities that give } & 1 & 2 & 3 & 4 & 5 & \text { N/A }\end{array}$ back to their communities (i.e., volunteering, community services, neighbourhood watch).

32 This Trust provides formal opportunities for Service Users, family members, service providers, and administrators to learn about recovery.

33 The role of Trust staff is to assist a person with fulfilling their individually-defined goals and aspirations.

$\begin{array}{llllll}1 & 2 & 3 & 4 & 5 & \text { N/A }\end{array}$

$\begin{array}{llllllll}34 & \text { Criteria for being discharged from the Trust are clearly defined and } & 1 & 2 & 3 & 4 & 5 & \text { NA }\end{array}$ discussed with Service Users upon entry to the Trust.

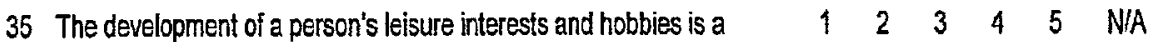
nimany focus of services.

36 Trust staff believe that people can recover and make their own treatment and life choices.

$\begin{array}{llllll}1 & 2 & 3 & 4 & 5 & \text { N/A }\end{array}$

$\begin{array}{llllll}1 & 2 & 3 & 4 & 5 & \mathrm{~N} / \mathrm{A}\end{array}$

Thank you for taking the time to complete this questionnaire. 


\section{APPENDIX 2: OPEN-ENDED}

\section{QUESTIONS}




\section{Recovery Service Related Research Project}

My name is $X$ and $I$ am a first year trainee clinical psychologist from the University of Surrey. I am working in conjunction with the recovery and social inclusion sub group of the $X$ Service Improvement Group (SIG). We want to look at staff views on recovery and how you feel the trust is facilitating this for its clients. I would be grateful if you could take the time to answer the few questions below and the attached questionnaire. It should take about 10 minutes to complete. After the data has been collected and analysed, I will arrange for the findings to be disseminated at a later date.

Thank you very much for your time.

1. What do you think the term recovery means?

2. What do you think facilitates clients' recovery? Please give a few examples.

3. What do you think you are doing at present that is recovery oriented? Please give a few examples.

4. Have you received any training on recovery? If so please state

What and when this was.

5. What barriers are there, if any, to working within a more recovery oriented framework? 
6. What do you think would help you as a staff member to work within a more recovery oriented framework? 


\section{APPENDIX 3: LETTER TO TEAM}

\section{MANAGERS, INSTRUCTIONS}

FOR COMPLETING MEASURES

AND DEMOGRAPHICS

RECORDING SHEET 
Promoting Recovery and Facilitating Social Inclusion:

\section{The Views of Staff Members of adult mental health services in X}

$29^{\text {th }}$ February 2008

Dear Team Manager,

In May 2007 the trust developed a strategy for Recovery and Social Inclusion. The trust recognises how challenging retaining or recovering a life that is meaningful, satisfying and valued can be. However, their purpose is to help people to achieve this. It notes that changes will need to take place at all levels of the organisation in order for the strategy to be implemented. Staff members of the trust will be required to think about what they do and how they do it to make sure that everything possible is being done to 'foster hope and facilitate the recovery and social inclusion of the people we serve' (SWL\&SG Strategy for promoting recovery and facilitating social inclusion, 2007:2).

The X Service Improvement Group (SIG) has set up a Recovery Sub Group. Part of their role is to see how best to facilitate recovery within $X$ services. They feel however, that before trying to change anything within the services they need to know what is already being done by staff in order to influence future training. Working in conjunction with the SIG, we would like to find out about your team's views on recovery and how they feel the trust is facilitating this for its clients. We would like to get as good a response rate as possible so we get a representative picture of everyone's views. We therefore wondered if this could be done in a team meeting, as it will only take about 10 minutes for everyone to fill this in together.

We appreciate what a difficult and stressful time it may be for everyone, however, it is hoped that by gathering the information we require before the reconfiguration takes place that the possible impact on future training would be most beneficial.

After the information has been collected and analysed we will arrange for the findings to be disseminated at a later date.

Please return in the internal post in the envelope provided by the end of March.

Thank you for your time.

$\mathrm{XX}$

Associate Director of Therapies, $X$ Borough and Chair of X SIG

$\mathrm{XX}$

Trainee Clinical Psychologist, $X \mathrm{CMHT}$ 


\section{Recovery Service Related Research Project}

Please could you give the project contents to your team members to complete in the following order (these items are labelled as follows):

1. Demographics

2. Open ended questions on recovery

3. Read the written information on recovery

4. Questionnaire

Please complete in the requested order as the results will be affected by any changes.

Many thanks 


\section{Recovery Service Related Research Project \\ DEMOGRAPHICS}

Please could you take a few moments to enter the demographics of your team members who fill out the questionnaire. This information will be kept separate from the questionnaires in order to retain anonymity and the results are being analysed as a service not by team or profession. However, we need this information in order to be able to describe the sample when writing up the results of the project.

Many thanks

\begin{tabular}{|c|c|c|c|}
\hline Profession & Gender & Age & Ethnicity \\
\hline & & & \\
\hline & & & \\
\hline & & & \\
\hline & & & \\
\hline & & & \\
\hline & & & \\
\hline & & & \\
\hline & & & \\
\hline & & & \\
\hline & & & \\
\hline & & & \\
\hline & & & \\
\hline & & & \\
\hline & & & \\
\hline & & & \\
\hline & & & \\
\hline & & & \\
\hline
\end{tabular}




\title{
APPENDIX 4: TABLE OF RESULTS
}

\section{RSA: MODAL VALUES FOR}

\author{
ITEMS RATED BY ALL
}

PARTICIPANTS 


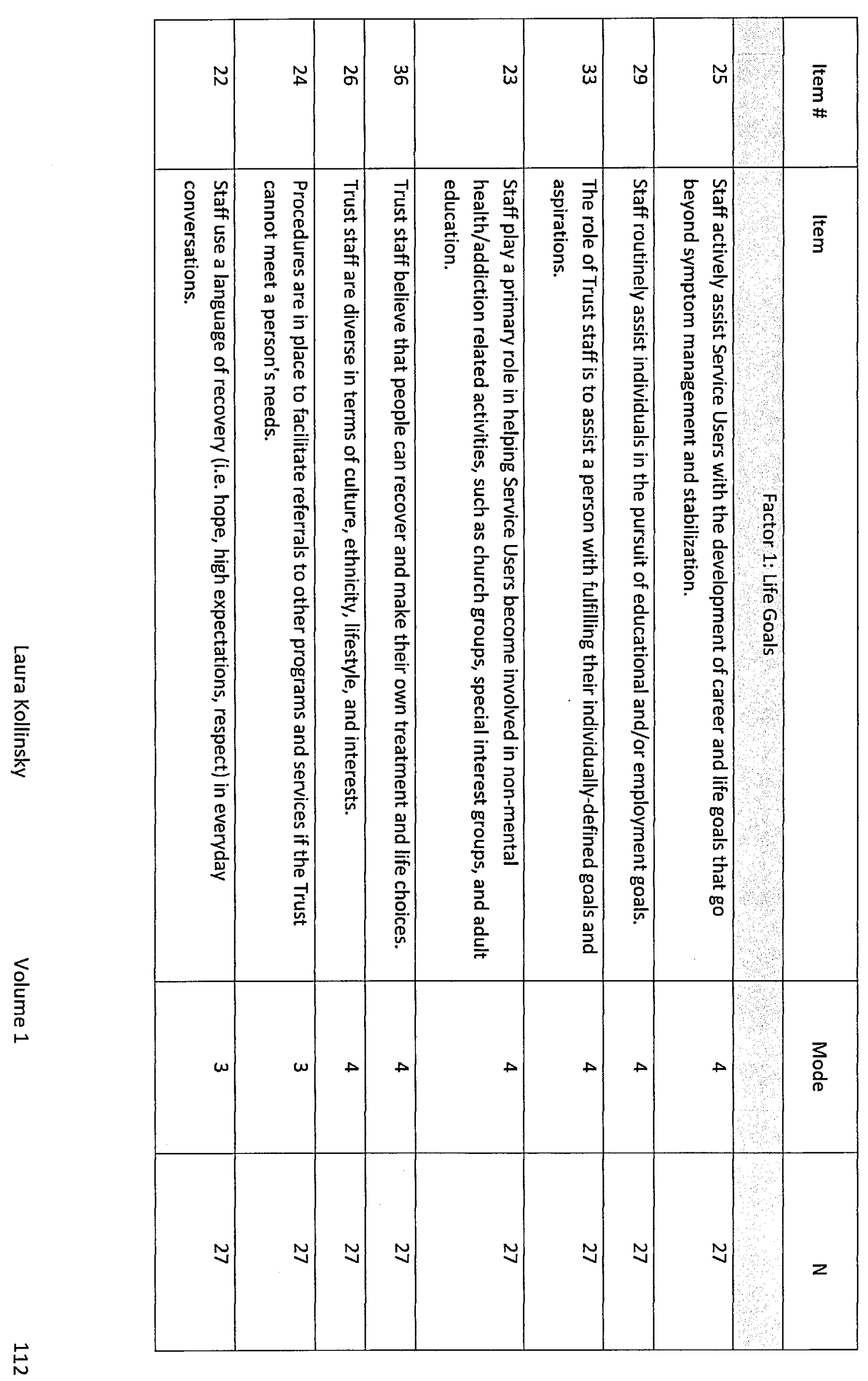




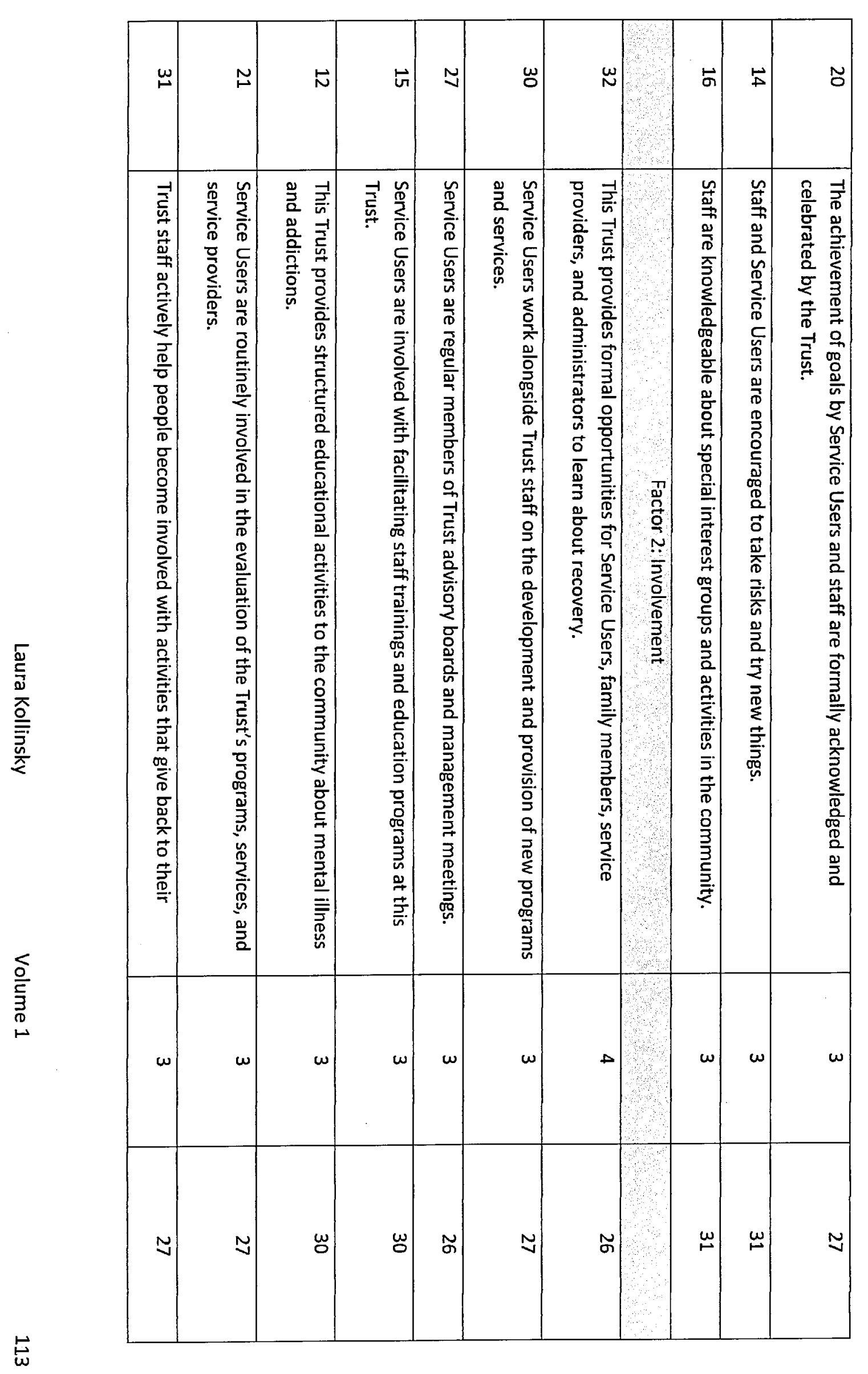

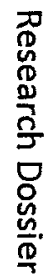

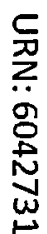




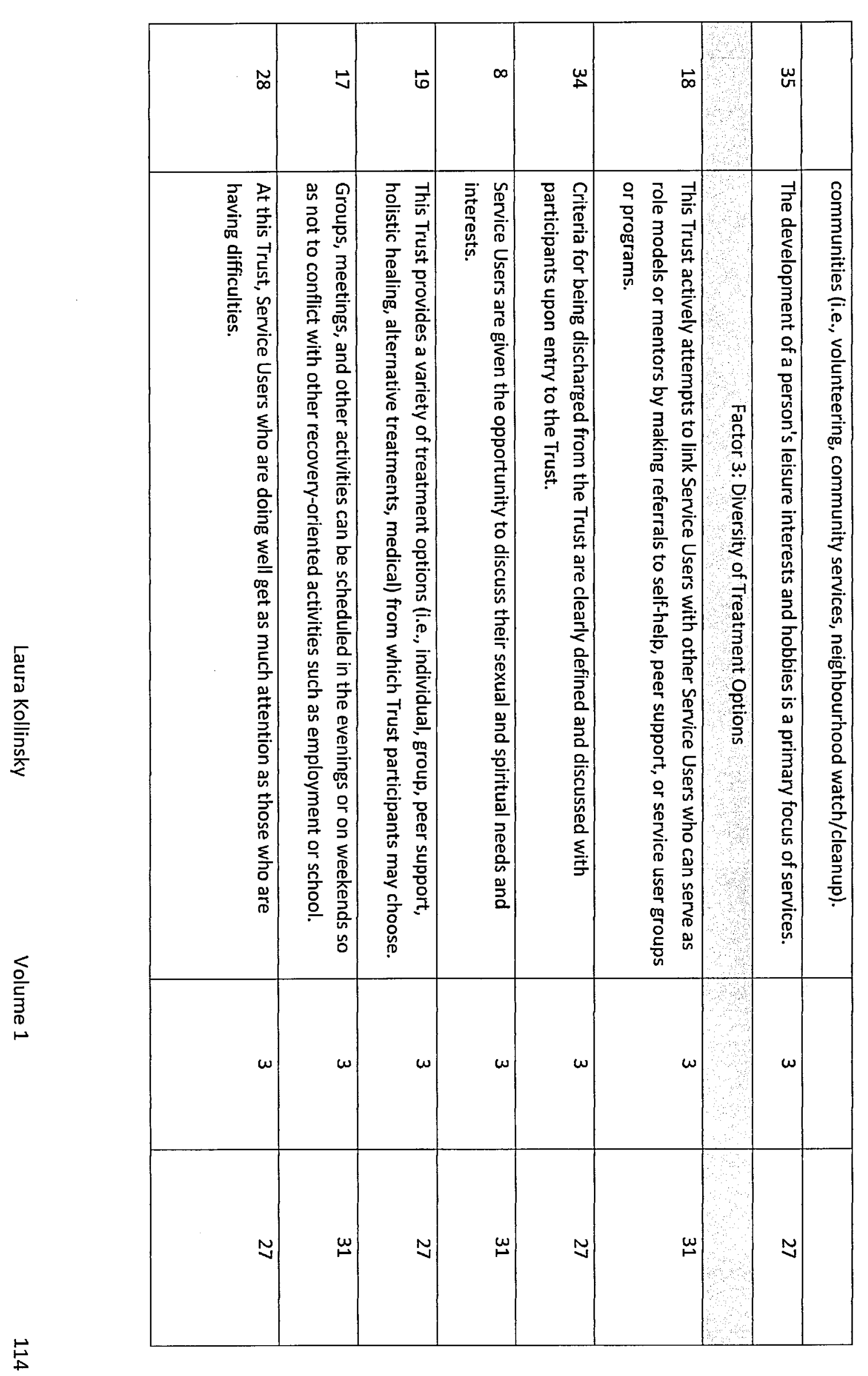




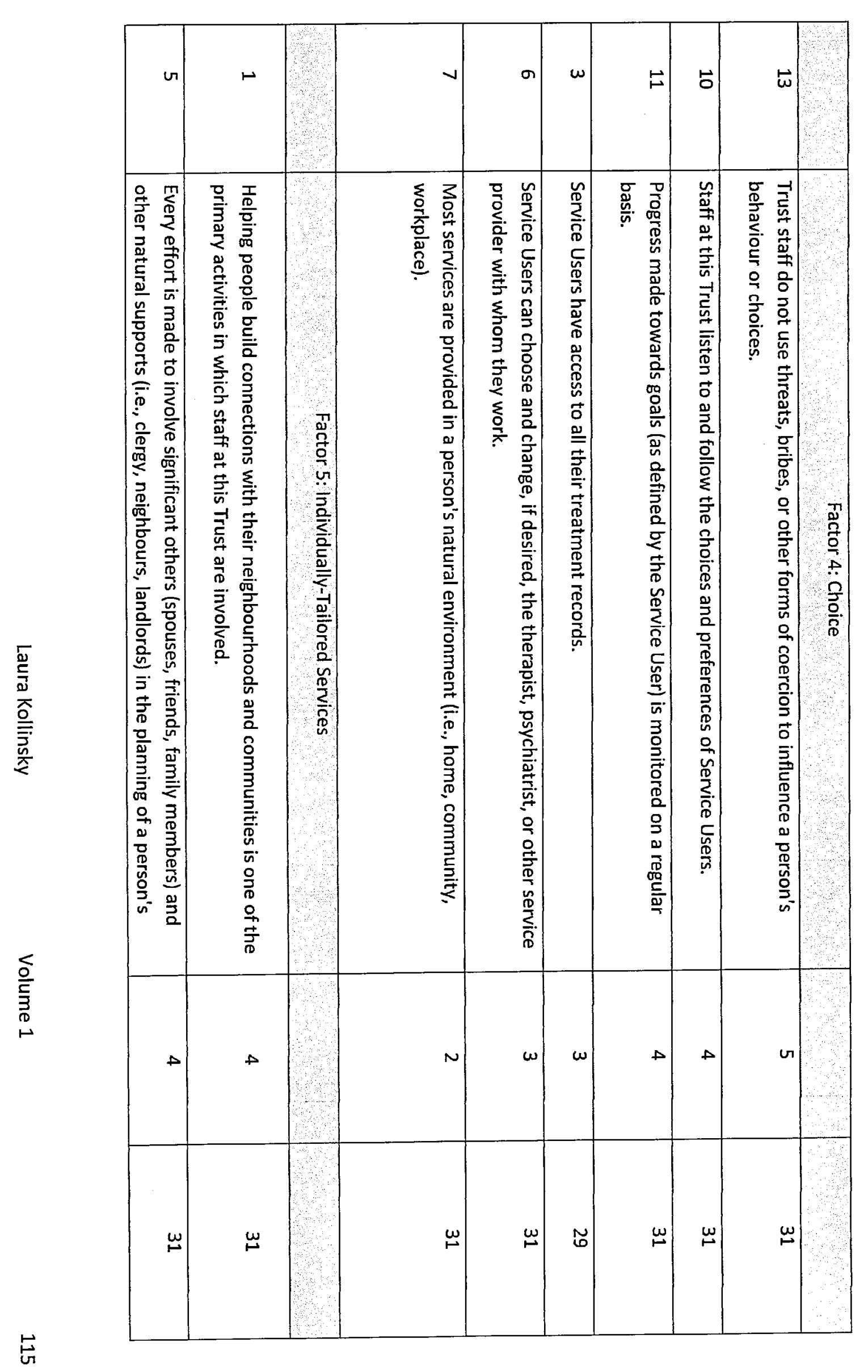

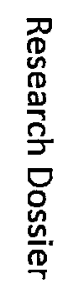




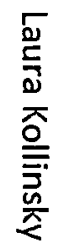

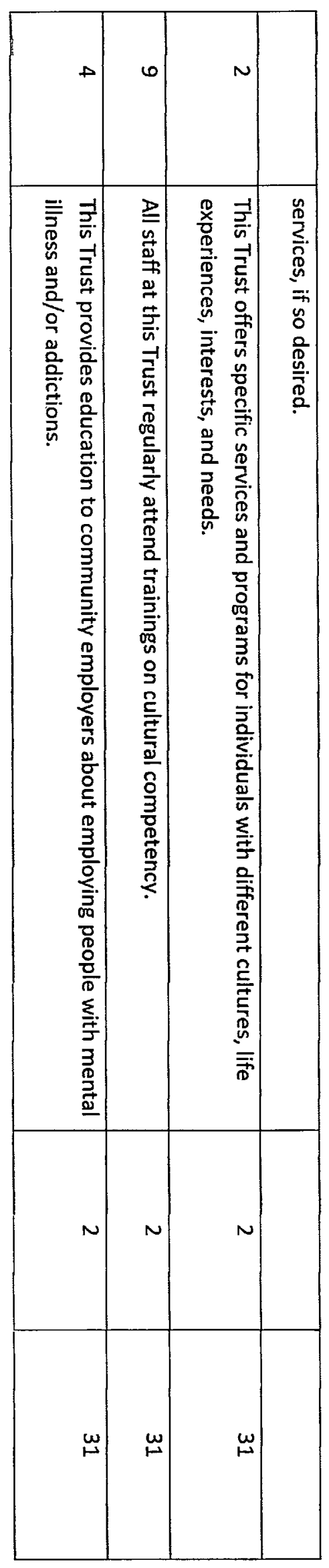

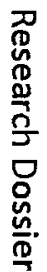

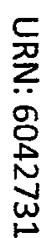

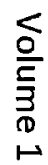

完 


\title{
APPENDIX 5: TABLE OF
}

\author{
RESULTS
}

\section{SUMMATIVE CONTENT}

\author{
ANALYSIS
}




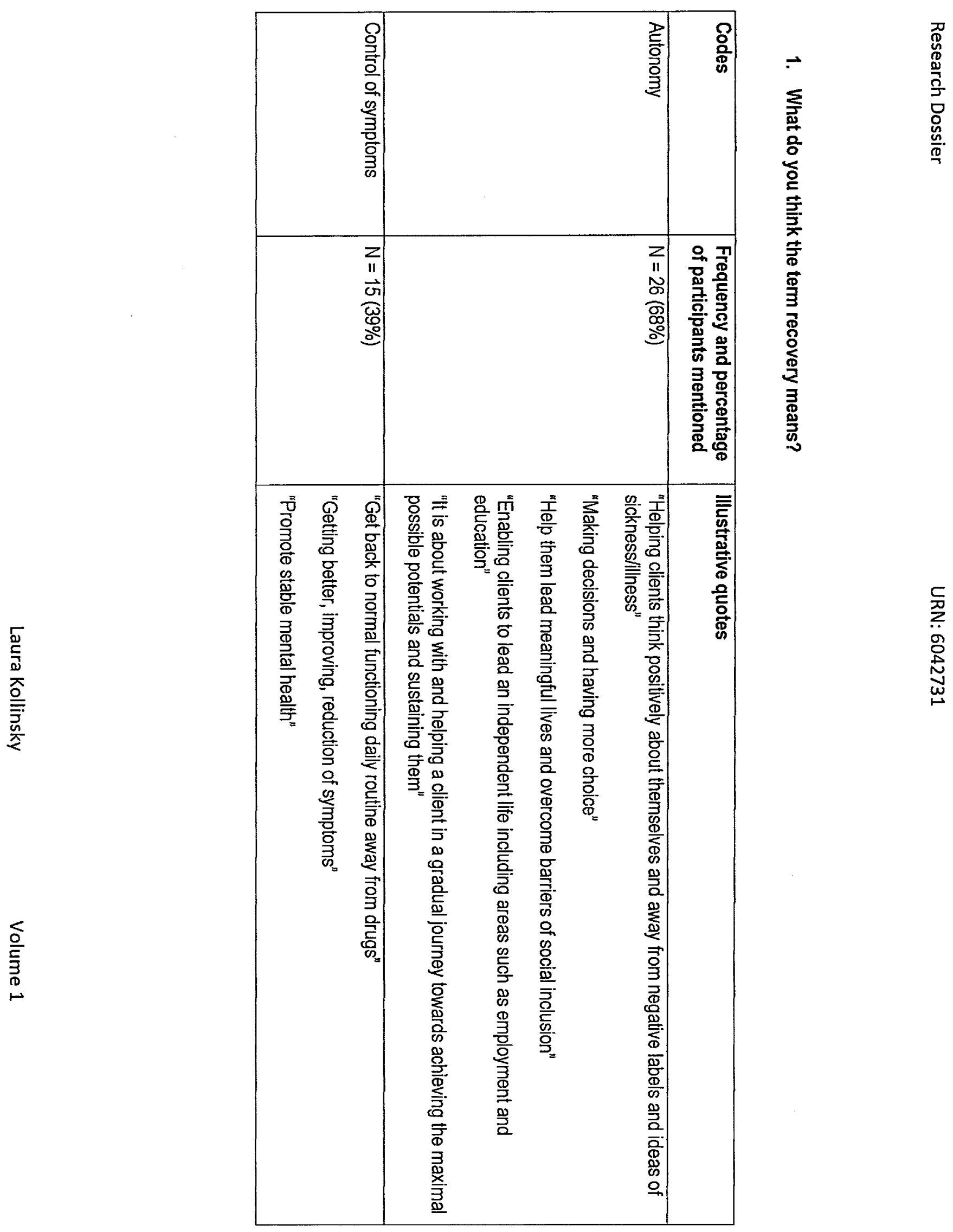




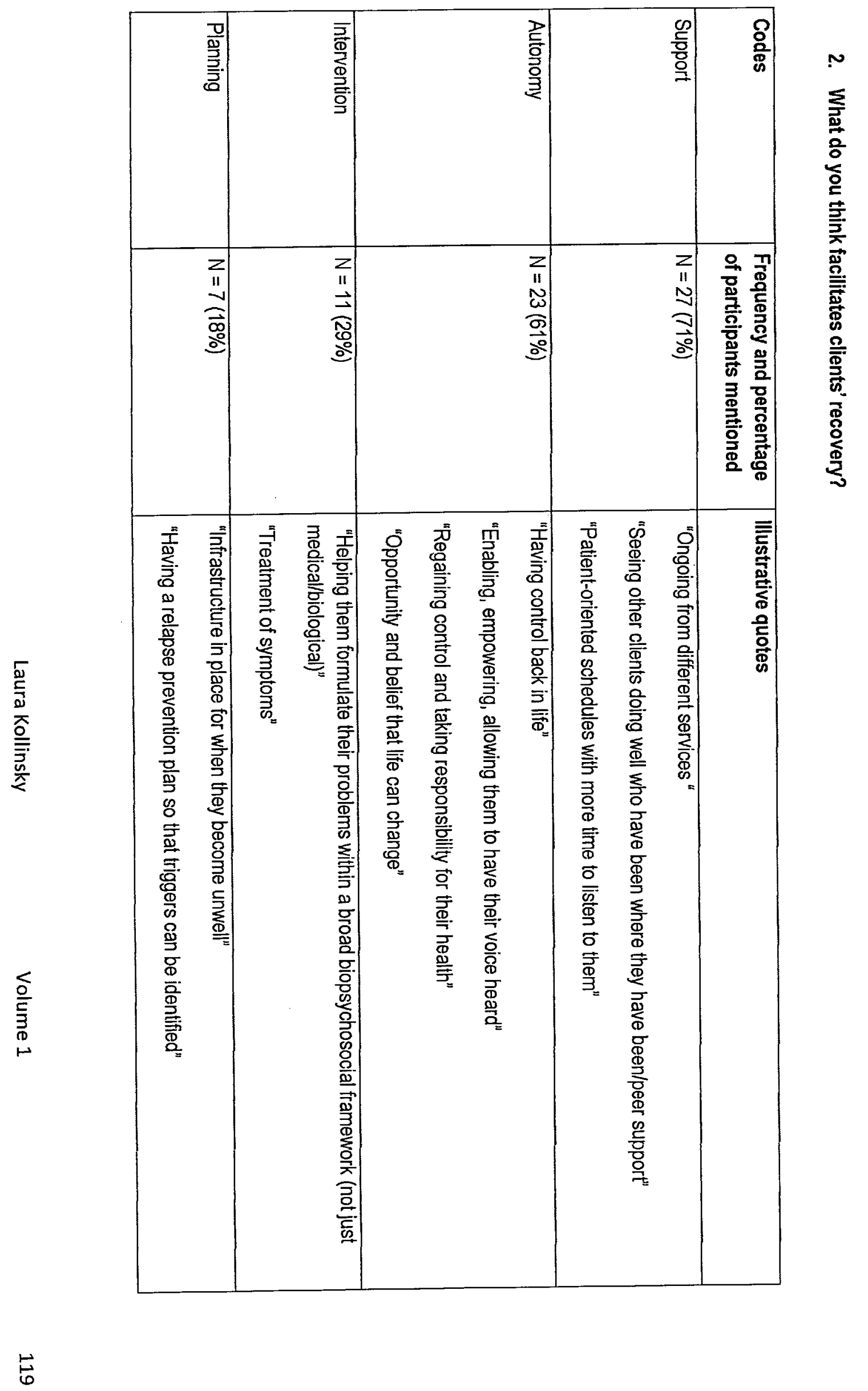




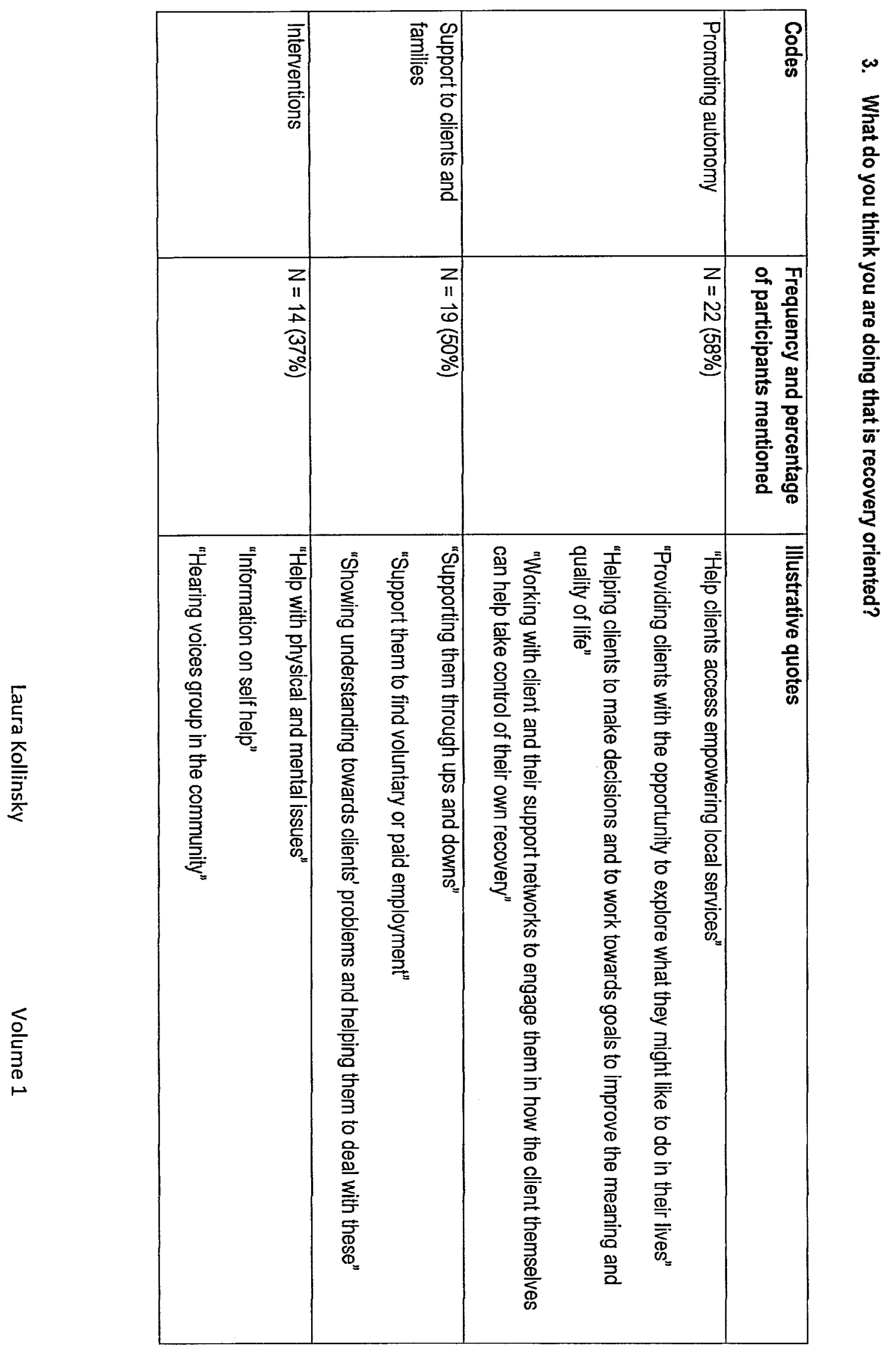




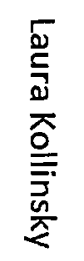

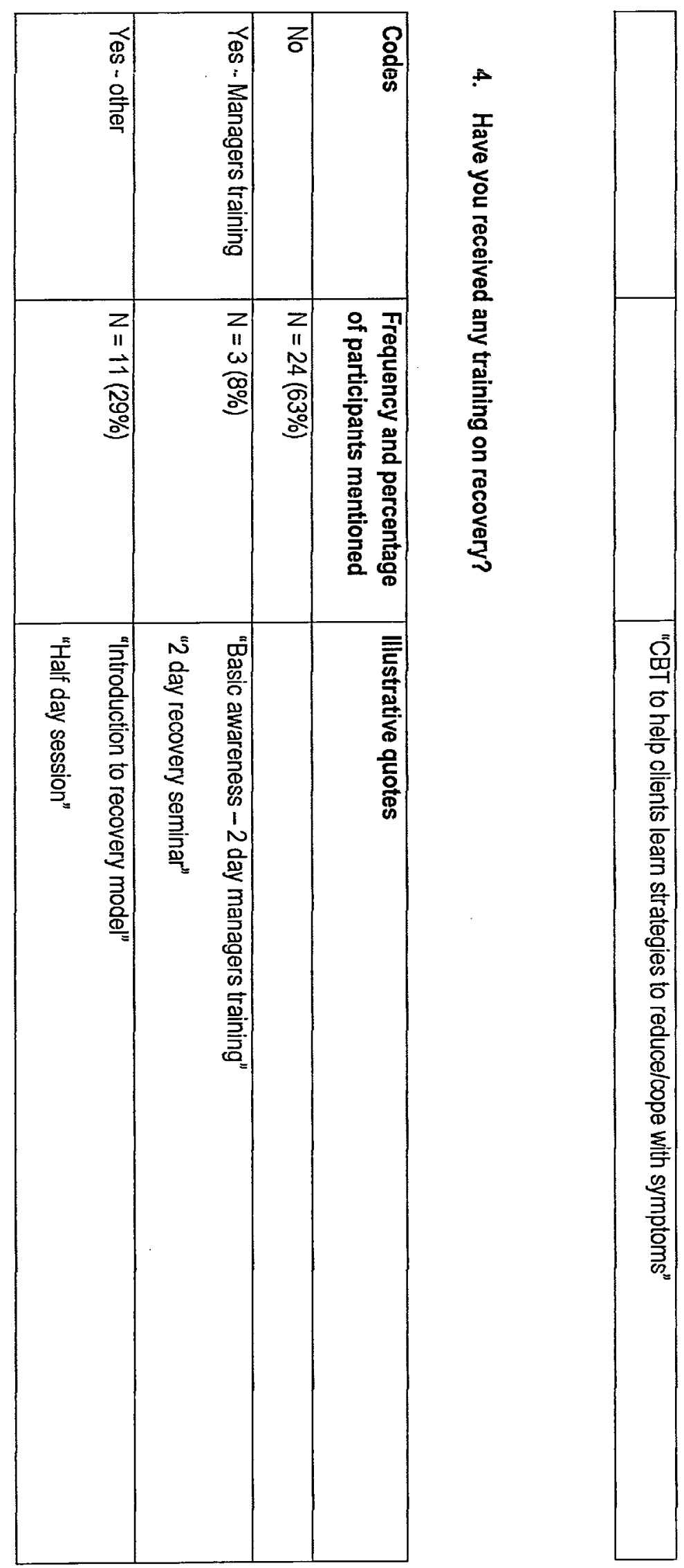

P
$\mathbb{D}$
0
0
$\frac{0}{5}$
$\frac{0}{8}$
0
$\frac{0}{0}$
$\frac{0}{9}$

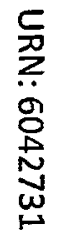

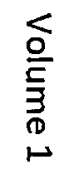




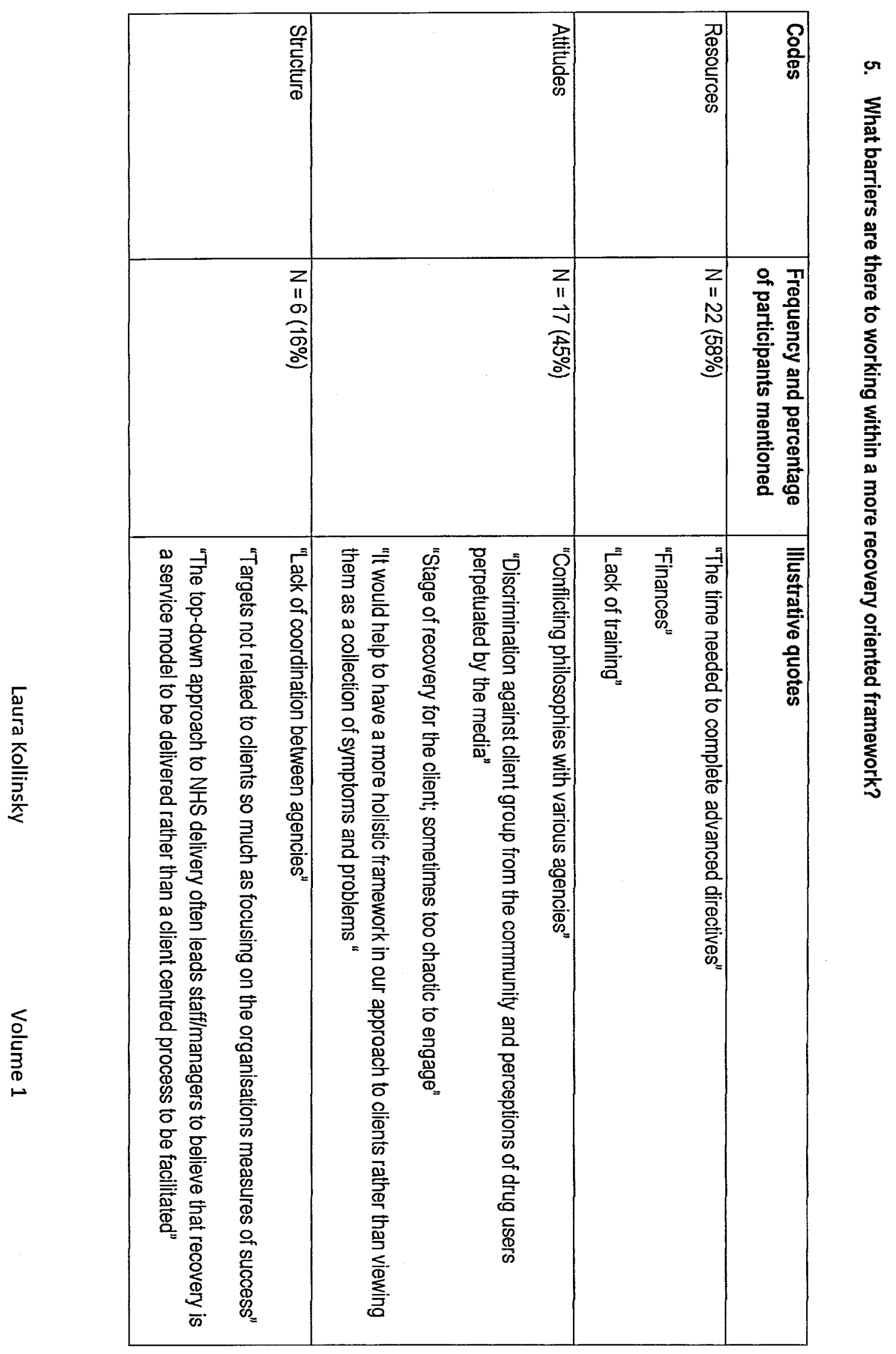

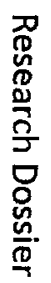

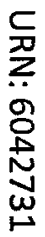




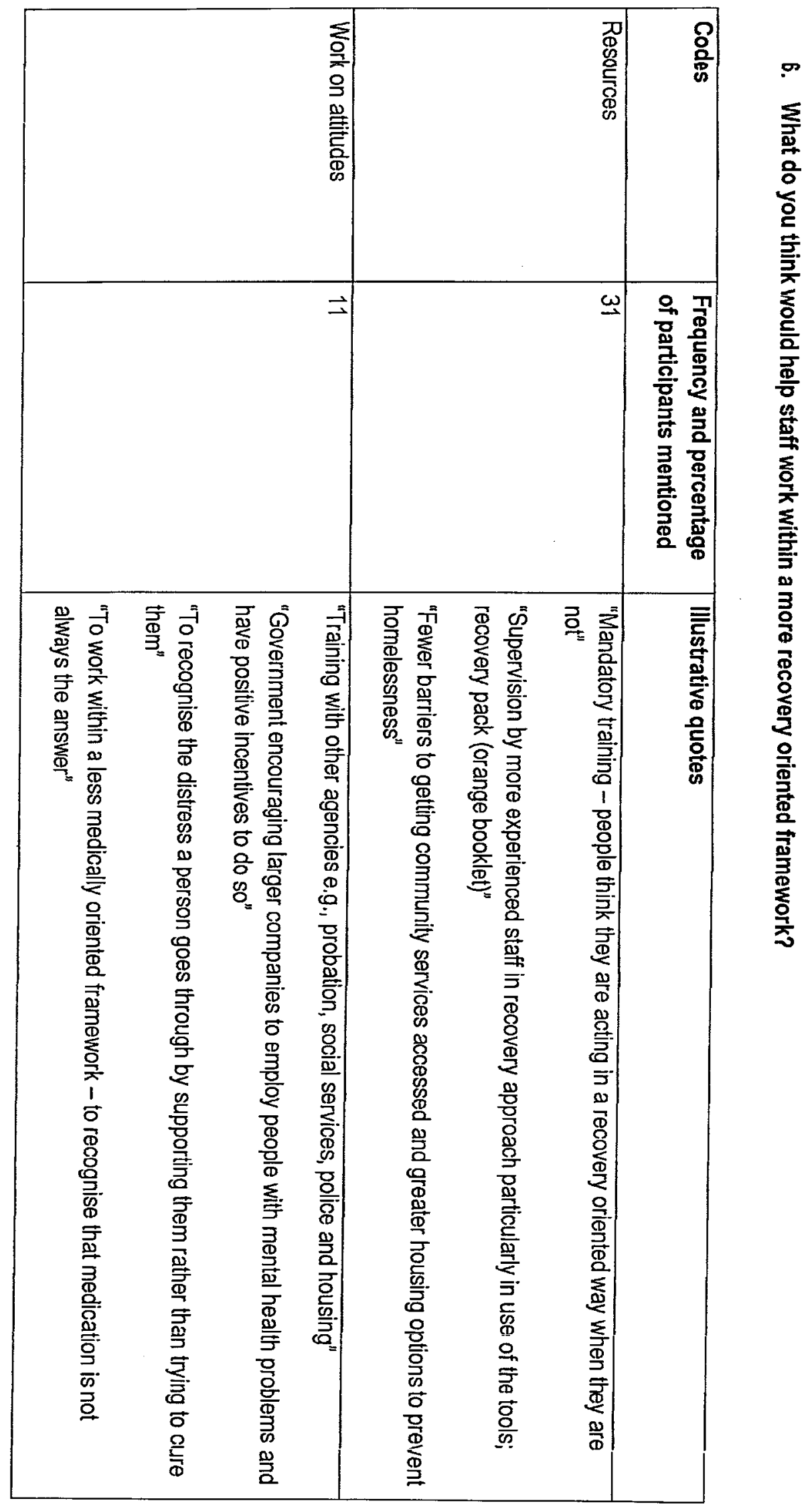




\section{APPENDIX 6: INFORMATION}

\section{TAKEN FROM THE TRUST}

\section{STRATEGY ON RECOVERY AND}

\section{SOCIAL INCLUSION}


Appendix 6: Information taken from the Trust strategy on recovery and social inclusion

In May 2007 the Trust Board approved a statement of vision, values and purpose of the organisation:

"Our vision is of a future in which people with mental health problems have the same opportunity as other citizens to participate in, and contribute to, our communities.

The Trust recognises that everyone with mental health problems faces the challenge of retaining and recovering a life that is meaningful, satisfying and valued as possible.

Our purpose is to help people to help do the things they want to do, live the lives they want to lead and access those opportunities that all citizens should take for granted."

The strategy states that:

'Recovery refers to the experience of people as they accept and overcome the challenge of mental health problems. Recovery is about retaining or rebuilding a new sense of self, meaning and purpose in life. It is not the same as cure. It is about growing beyond the catastrophic effects of mental illness, pursuing your ambitions and living well even if your problems continue.

The experience of people who have faced the challenge of rebuilding their lives with mental health and related problems shows us that three things are critical:

\section{HOPE, CONTROL AND OPPORTUNITY}

If we are to assist people in their journey of recovery we must:

- Foster hope and hope-inspiring relationships.

- Help people accommodate what has happened to them and take back control over their problems and lives.

- Assist people to access those opportunities that make life worthwhile those things that other citizens take for granted. 


\title{
APPENDIX 7: EMAIL FROM
}

\section{CLINICAL PSYCHOLOGIST}

\author{
(JOINT FACILITATOR OF
}

\section{RECOVERY WORKSHOP)}




\section{From: XXXhotmail.com}

To: X@hotmail.com

Subject:

Date: Fri, 11 Jul 2008 13:27:54 +0000

Dear $\mathrm{X}, \mathrm{X}$ and $\mathrm{X}$

I am writing on behalf of myself and XX (Chair of X Recovery Steering Group) to say thank you for your presentations of your service related research projects. These were a very important contribution to the Recovery Initiatives in $X$ afternoon, which was part of the $X$ Postgraduate Academic Teaching Programme on 12th June.

All the presentations were of an extremely high standard and were very clear and informative. The results were very valuable and provoked a lot of interesting discussion.

I understand that you will all be meeting with $X X$, and the rest of the $X$ Recovery Steering Group in mid-July to discuss how the results can be used to help staff within the local trust services work within a more recovery oriented framework. I know that the group really value the time and effort you have put into these projects and are looking forward to working with you all so the recommendations can be put into practice locally.

Many thanks again

$X$

Dr XX

Chartered Clinical Psychologist

$X$ CMHT 


\title{
“'At the moment we're just
}

\section{sharing space not sharing the}

experience." Investigating

Division in a shared learning

\author{
environment'
}

Abstract of qualitative research

project

June 2008

Year 1 
Whilst there are benefits to inter-professional learning, bringing multiple viewpoints to the classroom can result in tension (Crow \& Smith, 2003). This study aimed to explore the experience of counselling and clinical psychology trainees in joint weekly research methods teaching sessions. The research sought to explore the constructions of reality which resulted from the different subjective experiences and how the professionals in the two groups made sense of these experiences. Interpretive Phenomenological Analysis (IPA) was used to analyse the transcripts of two focus groups, one made up of six clinical trainees and another of two counselling trainees. Seven superordinate themes arose from the analysis and the report focuses on the theme of 'division' as this was of most relevance to the research question. Firstly the theme 'we all write separate reports' was important in illustrating the trainees were unable to work towards a common goal, and were blaming course structure for divisions. Further 'it wasn't the right kind of room' was a reflection of the limitations in the physical environment. Finally 'it seems almost symbolic' is concerned with the trainees' responsibilities to integrate with the other group, and focused on trainees choices to sit with members of their own cohort and not seek collaboration. It was concluded that rather than being a shared learning environment, the research lectures simply functioned as shared teaching. To overcome divisions more cooperation is required, with a reliance on others to achieve common goals. Limitations and implications for practice are discussed.

\section{Reference}

Crow, J. \& Smith, L. (2003). Using co-teaching as a means of facilitating interprofessional collaboration in health and social care. Journal of interprofessional care, $17(1), 45-55$. 


\title{
'A qualitative exploration of
}

the views and experiences of

\section{family court magistrates}

making decisions in care

proceedings involving parents

\section{with learning disabilities'}

\author{
Major Research Project \\ July 2010 \\ Year 3
}


A Qualitative Exploration of the Views and Experiences of Family Court Magistrates Making Decisions in Care Proceedings involving Parents with Learning Disabilities

by

Laura Kollinsky

Volume 1

Major Research Project

(19,950 words)

Submitted for the degree of Doctor of Psychology

(Clinical Psychology)

\author{
Department of Psychology \\ Faculty of Arts and Human Sciences \\ University of Surrey
}

October 2010

(C) Laura Kollinsky 2010 


\section{Acknowledgements}

I would like to acknowledge and offer special thanks to Laura Simonds (Academic Supervisor) and Julie Nixon (Field Supervisor) for all their help and support throughout this research project. I would also like to extend my gratitude to the participants of this study for giving up their time and sharing their experiences with me.

Finally, I would like to thank my family and friends for their endless love and support over the last three years and for always believing in me. In particular, my parents, my husband Laurence, Becky and Anna, and the girls at university for all the laughter we have shared together. 


\section{Abstract}

The number of parents with learning disabilities appears to be increasing in the United Kingdom; however, there is some evidence to suggest that parents with learning disabilities are more likely to have their children permanently removed than other parents. As yet there has been no known research involving magistrates in England and this is surprising considering they are at the forefront of decision-making in care proceedings. This study aimed to explore the experience of magistrates making decisions in care proceedings involving parents with learning disabilities, in particular, views about people with learning disabilities and influential factors in decision-making. Interpretative Phenomenological Analysis (IPA) was used to analyse the transcripts of interviews with four family court magistrates and the report focuses on the three superordinate themes that arose from the analysis. The results highlighted some contrast in views about people and parents with learning disabilities. Three participants appeared keen to regard people with learning disabilities as very individual, whilst one participant made some generalisations about some groups of people with learning disabilities all being the same. Four main influential factors when determining the best interests of the child were spoken of, which included the timescale and age of the child, expert opinion, parenting abilities and support. Finally, participants spoke of the influence of experiences with people with learning disabilities on the role they adopt within care proceedings and the awareness they have developed regarding the limits of their own knowledge. To overcome making generalisations about parents with learning disabilities and to enable magistrates to be more active in care proceedings, some participants raised a need for magistrates to receive training about learning disabilities. Limitations and implications for practice are also discussed. 
Contents

Abstract 133

1. Introduction 136

1.1 Definition and prevalence of learning disabilities 136

1.2 A brief history regarding parents with learning 136

disabilities

1.3 Parents with learning disabilities and contact with 137

services

1.4 Parents with learning disabilities in the child protection $\quad 138$

system

1.5 Factors contributing to involvement in the child protection $\quad 140$

system

1.6 The magistracy and decision-making frameworks 142

1.7 Decision-making 144

1.8 Magistrates' decision-making in care proceedings $\quad 145$

1.9 Decision-making in care proceedings involving parents with $\quad 146$ learning disabilities

1.10 Rationale for study $\quad 149$

1.11 Research aims $\quad 150$

1.12 Research question $\quad 151$

2. Method 151

2.1 Rationale for qualitative methodology and Interpretative $\quad 151$

Phenomenological Analysis (IPA)

2.2 Inclusion criteria and recruitment sources 152

2.3 Sample size $\quad 153$

2.4 Materials $\quad 156$

2.4.1 Semi-structured interviews $\quad 156$

2.4.2 Development of the interview schedule $\quad 156$

2.5 Procedure 157

2.6 Ethical considerations 157

2.7 Analysis 158

2.8 Enhancing and demonstrating the validity of the analysis $\quad 159$

$\begin{array}{ll}\text { 2.8.1 Personal reflections } & 161\end{array}$

3. Results 162

3.1 Context of findings $\quad 162$

3.2 Overview of findings $\quad 162$

3.3 Theme 1: Learning disability as a continuum 164

$\begin{array}{ll}\text { 3.3.1 Heterogeneity } & 164\end{array}$

3.3.2 Homogeneity 167

3.4 Theme 2: Determining the best interests of the child 170

3.4.1 Timescale and age of the child 170

3.4.2 Expert opinion $\quad 172$

3.4.3 Parenting abilities $\quad 173$

3.4.4 Support 176

3.5 Theme 3: Self-characterisation within the system 178

$\begin{array}{ll}\text { 3.5.1 Knowledge } & 178\end{array}$

$\begin{array}{ll}\text { 3.5.2 Role as a magistrate } & 180\end{array}$ 
4. Discussion 184

4.1 Limitations of the study 184

4.2 Main findings and links with existing literature $\quad 186$

4.2.1 Learning disability as a continuum 186

4.2.2 Determining the best interests of the child 188

4.2.3 Self-characterisation within the system 190

4.3 Implications for clinical practice and organisations $\quad 191$

4.3.1 A need for training $\quad 191$

4.3.2 Involvement of 'experts' 192

4.3.3 Parenting assessments and interventions 193

4.3.4 Finding the 'right' support 193

4.3.5 Parents with learning disabilities $\quad 194$

4.4 Implications for future research $\quad 194$

4.5 Final reflections $\quad 195$

$\begin{array}{ll}4.6 \text { Conclusions } & 196\end{array}$

$\begin{array}{ll}\text { References } & 197\end{array}$

Appendices 203

Appendix 1: Welfare checklist from The Children Act (1989) 204

Appendix 2: Detailed information on Section 8 orders 206

Appendix 3: Further explanatory notes regarding recruitment 208

Appendix 4: Email correspondence with Executive Committee. 211

Appendix 5: Interview schedule 216

Appendix 6: Participant information sheet $\quad 219$

Appendix 7: Demographic sheet 223

Appendix 8: Consent form $\quad 228$

Appendix 9: Ethical approval from University of Surrey 230

Appendix 10: Example of annotated transcript 232

Appendix 11: Feedback questionnaire 256 


\section{Introduction}

\subsection{Definition and prevalence of learning disabilities}

The term 'learning disability' is most commonly used within the United Kingdom (UK) and replaced the term 'mental handicap' (British Psychological Society (BPS), 2001). 'Learning disability' will be used throughout the current study; however, literature referenced has also included the terms 'learning difficulty', 'intellectual disability' and 'mental retardation'. The BPS states that for a person to be considered as having a learning disability, three criteria must be met: 'significant impairment of intellectual functioning' and 'significant impairment of adaptive/social functioning', which have been acquired before adulthood (BPS, 2001, p.4). It is important to recognise that all levels or types of learning disabilities are on a spectrum and there are no clear ways of differentiating between them (British Institute of Learning Disabilities (BILD), 2007). It was estimated there will be approximately 850,000 people with learning disabilities in England by 2011, making up about $2 \%$ of the population; with numbers expected to increase by $11 \%$ between 2001 and 2021 (Emerson \& Hatton, 2004).

\subsection{A brief history regarding parents with learning disabilities}

There has been a long history in which people with learning disabilities have been stigmatised and viewed by some as 'eternal children' who are dependent on others and unable to parent (McConnell \& Llewellyn, 2000). Early research in the 1940 s showed there was mixed opinion in society about whether or not people with learning disabilities should be allowed to have children (Llewellyn et al., 2008). The contemporary context is quite different and a number of UK government drives and initiatives have been developed to try to change the way people with learning disabilities are treated within society. With this shift, also came a focus on changing attitudes regarding people with learning disabilities having intimate, sexual relationships and reproducing (Aunos \& Feldman, 2002). This, combined with the introduction of The Human Rights Act (1998), has meant that people with learning disabilities now have the right to intimate relationships, unless they lack capacity to consent. This has been reflected in more recent UK government initiatives such as the 2009 White Paper Valuing People Now: A new three year strategy for people with learning disabilities (Department of Health 
$(\mathrm{DH}))$, which emphasises the rights of people with learning disabilities to become parents and receive appropriate support to keep the family unit together.

\subsection{Parents with learning disabilities and contact with services}

The current number of parents with learning disabilities in the UK is not accurately known due to factors such as a lack of common definitions of the term 'learning disability', fragmented services and poor records (Booth et al., 2005). Another factor is that figures are usually gained from services and it is accepted that there is likely to be a proportion of parents with learning disabilities who are unknown to services ( $(b i d)$. The first national survey of people with learning disabilities in England was completed by Emerson et al. (2005) in 2003/4. The study aimed to include a representative sample of adults with learning disabilities and therefore included people, other than only those in contact with specialised learning disability services. Of the 2,898 adults with learning disabilities interviewed, one in 15 had children; making up around $7 \%$ of their sample $(n=202)$. Despite difficulties in determining accurate figures, the number of parents with learning disabilities and those in contact with services is said to be increasing in the UK (DH, 2001), including referrals to adult learning disability teams and clinical psychology departments where parents with learning disabilities are said to 'feature prominently on practitioners' workloads' (Booth et al., 2005, p.8).

Although intelligence quotient ( $I Q$ ) alone is not deemed to be a good predictor of parenting, unless it falls below 60 and adequate support is absent (McGaw \& Newman, 2005); parents with learning disabilities may have a number of difficulties which mean they require contact and support from services (Department for education and skills (DfES) \& DH , 2007). Cognitive impairments may affect skills such as reading, problem solving and decision-making; all of which may affect a person's abilities to parent and their need for support (/bid). People with learning disabilities are also likely to experience difficulties in other areas, such as poverty, poor housing, social exclusion, undiagnosed mental and physical health problems and low self-esteem (/bid). The parent's learning disability can also impact on the child. It has been suggested that there is strong evidence to support a genetic link between a parent's learning disability and developmental delay in the child (McGaw \& Newman, 2005). Genetic 
vulnerability may also be affected by other issues such as a lack of environmental stimulation (Ibid) or specific difficulties the parents have such as language difficulties (DfES \& DH, 2007). Children have also been known to present with behavioural issues, particularly if the child's intellectual abilities exceed those of the parent (McGaw \& Newman, 2005). These factors help to explain why parents with learning disabilities may come into contact with services and may require specialist support (Tarleton et al., 2006). An evidence base has shown that a number of characteristics in relation to support have been identified as effective for some parents with learning disabilities (e.g. a focus on parents' strengths and training in the person's home. See McGaw and Newman (2005) for more details).

Whilst an evidence base has been created regarding parents with learning disabilities, it should be recognised that the research completed has usually focused on those parents already involved with services and who are having difficulties with parenting (DFES \& DH, 2007). Emerson et al. (2005) estimate that only a quarter of adults with learning disabilities in England use specialised learning disability health or social services. Subsequently, relatively little is known about parents with learning disabilities who are doing well and are not in contact with services. Hence, these conclusions cannot be seen to be representative of all parents with learning disabilities.

\subsection{Parents with learning disabilities in the child protection system}

Despite comprising only a small proportion of families in the UK population and an evidence base suggesting that some people with learning disabilities can parent adequately, Booth and Booth (2004b) propose that parents with learning disabilities are 'disproportionately represented' in the child protection system. Booth and Booth (2004a) undertook one of the only larger scale research studies in England focusing on parents with learning disabilities and the child protection system. As part of the research, 437 court files were reviewed from care applications to courts in Leeds and Sheffield in the year 2000. The authors found that over one in every six of the 828 children involved in their sample had at least one parent with a learning disability. Furthermore, if parents with a diagnosis of a borderline learning disability had been included, this figure would have reached one in four (i.e. 183 children) (lbid). The authors suggested that based on 
estimates of their numbers in the general population, parents with learning disabilities were between 30 and 60 times more likely to be the focus of a care application than parents without learning disabilities (Booth \& Booth, 2004b). However, this was the only study in the UK found which has investigated the prevalence of parents with learning disabilities in care applications and therefore cannot be seen to reflect all findings in the UK.

The literature also portrays a picture in which parents with learning disabilities are at a higher risk of having their children removed than parents without learning disabilities. This has been demonstrated in numerous UK and international studies; with figures showing that $40-60 \%$ of children of parents with learning disabilities in the UK are placed into alternative care (Booth \& Booth, 2004b). These figures are reflected in the national survey by Emerson et al. (2005) which revealed that $48 \%(n=97)$ of parents with learning disabilities interviewed were not living with their children. Booth and Booth (2004a) also found that $75 \%$ $(n=95)$ of the children of parents with learning disabilities in their study had been placed outside of their family home. They also identified that children of parents with learning disabilities were significantly more likely to be the subject of freeing orders (i.e. freed for adoption) and placed outside of the family or 'kinship network' than children of other parents (i.e. parents with: mental illness, drug/alcohol problems, or no disabilities) (/bid). The authors suggested the higher freeing order rates may have been related to the larger proportion of newborn babies in their sample whose parents had learning disabilities and the importance that is placed on seeking permanent placements when such young children are involved.

In contrast to the above findings, Cleaver and Nicholson (2008) reviewed social work case files, taken from 10 English local authorities, and found that $83 \%$ of a group of 64 children of parents with learning disabilities were still living with their parents three years after the referral had been received by the local authority. Whilst these findings may suggest that higher removal rates are not representative of the results for all parents with learning disabilities in care proceedings in England, they may also reflect methodological variations in studies. For example, Booth and Booth (2004a) reviewed cases that had already Laura Kollinsky 
proceeded to court, whilst Cleaver and Nicholson (2008) reviewed social work case files, which may have included cases that did not require legal proceedings.

\subsection{Factors contributing to involvement in the child protection system}

It has been suggested that parents with learning disabilities may be more likely to be involved in the child protection system for a number of reasons. Tarleton et al. (2006) completed a mapping study of support available to parents with learning disabilities and their children; gathering information from parents with learning disabilities $(n=17)$ and professionals in the UK $(n=85)$ through a web-based questionnaire and interviews. The authors found that parents with learning disabilities were often only referred to services at crisis point, at which time it was too late for some parents to receive support and resulted in child removal. Some parents with learning disabilities also described difficulties engaging with services who were concerned about their children's welfare and even 'taking a deliberate stance against services and professionals who they thought were threatening their family' (Ward \& Tarleton, 2007, p.24). Some parents related this to fears about having their children removed; confusion about what professionals had concerns about, or what was being said to them at times (lbid).

However, once involved in the child protection system, parents with learning disabilities may be unsupported, as even when it has been established that the parent requires support, this may not always be available or provided (Booth \& Booth, 2004a). Issues with support have been related to the eligibility criteria present in some services, as parents with learning disabilities may not always be able to access support from the services most appropriate for their needs e.g. adult learning disability teams (Tarleton et al., 2006). Additionally, it has been identified that some staff may not be well enough equipped with the knowledge required to assess or support parents with learning disabilities (Goodinge, 2000; Tarleton et al., 2006). Even if issues with support do not occur, Booth and Booth (2004a) also proposed that parents with learning disabilities are more likely to be blamed if the support provided fails, rather than attributing failure to the type or availability of support offered. 
Tarleton et al. (2006) identified some 'barriers to support' for parents with learning disabilities including negative stereotypes and attitudes of some professionals who had no specialist experience of working with adults with learning disabilities. These included assumptions that people with learning disabilities: 'were incompetent and never going to be "good enough parents", 'would be unable to understand their child's needs' and 'would be unable to learn skills quickly enough to meet their child's developmental needs' (Ibid, p.23). Booth and Booth (1993) have also argued that it is possible for parents with learning disabilities to have their difficulties with parenting attributed to their learning disability alone, rather than other factors such as poverty, social exclusion and lack of family support. This was highlighted in the study by Booth and Booth (2004a) in which the parent's learning disability was specifically cited as a risk factor to the welfare of the child in half of the 66 cases involving parents with learning disabilities in their sample. The authors suggested that professionals regarded the parent's difficulties with parenting as being 'irremediable' due to the learning disability itself. It is important to note, however, that in the study by Cleaver and Nicholson (2008), the removal of 11 children from parents with learning disabilities in their sample was reported to be a "last resort" and it was noted that there was no evidence to suggest that the parent's learning disability itself was used as a reason to remove the child.

It has been reported that parents with learning disabilities may also experience discriminatory treatment in which they are judged using stricter criteria than other parent groups; for example, being expected to provide a higher standard of parenting than those without learning disabilities (Tarleton, 2007). Reports also suggested that evidence had been used against parents with learning disabilities, which would not have been deemed acceptable in cases with parents without learning disabilities ( $/$ bid). Booth and Booth (2004a) also found that children of parents with learning disabilities were more than twice as likely to be newborn babies when care proceedings were instigated when compared to other parents without learning disabilities. The authors suggested this could relate to the tendency for concerns to be raised about babies based on previous issues with older children of the parents involved. As a result, nearly a third of the 127 
children of parents with learning disabilities in their sample had no allegations of neglect or abuse related to them (Ibid).

Booth and Booth (2004a) also suggested that parents with learning disabilities may lack legal representation during the child protection process. This was highlighted in their study in which only a few of the 31 parents with learning disabilities interviewed had been advised about their legal rights; only one parent was put in touch with an advocacy service and no one was referred to an adult learning disability service or social worker for assistance during the care application process ( $(\mathrm{bid})$.

\subsection{The magistracy and decision-making frameworks}

In England and Wales, family cases are often heard in the family proceedings court where care applications are made when a child is thought to be suffering, or at risk of suffering, significant harm (Judiciary of England and Wales, n.d.). These cases are usually brought to court by the local authority and during proceedings panels must decide whether to impose any orders. Panels can be comprised of magistrates, a district judge, or both. Whilst district judges are trained lawyers with at least seven years experience and are paid, magistrates are lay people who take on the role voluntarily and are unpaid (Her Majesty's Courts Service, n.d.). Although magistrates are not trained lawyers, they receive training for their role. Magistrates usually sit in a panel of three and the weighting of the decisionmaking is split equally (Judiciary of England and Wales, n.d.).

The Children Act (1989) and The Adoption and Children Act (2002) provide the main principles and restrictions to guide magistrates' decision-making with regard to determining if a child is in need of protection; the process of intervening, and the orders the court can make. The underlying principles of The Children Act (1989) are: the welfare of the child must be of paramount consideration when courts are making their decisions; a child's welfare overrides any rights or interests of the parents and the court should consider the general principle that any delay when determining the future upbringing of a child 'is likely to prejudice 
the welfare of the child' $(1(2))^{1}$. It also provides a 'welfare checklist' (see Appendix 1) in which a number of issues must be considered in each case, prior to the court making their decision.

When making decisions, magistrates are able to make various orders, if any. However, The Children Act (1989) states that these orders should only be made if the court is satisfied the threshold criteria have been met i.e. that the child is suffering, or is likely to suffer, significant harm (31(2a)), and this is because;

- The care being provided to the child is not what would be reasonable to expect of a parent (31(2bi)) or,

- The child is out of the parent's control (31(2bii)).

If the court is satisfied the threshold criteria have been met, magistrates can make the following orders:

- A Care Order in which the child will be placed in the care of a designated local authority (31(1a))

- A Supervision Order in which the child will be put under the supervision of a designated local authority or probation officer (31(1b)).

The magistrates may also make Section 8 Orders (see Appendix 2 for more details), whether or not the threshold criteria have been met. Finally, if a child is the subject of a Care Order, magistrates can make a Placement Order in which the local authority is given permission to place the child for adoption (21(1) The Adoption and Children Act 2002).

The information above indicates that magistrates are involved in complex and emotive decision-making in care proceedings. With this in mind, a wider body of literature regarding decision-making will be referred to in order to provide a theoretical basis to the research.

\footnotetext{
${ }^{1}$ Numbers in brackets indicate section number and part of the Act. 


\subsection{Decision-making}

Making complex decisions often involves managing uncertainty as outcomes of decisions cannot always be predicted. In any decision, magistrates adopt strategies such as relying on evidence provided in care proceedings and the opinions of experts or professionals to try to support their decision-making. Naturally, the decisions magistrates are required to make are not always straightforward and often involve high levels of complexity and vast amounts of information; presented in the form of reports and through appearances in court by different parties involved. During decision-making, particularly with more complex decisions where there is more information to take in, people cannot always use exhaustive strategies as these can be inefficient due to constraints on resources such as time and money (Zimbardo \& Weber, 1997). Research has shown that consequently people often take shortcuts when decision-making by using heuristics, which are cognitive strategies or 'rules of thumb' (/bid). Although these are usually quite useful and indeed necessary, they can result in cognitive biases or errors which may affect decision-making (lbid).

Drawing on the literature on social cognition and decision-making, it could be hypothesised that some more common biases or errors may influence the treatment of people with learning disabilities in the child protection system. One of these is the universal tendency for people to be influenced by stereotypes (social categorisations); in this case about people with learning disabilities and their parenting abilities. People develop categories based on knowledge they have gained that correspond to concepts or classes of objects (Fiedler \& Bless, 2001). When categories are made in relation to social groups, they are termed stereotypes and involve 'shared beliefs about personality traits and behaviours of group members' (Ibid, p.123). By identifying certain individuals as belonging to a social category, this can allow more information to be inferred about that individual than is actually given $(/ \mathrm{bid})$. Although the use of social categorisation (aka stereotyping) is common and necessary (i.e. this allows one to save on effort) and often valid inferences from categories are made; issue comes when a category generalisation is made $(\mathrm{lbid})$. If a social category is therefore created in which people with learning disabilities are regarded as unable to parent and is 
then generalised to all parents with learning disabilities; this risks overlooking those who do possess the abilities to parent.

Another error that may affect the treatment of parents with learning disabilities in the child protection system is when difficulties with parenting are attributed to the learning disability alone, rather than considering situational factors that parents may be experiencing such as poverty and a lack of support. These errors or biases may relate to attribution theory, which proposes that individuals make causal inferences, as a result of processing information available to them, on a number of dimensions such as whether behaviour is due to situational or dispositional factors (Försterling, 2001). Related to this theory is the fundamental attribution error in which 'people over-attribute others' behaviour to dispositions and their own behaviour to the situation' (Ross, 1977, cited in Hogg \& Abrams, 2001, p.6). A similar effect is said to occur at a group level where the ultimate attribution error is made in which 'people tend to attribute negative acts performed by an outgroup member to underlying dispositions; often with genetic correlates, whereas the same act performed by an ingroup member is externally attributed to chance or situational factors' (Hogg \& Abrams, 2001, p.130). It has been noted that Pettigrew (1979) 'believed that the ultimate attribution error helps maintain ethnocentric attitudes', which involve overgeneralisations about others based on limited or often skewed evidence, if any at all (Ibid, p.130).

The material above is not introduced to suggest that this study will be looking to find evidence for the use of heuristics and biases in magistrates' decision-making, but rather to frame a discussion on the constraints when decision-making in complex and emotive environments.

\subsection{Magistrates' decision-making in care proceedings}

Limited research has been completed involving magistrates and their decisionmaking regarding care proceedings; however, one study was found which was completed in Australia. Sheehan (1999) interviewed 15 magistrates, who were all qualified legal practitioners, a requirement in Australia. The aim was to explore the factors that influence magistrates' decision-making in care proceedings cases. Sheehan (1999) noted that magistrates found family court decisions more difficult 
than those in other jurisdictions and this was due to the social and psychological nature of decision-making involved in this area rather than more straightforward legal decision-making in criminal matters. Factors that made decision-making more difficult were reported to be a lack of evidence, the competing interests of parents, and the distress present in child abuse cases. Participants noted that their work was made more difficult by the lack of training they received in this area.

For the majority of participants, the welfare of the child was a central issue in their decision-making and this was often determined by their reliance on a legal framework; since the welfare of the child is a guiding principle of The Children and Young Persons Act (1989) in Australia (Sheehan, 1999). Magistrates reported the need to consider facts and evidence presented to them. If evidence was not available or was of poor quality (as was noted to occur quite regularly), magistrates reported relying on elements from their legal training. They were also reported to draw on their own personal experiences of parenting and reports on child protection issues in the media. Sheehan (1999) suggested that a number of cognitive schemas appeared influential in magistrates' decision-making including views that intact families were easier to take risks with (i.e. returning children to the family home), as were parents prepared to accept treatment programmes. Magistrates also reported having concerns about the inexperience of professionals involved in the child protection system and as a result lacked confidence in the assessments or interventions regarding families. Despite this, Sheehan found that in court records 'magistrates' decisions generally agreed with statutory authority recommendations' $(1999$, p.8). This research suggested that magistrates' decision-making in care proceedings cases is 'not really law' and that magistrates therefore require more specialist training and knowledge regarding social and psychological consequences for children in order to make their decisions appropriately.

\subsection{Decision-making in care proceedings involving parents with learning disabilities}

McConnell et al. (2002) carried out research in 1998/99 in Australia, in which they reviewed court files, observed care proceedings in court and completed individual 
or group interviews with eight children's magistrates, 34 legal representatives and 155 child protection workers. Their aim was to examine the court process and decision-making in cases involving parents with learning disabilities. The findings suggest that when magistrates were making decisions on court outcomes they tried to determine the abilities of parents to 'lift their game' and a number of things were influential when doing this. The authors noted that magistrates had a keen interest in deciding whether or not the parents had been given a fair chance to correct their difficulties through the provision of support. If the statutory authority had made serious attempts to offer support but there had been no change, magistrates were more likely to decide upon a placement outside of the family home. However, if attempts were insufficient then magistrates were more likely to consider other options within the family unit. Magistrates were also influenced by the compliance of the parents, including their willingness to cooperate and accept direction from statutory authorities as well as to show an insight into their difficulties and demonstrate they could make changes.

Another influence was the weight that magistrates placed on expert opinion, which was usually sought in cases involving parents with learning disabilities. In relation to expert opinion, McConnell et al. (2002) noted that prejudicial views may be held by magistrates when determining if parents are able to change. They reported that magistrates looked to experts for a diagnosis and an explanation for how the diagnosis related to the behaviour of the parents and the child, and potential for change in the future. The authors suggested that $1 Q$ assessments were regularly used in order to gain a diagnosis and this implied that magistrates attributed perceived difficulties with parenting to the learning disability rather than other factors such as their living circumstances. This was proposed to translate to a view that the parenting difficulties of people with learning disabilities could not be remedied.

Magistrates also acknowledged that the availability of support was influential in their decisions and, although they recognised adequate support was not available for people with learning disabilities, they had to base their decisions on what was available rather than what they thought should be available. They also reported there may be a tendency to put parents with learning disabilities into the 'too 
hard basket' as the support they required was deemed to be too intensive. As a result, they were more likely to seek placements 'out-of-home'. Many participants noted that 'out-of-home' placements in many cases could have been avoided if adequate support had been available. Finally, if the situation was deemed 'irredeemable' for the child, magistrates then tried to determine if there was a suitable person who could act as a substitute parent.

As part of the study by Booth and Booth (2004a) in England, individual and group interviews were conducted with nine lawyers and five judges, however, the results were not presented according to profession. It should also be noted that participants were asked to discuss the higher prevalence of removal and adoption rates of children of parents with learning disabilities in the study's sample and factors that may account for this, rather than decision-making specifically. Most participants were not surprised that so few children (one in 10 in the sample) of parents with learning disabilities were returned home to live with their parents (Booth \& Booth, 2004a). Participants put forward a number of reasons to explain why so few children returned home to live with their parents and why they thought parents with learning disabilities were more likely to have their children freed for adoption.

It was proposed that the seriousness of cases coming to court meant the likelihood of children being returned home was low. Participants also explained that parents with learning disabilities were either unable to learn new skills or learn them quickly enough to correct their difficulties with parenting in time to meet the needs of their developing child. It was suggested that a slower rate of learning by the parent would increase the likelihood of the child being damaged in the process. The pressures placed upon participants to avoid unnecessary delays in finding permanent placements for children were also talked about in relation to higher freeing order rates, especially as they noted that delays could 'prejudice a child's future placement' (Booth \& Booth, 2004a, p.148). A lack of support from family and statutory services was also acknowledged as a factor that may account for the failure of the parents and, hence, higher removal rates. Participants explained that services may not be committed to working with people with learning disabilities in order to support them, which they presumed was affected Laura Kollinsky 
by time and financial constraints. It was also proposed that the parent's needs may be too complex and difficult to resolve i.e. 'their problems are more intractable than others and less susceptible to intervention that achieves changes (local authority solicitor)' (Booth \& Booth, 2004a, p.146).

Participants suggested that parents with learning disabilities often lack insight about concerns professionals have regarding their children or their parenting and may even deny that there is a problem at all. As a result participants proposed that this made change less likely and therefore permanent removal more likely. In addition, participants drew attention to the consequences of parents' failure to comply or cooperate with services in order to make the necessary changes, as this caused antagonism between the parties involved and could be viewed as a sign of possible harm to the child. Finally, participants spoke of their reluctance to take risks by returning children to live with parents with learning disabilities. The authors noted that not only did participants appear to suggest that professionals involved in child protection tend to assume that failure by parents with learning disabilities would be inevitable, but that freeing a child for adoption was an easier option (Booth \& Booth, 2004a).

The authors concluded that the results suggest that discriminatory incentives are present in cases involving parents with learning disabilities, as local authorities are unable or reluctant to provide the necessary support due to constraints placed upon them. As a result, or in order to avoid finding ways to provide the support, they seek to have the children removed and placed for adoption. However, the authors suggested that issues of discrimination are rationalised by the importance placed on the need to prevent delay in the interests of the child (i.e. the effect on their development and their prospects for adoption). Despite these conclusions, Booth and Booth (2004a) noted that when the participants were presented with this suggestion, they stated that any discrimination would be picked up on during the court process and exposed for what it was.

\subsection{Rationale for study}

The White Paper Valuing People Now: A new three year strategy for people with learning disabilities (2009) emphasises the rights of people with learning Laura Kollinsky 
disabilities to become parents and receive appropriate support to keep the family unit together. However, the foregoing review has indicated that parents with learning disabilities may be disadvantaged during care proceedings in England (e.g. Tarleton et al., 2006). In line with this, it has been noted that a " "philosophical shift" is needed in the courts if the human rights of the parents are to be squared with the best interests of the child in such families' (Booth \& Booth, 2004a, p.167).

Very little research has been completed regarding parents with learning disabilities and those involved in decision-making in care proceedings. As yet there has been no known research involving magistrates in England and this is surprising considering they are at the forefront of decision-making in care proceedings along with district judges. Although some research has been completed with magistrates in Australia, it is important to note that they are required to be trained lawyers, whereas magistrates in England are lay people. The same principle applies when considering the research in England with judges and lawyers. Subsequently, one cannot assume that magistrates experience decision-making in cases involving parents with learning disabilities in the same way as these groups. Research with magistrates in England therefore seems overdue.

The limited amount of research available in this area makes it difficult to determine what variables should be explored. This, coupled with a desire to understand the meaning magistrates give to their decisions regarding parents with learning disabilities, meant a qualitative methodology was adopted.

\subsection{Research Aims}

This study aimed to explore the experience of magistrates making decisions in care proceedings cases involving parents with learning disabilities. In particular, the study sought to explore magistrates' views and perceptions of people with learning disabilities as parents and the factors that are and/or have been influential in their decision-making. 


\subsection{Research Question}

The study was designed to explore the following broad research question:

What are magistrates' experiences of making decisions in care proceedings cases involving parents with learning disabilities?

\section{Method}

\subsection{Rationale for qualitative methodology and Interpretative} Phenomenological Analysis (IPA)

Quantitative and qualitative methodologies are similar 'in that they involve the collection, analysis and interpretation of observations or data' (Ponterotto, 2005, p.128), however, they also vary in their aims and the ontological positions they adopt. Qualitative research aims to contribute to a process in which individual experiences are explored so that understanding is revised and enriched, whereas quantitative research aims to determine causal relationships between variables that can be generalised, and existing theory or conclusions can be verified (Elliot et al., 1999). The methodologies also vary. A common assumption in qualitative approaches is that 'there is no "objective" reality or universal truth' (Lyons, 2007, p.4), but rather there is a more 'subjective' reality in which the production of knowledge is affected by context (lbid) i.e. the individual's experiences, their perceptions, the environment, and their interaction with the researcher (Ponterotto, 2005). This contrasts to quantitative methodologies where there is a belief that there is a 'true' reality in which causal relationships can be measured and analysed, leading to 'prediction and control of phenomena' (Ibid, p.128).

As noted above, there is a gap in the literature regarding magistrates' views and experiences of decision-making in care proceedings involving parents with learning disabilities. Therefore, an exploratory qualitative approach was deemed necessary as there were no existing theories or conclusions to be verified. This study aimed to explore the individual experiences of magistrates making decisions in care proceedings involving parents with learning disabilities. Specifically, to discover participants' views and perceptions about people with learning disabilities as parents and how they make sense of the context of their decisionmaking. It has been proposed that IPA is well suited to areas of research within 
health, social and clinical psychology, particularly where aims are to explore how people understand and perceive their experiences (Smith \& Eatough, 2007). As a result, the views and perceptions of participants have been noted to be a common focal point in IPA research (Smith et al., 2009). IPA was therefore deemed to be a suitable approach to adopt in this study.

IPA was also deemed appropriate to explore this area of research as it has been used in studies focusing on professionals' understanding of their practice and decisions. For example, Carradice et al. (2002) looked at the use of theoretical models by nurses completing assessments with family carers of people with dementia, whilst Golsworthy and Coyle (2001) examined therapists' conceptualisation of religious and spiritual issues, the perceived influence of therapists' beliefs on their practice and the processes involved in therapy when working with religious and spiritual issues.

One of the underlying principles of IPA is symbolic interactionism which suggests that individuals ascribe meanings to experiences through a process of interpretation (Carradice et al., 2002). It is proposed that in order to work through what an experience means an individual will engage in reflecting, thinking and feeling (Smith et al., 2009). By attempting to make sense of an experience this is deemed to be interpretative i.e. 'the accounts which participants provide will reflect their attempts to make sense of their experience' (Ibid, p.3). IPA also recognises that the researcher has a role in the process and is said to be engaged in a 'double hermeneutic' i.e. a 'two-stage interpretation process' in which the researcher must interpret the account that the participant is providing in order to try and understand their experience. That is they are 'trying to make sense of the participant trying to make sense of what is happening to them' (lbid, p.3).

\subsection{Inclusion criteria and recruitment sources}

The criteria for participation in the study included:

- Currently acting as a magistrate in family proceedings courts.

- Having experience of being involved in care proceedings invoiving a parent(s) with learning disabilities. 
Four family proceedings courts were located within Surrey and London. Contact was also made with the Magistrates' Association and the Executive Committee of a London family court. Packs containing information about the study and inclusion criteria were provided by post or email with the request that they be circulated to family court magistrates for them to determine if they would like to participate in the study. Magistrates who had taken part in the study were also requested to pass on information regarding the study to their magistrate colleagues in their constituency (see Appendix 3 for further explanatory notes regarding recruitment).

Magistrates were recruited via the Magistrates' Association, but there was no response from any of the courts or colleagues of participants. The Executive Committee did not recommend to their bench (magistrates) that they participate (see Appendix 4 for correspondence). This was despite providing further information about the study when requested and offering to meet face-to-face to discuss it.

\subsection{Sample size}

The study aimed to find a relatively homogenous sample with the aim of ensuring that those selected could provide an insight into the area being studied and 'represent' the perspective being explored (Smith et al., 2009). in order to find such a sample it has been suggested that participants should be selected purposively and this approach was therefore adopted in this study by incorporating a specific inclusion criteria (/bid).

Four family court magistrates volunteered and participated in the study; including three males and one female (see Table 1 for details). Unfortunately, the response rate is not known, since the distribution of information about the study was via intermediaries. However, it is assumed to be small. The participants recruited came from four constituencies: Surrey, London, Kent and Hertfordshire. Their ages ranged from $54-68$ years and the range of experience as a family court magistrate ranged from $15-21$ years. Although some participants were unable to report how many cases they had been involved with where a parent had a learning disability, others reported involvement with 6 or 10-20 cases Laura Kollinsky Volume 1 
approximately. Most participants had contact with people with learning disabilities outside of the court environment; however, one participant reported having none. All participants were of white British ethnic origin and were parents.

Smaller sample sizes have been said to benefit research using IPA due to a main priority being to gain detailed accounts of individual's experiences (e.g. Smith et al., 2009). Some authors have reported five to eight participants as being an acceptable sample size when conducting IPA studies (e.g. Smith \& Osborn, 2008), yet note that when using IPA for the first time, a sample of three can be beneficial as it can prevent the researcher from becoming overwhelmed by larger amounts of data (ibid). More recently Smith et al. (2009) noted a sample size of four to ten interviews as appropriate in doctoral pieces of research and also suggested that larger sample sizes should not be seen as a sign of 'better' work. All four magistrates provided rich interview material that was deemed suitable for IPA which would achieve its aim of being idiographic, but also allow commonalities to be commented upon. 


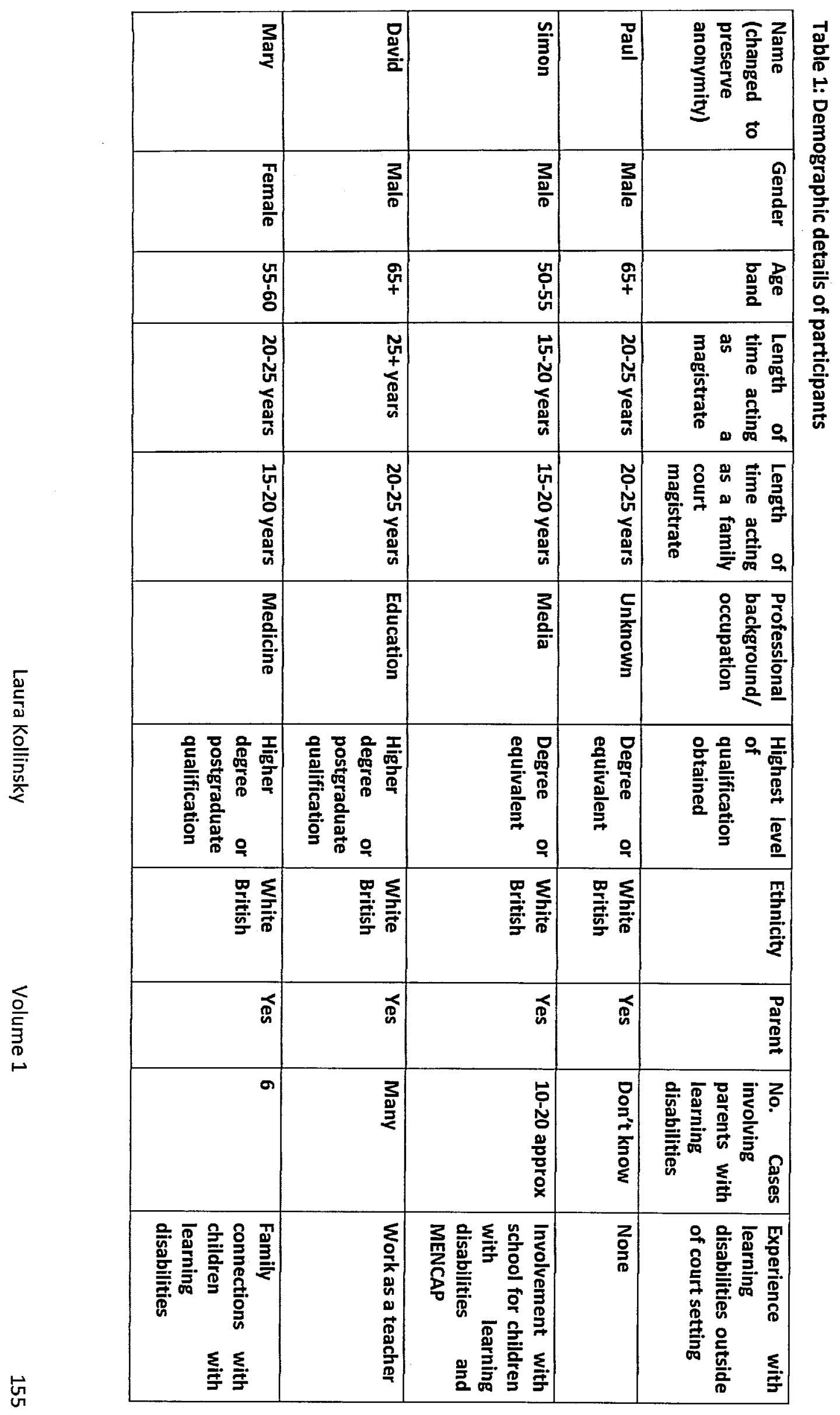

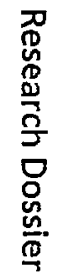




\section{$2.4 \quad$ Materials}

\subsubsection{Semi-structured interviews}

One of the most appropriate methods to adopt with IPA is the use of in-depth, one-to-one interviews which can offer fuller and detailed accounts of individuals' experiences (Smith et al., 2009). Semi-structured interviews are said to enable participants to have opportunities 'to tell their stories, speak freely and reflectively, and to develop their ideas and express their concerns at some length' (/bid, p.56). Semi-structured interviews also enable the researcher to explore their area of interest whilst allowing the participant to play an active part in guiding the interview process; helping the researcher to gain an insight into participants' psychological and social worlds. This is important as the participant can be regarded as the 'experiential expert' (Smith \& Eatough, 2007).

\subsubsection{Development of the interview schedule}

I held discussions with my field and academic supervisors, one of whom had experience of involvement with parents with learning disabilities subject to care proceedings and the other of whom had experience in conducting qualitative research, including IPA. Issues of potential relevance were identified and an initial interview schedule (see Appendix 5) was developed. This included general openended questions and prompt questions, with the hope that these would facilitate participants to provide fuller accounts of their experiences, yet be guided in areas which were more difficult to answer (Smith \& Eatough, 2007). The interview schedule was then discussed with a friend who is a magistrate and works with adults with learning disabilities, in order to gain feedback. Subsequently, some adjustments were made to the original interview schedule.

The main issues explored were:

- Understanding, experiences and perceptions of 'learning disability'

- Views and perceptions of how a learning disability may impact on parenting

- Influential factors in decision-making in care proceedings involving parents with learning disabilities

- Training, guidelines or policies drawn upon when decision-making in care proceedings with parents with learning disabilities 


\section{$2.5 \quad$ Procedure}

Participants were provided with an information sheet (see Appendix 6) and given a number of weeks to consider the information and their participation. The participants chose the location for the interviews to take place, with the aim of finding a familiar setting for them in which they could feel most comfortable (Smith \& Osborn, 2008). Two interviews were carried out in participants' homes, one at the participant's place of work and one at the family court. All interviews were administered in a quiet, private room in order to minimise interruptions and maintain confidentiality. Participants completed a demographic sheet (see Appendix 7) and consent form (see Appendix 8) prior to the interviews. All interviews were recorded and lasted between 35 and 70 minutes.

The first interview was conducted and transcribed, after which discussions took place with my academic supervisor in order to evaluate the usefulness of the questions included in the interview schedule. This has been recommended when adopting IPA with the aim of developing the suitability of the interview schedule (Smith et al., 2009). Overall the questions remained unchanged and it was considered appropriate to include the first interview in the analysis.

In addition to regular contact with supervisors, I attended qualitative group meetings at university and IPA discussion groups with colleagues. These meetings provided opportunities to discuss my area of research, any challenges and the rationale for adopting IPA. They also enabled transcripts and emerging themes to be discussed and developed.

\subsection{Ethical considerations}

A favourable ethical opinion was given by the University of Surrey Faculty of Arts and Human Sciences Ethics Committee (see Appendix 9 for evidence). The Magistrates' Association were contacted regarding additional ethical approval and this was deemed unnecessary.

Prior to and following interviews, participants were told about their rights to withdraw from the study. Issues regarding confidentiality and anonymity were 
discussed and participants were aware that confidentiality may need to be broken if I developed concerns about their practice during the interview.

The possible emotional impact on participants was considered throughout the research process, as I was aware that reflecting on their experiences may affect participants. This was therefore highlighted in the information provided to the participants, along with my contact details and those of my academic supervisor for if they wanted to discuss any issues or ask questions following the interviews.

Participants were instructed not to provide information on specific cases or to show me case file data that could identify the cases they were discussing. This was in order to preserve confidentiality and as this was not necessary to the study's aims.

\subsection{Analysis}

Various approaches to IPA have been reported, however, the following guidelines by Smith et al., (2009) were adopted in this study:

1. 'Reading and re-reading' - the recording of the first interview was listened to a few times, before moving on to reading and re-reading the transcript.

2. 'Initial noting' - whilst reading the transcript I made notes of things that seemed interesting or significant in relation to what the participant was saying. Notes focused on the context of what was said, the language used and thoughts about how the participant was making sense of what was being discussed.

3. 'Developing emergent themes' - initial notes were then reviewed along with the transcript in order to identify emerging themes. These were key words which aimed to capture the content of the initial notes as well as the exact content of what the participants had said (see Appendix 10 for an annotated transcript).

4. 'Searching for connections across emergent themes' - the emerging themes were then written up and grouped into clusters. These clusters were labelled super-ordinate themes and included emerging themes which seemed related to each other. Super-ordinate and 
subthemes (emerging themes) were then brought together, along with the page/line numbers and a short quote from the transcript.

5. 'Moving to the next case' - the above steps were then adopted in relation to the other transcripts.

6. 'Looking for patterns across cases' - the groups of super-ordinate and subthemes were then reviewed together and compared in order to identify patterns between participants. Themes were then combined, condensed and re-worded to produce a final table of super-ordinate themes and subthemes.

\subsection{Enhancing and demonstrating the validity of the analysis}

A number of guidelines have been produced for the researcher to assess and enhance validity and quality when adopting a qualitative approach. Guidelines produced by Elliot et al. (1999) and Yardley (2008) were referred to and a number of strategies were adopted during the research process.

To enhance the validity of the themes that arose from the data, a summary of the initial super-ordinate themes and a feedback questionnaire (see Appendix 11) were circulated to the participants. The questionnaire was devised to capture participants' opinions about the initial findings and check their views had not been misrepresented ( $/$ bid $)$. Written feedback was chosen in preference to faceto-face feedback as I thought this may allow participants to be more open and honest. Two participants responded and said they agreed with the themes.

Guidelines also recommend that the researcher's codes are compared with other researchers', to ensure they make sense to others. The transcripts were therefore reviewed during meetings with my academic supervisor, where we discussed the emerging themes and how these could be condensed and arranged to be grounded in data and capture the experiences of the participants. The transcripts were also compared at a later stage during the research process to the final themes and my interpretation of the results to determine that the understanding I had developed fitted together to form a 'data-based story/narrative' of the area being studied (Elliot et al., 1999). This process was also completed with another 
colleague; who works with people with learning disabilities and has completed research using IPA.

Yardley (2008) provides a set of broad principles to demonstrate the validity of qualitative research including: 'sensitivity to context', 'commitment and rigour', 'coherence and transparency', and 'impact and importance'. Regarding 'sensitivity to context', I have aimed to incorporate a review of the relevant literature above to orient and demonstrate a rationale for the study. I have also tried to demonstrate an appreciation of this principle by adopting a semistructured interview schedule so as not to constrain the participants. It is hoped that 'sensitivity to context' will also be demonstrated in further sections by ensuring that claims made are grounded in accounts from participants. I have endeavoured to enable readers to appraise the fit between the data and the understanding that I have developed, and find alternative understanding and meanings if necessary. With regard to 'commitment and rigour', and 'coherence and transparency' it is hoped that the processes in the study outlined above, when combined with the results and discussion later in this study, will help to show the reader what I have done and why, and also demonstrate that I have 'carried out an analysis that has sufficient breadth and/or depth to deliver additional insight into the topic researched' (Yardley, 2008, p.248).

Guidelines also suggest that it is good practice for the researcher to reflect on their 'values, roles and assumptions' (Elliot et al., 1999, p.221) to determine what role they play in the understanding they develop during the research process. Reflections on my perspective will therefore be outlined below and during the discussion in this study with the hope that they highlight elements which may have been affected by my experiences and may help the reader make their own interpretations about the data and enhance their understanding.

Finally, it is hoped that the 'impact and importance' of this study will be demonstrated throughout. 


\subsubsection{Personal reflections}

I have never acted as a magistrate involved in care proceedings and I do not have any friends or family members who have. As such, my experience regarding care proceedings has been professional. As an assistant psychologist in a community team for people with learning disabilities I was involved with a woman who was subject to care proceedings. The woman was referred for an assessment of cognitive functioning by her children's social worker and corresponding reports were requested for court in relation to the care application that had been made. During this process I had numerous interactions with the woman, her children, her parents, the local authority, the children's guardian and the woman's solicitor. 1 also attended court with the woman and witnessed her involvement in care proceedings. Throughout, I was very aware of my emotional reactions to what appeared to be an unfair system in which the woman seemed to be treated in a discriminatory way; having not been provided with any support prior to the care proceedings or been made aware of her rights and the importance of receiving legal advice and support. During this time, I sought regular supervision and discussions with the clinical psychologist and community nurse in the team, who were also involved and realised that I was not alone in the views I developed.

Since, I have had further experiences during clinical training working with people with learning disabilities and although I was not involved with parenting issues, I was reminded of the diversity of people in this client group and how varied parenting abilities would be as a result. I have also gained experience of working with children and families during clinical training and been exposed to other perspectives about parenting and the impact on children. Subsequently, my opinions about the child protection system have changed and I understand more about concerns professionals may develop regarding the welfare of children and the responsibilities to protect them. 


\section{Results}

\subsection{Context of findings}

Participants were asked to talk about their experiences of making decisions in care proceedings involving parents with learning disabilities. They were encouraged to talk as widely as possible, including their understanding of the term 'learning disability', a case(s) they have been involved with (although not for specific details), and factors that are/have been influential in their decisionmaking. Some participants had more experiences with people with learning disabilities than others and this appeared to be reflected in their accounts.

Participants described becoming aware of people with learning disabilities being different to themselves, personal experiences of family members with a learning disability and professional contact with people with learning disabilities, both in and outside of their role as magistrates. During discussions about the term 'learning disability', three magistrates referred to a spectrum of difficulties, usually caused through genetics or brain damage; whilst Paul also referred to the influence of upbringing (e.g. lack of stimulation may affect brain development).

Magistrates highlighted various areas of functioning that a learning disability may affect, such as abilities to learn in an educational sense, abilities to interact with others socially, abilities to communicate and having below average intellectual capabilities. Magistrates also discussed how they determine if a person has a learning disability. These included the presence of 'immediately identifiable' (Mary) signs such as the characteristic facial features in Down syndrome and less obvious signs, such as a person's ability to 'answer questions' and 'understand what's being said to them' (Paul).

It is hoped that this contextual information will provide a broad frame within which the findings should be understood.

\subsection{Overview of findings}

This results section endeavours to describe three super-ordinate themes that emerged following Interpretative Phenomenological Analysis (IPA) of the transcripts (see Table 2). Participants spoke of views held about people and 
parents with learning disabilities, which appeared to be determined by experiences with people with learning disabilities. Experiences seemed to be regarded as allowing people to gain knowledge about the continuum involved in learning disabilities; in turn widening views about people with learning disabilities and the limits of one's own knowledge. In contrast, Paul's account seemed more connected to his limited experiences with people with learning disabilities leading him to regard learning disabilities as involving less variability. Whilst there were commonalities when determining the best interests of the child in cases with parents with learning disabilities, experiences also appeared to relate to the role taken on in care proceedings and interactions with experts.

In the information provided below, pseudonyms are used in place of participants' real names. Verbatim extracts from participants' transcripts are included throughout the account; however, ellipses (...) have been used to ease readability and these indicate material that has been omitted. It is important to note that the subthemes are not distinct components but are inter-related aspects of the participants' experiences.

Table 2: Summary of themes

\begin{tabular}{|c|c|}
\hline Super-ordinate theme & Subtheme \\
\hline $\begin{array}{l}\text { 1. Learning disability as a } \\
\text { continuum }\end{array}$ & $\begin{array}{l}\text { i) Heterogeneity } \\
\text { ii) Homogeneity }\end{array}$ \\
\hline $\begin{array}{l}\text { 2. Determining the best interests } \\
\text { of the child }\end{array}$ & $\begin{array}{l}\text { i) Timescale and age of the child } \\
\text { ii) Expert opinion } \\
\text { iii) Parenting abilities } \\
\text { iv) Support }\end{array}$ \\
\hline $\begin{array}{l}\text { 3. Self-characterisation within } \\
\text { the system }\end{array}$ & $\begin{array}{l}\text { i) Knowledge } \\
\text { ii) Role as a magistrate } \\
\text { iii) Training }\end{array}$ \\
\hline
\end{tabular}




\subsection{Theme 1: Learning disability as a continuum}

This super-ordinate theme encapsulates the views and perceptions participants expressed about people and parents with learning disabilities. Participants referred to their experiences of learning disabilities and how they perceived a learning disability to impact on parenting. Most participants presented views regarding awareness they have developed in which people with learning disabilities are regarded as a multi-faceted, complex group, whilst one participant seemed to regard people with learning disabilities as a discrete group with little variability. Some participants also talked about how they think others view people with learning disabilities and these participants appeared to suggest they are involved in a system where others fail to appreciate the diversity involved in learning disabilities. The theme is therefore divided into two subthemes: heterogeneity and homogeneity.

\subsubsection{Heterogeneity}

Throughout the interviews, participants drew on their experiences of being involved with people with learning disabilities; however, they differed in the amount and type of experiences. David, Mary and Simon had experiences of coming into contact with people with learning disabilities personally and professionally (see Table 1), however, Paul revealed having had no 'real experience outside of the court environment of actually dealing with or working with people with a learning disability'.

Those magistrates who spoke of having more experiences with people with learning disabilities talked about the term 'learning disability' covering a wide spectrum of abilities and difficulties:

'the whole range of learning disability, because it's a spectrum, you know there isn't a cut off' (David).

These participants viewed people with learning disabilities to be very individual and described becoming more aware of the diversity involved in learning disabilities due to their contact with people with learning disabilities throughout their lives. 
Simon and Mary reported that as they had gained this awareness it had become more important for them to look at the individuals involved in care proceedings and not 'compartmentalise' (Simon) people if they have a diagnosis of a learning disability (i.e. not make generalisations). Mary's quote encapsulates this experience:

'you can't make that decision about that person without looking at the whole person...not just looking at the immediate presentation'.

This highlights the importance Mary placed on not making assumptions about people based on how they first seem and the need to consider the individual when making-decisions in care proceedings. Not only was this opinion informed by her experiences with people with learning disabilities, but also her experiences of having a brother with physical disabilities.

Within the focus of viewing people with learning disabilities as individual, Simon talked about the importance of gaining information regarding more specific diagnoses. He highlighted the need to consider the impact a certain diagnosis may have on an individual and their capabilities and not make assumptions based on the diagnosis alone:

'you need to look at that individual and their particular circumstances and disability and not just say, "he's autistic and therefore he needs this and that and the other"'.

By drawing attention to the individuality of people with learning disabilities, it seemed that Mary, Simon and David wanted to ensure they presented themselves as fair and just magistrates. It appeared important for them to emphasise that they do not judge people with learning disabilities based on any stereotypes or make assumptions about them, but rather take an individualistic approach with each case they deal with. Although it may have been that these participants wanted to present accounts that were socially acceptable in the interviews, other information they discussed appeared to reflect genuineness about their accounts, 
such as how the role they take on within care proceedings has been affected by how they view people with learning disabilities.

In contrast, Paul's account revealed less complex views and ideas about people with learning disabilities, based on certain diagnoses:

'Down syndrome people tend to become adults with...an age of perhaps a child...and in those circumstances the learning disability would severely restrict their ability to look after children and indeed to lead.... a normal life on their own'.

This highlights a more negative attitude that came through in Paul's account, perhaps reflecting some underlying assumptions that adults with Down syndrome have intellectual capabilities equivalent to those of children. He suggests that people with Down syndrome are restricted in their abilities to lead a normal life independently and parent and appears to apply this view to all people with Down syndrome. Despite this, during the interview, Paul referred to different severities of learning disabilities, suggesting that he has some awareness of a spectrum involved in learning disabilities. It seemed that Paul's lack of contact with people with learning disabilities may have affected his knowledge and awareness of the complexity involved and this may help to explain some of the contradictions raised during his account.

Participants also spoke about the impact of a learning disability on parenting and were unanimous in their views that this would be dependent on severity of the learning disability. Within their accounts David and Mary expressed opinions that the presence of a learning disability would not always result in difficulties and that some people without learning disabilities are unable to parent adequately. In order to highlight this Mary drew attention to the possibility that in some cases people with a learning disability may actually be able to offer better parenting than some parents without this diagnosis:

'parenting has to be good enough and parents who have not got learning difficulties; some of their parenting is it good enough? Can seriously be debatable. 
And some parents with learning difficulties; their standard of parenting might actually be rather better'.

All magistrates also talked about the abilities of parents to learn new skills being dependent on the severity of the learning disability and Simon, David and Mary, again made reference to the importance of viewing this ability as being very individual.

\subsubsection{Homogeneity}

Throughout their interviews, David, Simon and Mary made reference to others, both in and outside of the care proceedings system, and they talked about their experiences of how others view people with learning disabilities. When referring to others, participants spoke about social workers, guardians, other magistrates and those in society or the community. In contrast to the above section (with the exception of Paul), the magistrates' accounts presented a picture in which they have been involved within a system where other people often fail to appreciate the diversity and complexity in learning disabilities:

'They just have an attitude of they've got a learning disability and that's it' (Simon).

"I think people see... a learning disability...as cut and dried but it's not, there is a wide spectrum of learning disability' (Mary)

These quotes highlight a shared experience talked about by Simon and Mary in which others may not realise that 'learning disability' covers a wide spectrum and may make generalisations; grouping people with learning disabilities together as all being the same. Simon and Mary related these views about people with learning disabilities being the same to a lack of understanding of what the term 'learning disability' means and what it entails. Included in this was that people commonly struggled to distinguish between mental illness and learning disability:

I think people get confused between a learning difficulty and mental illness and I think this is where a lot of people come unstuck' (Mary). 
Although this lack of understanding by others was raised, Simon suggested that he was not surprised by this and that others should not to be blamed for this:

'they've got no reason to know any different'.

In turn, Simon, Mary and David suggested that only those with a more specialist knowledge of learning disabilities or more experiences with people with learning disabilities would have the opportunity to develop awareness regarding the heterogeneity the term covers. Subsequently, this seemed to imply that they regarded themselves to be somewhat different to others.

Simon also drew attention to his experience of how other people have made assumptions about the abilities of people with learning disabilities:

'a common thing I find, whether they are children or adults, is that the population largely underestimate what their capabilities actually are'.

Simon highlights how common this experience is and supports this by drawing on his work with children and adults with learning disabilities where even their own parents have underestimated their abilities. By raising this, Simon again seems to imply that this is not surprising and that this may be an easy thing for people to do, especially if an individual's own parents have done it.

As well as highlighting the tendency for people with learning disabilities to be grouped together, Simon and Mary also suggested that this can be applied to parents with learning disabilities:

'mental disability gets lumped into one, people think it's all or nothing and I think a lot of people don't realise the range of learning difficulty and people don't understand whether anybody with learning difficulties has actually got the capacity to parent' (Mary). 
'there tends to be an assumption that somebody with a learning disability isn't able to bring up a child' (Simon).

These quotes highlight the tendency these participants raised in which others make assumptions that people with learning disabilities are unable to be parents.

There seemed to be consequences, in terms of decision-making, if others in the system viewed parents with learning disabilities as being the same. Mary described her experience of a case in which the local authority wanted to remove the child and place it up for adoption even when the parent appeared to be coping and getting on extremely well' following the input of support and entering into a new relationship with a partner. It seemed that as a result of how others in the local authority viewed the mother with learning disabilities, she had been 'severely disadvantaged' and Mary thought 'the local authority had almost set her up to fail'. Mary captured this experience when she said:

They weren't...supporting her and the initial reactions were that she couldn't possibly cope with support and with the new partner'.

Mary was not alone in her experience of thinking that some parents had been 'set up to fail' due to the views of others in the care proceedings system. Simon spoke of similar experiences:

'the worry is that...because the needs of learning disabled parents...in being able to support them to bring up children is often quite sort of complex and needs an understanding of the people providing that support...the temptation is to put it into the 'too difficult box' and say "okay, they can't do it".

Simon's quote highlights his experiences of others perceiving parents with learning disabilities as being in need of support that is too difficult to find or too complex to determine and in essence seek simple solutions to this problem. Simon explained that the consequences of such may be that children are removed from their parents unnecessarily. 


\subsection{Theme 2: Determining the best interests of the child}

All participants spoke about the welfare of the child as being of 'paramount' importance when making their decisions in care proceedings:

'Some cases are always cut and dried...you read the case papers... and sometimes you don't actually need to go very much further. Other cases are more difficult and there are always grey areas and you have to balance...everything up, but the most important thing is the welfare of the child' (Mary).

However, participants also indicated that decision-making is not always simple and that there are a number of other factors that are influential when determining the best interests of the child. These included the timescale and age of the child, the opinions and advice from experts, parenting abilities and the availability and provision of support. These four subthemes are described in detail below.

\subsubsection{Timescale and age of the child}

All participants spoke about the need to prevent delay in care proceedings in the interests of the child and Simon highlighted how often magistrates are reminded to consider this:

in the interests of the child another aspect that we have to think about is the delay that all this causes because in the meantime the child is...growing up and all the attachment aspects and everything, so you know we're told constantly, which is quite right that we can't delay things indefinitely'.

This quote also encapsulates the reasoning behind the need to prevent delay and was spoken about by Paul and Simon in relation to the bonds that are formed by the child. This reasoning seemed to be based upon an understanding of attachment theory and child development, which they referred to.

All magistrates also talked about the age of the child in relation to the timescales involved in care proceedings: 
The problem with assessments is that they take a long time; we're talking about months and for a small baby, months is a big chunk of time, not so much for an older child' (David).

This quote highlights a common opinion expressed by the magistrates, suggesting that with older children (i.e. not babies) delaying a case could be better tolerated. Some magistrates also spoke about an increased likelihood that they would delay cases in order to gain further information to inform the decision-making process, such as by requesting further assessments from experts, if the child involved was older. This opinion was also expressed in relation to the bonds that children develop, implying that with older children the important time frame may have passed. However, with babies there is more opportunity for bonds to be affected by the amount of time the child remains with the parent and subsequently there is more of a sense of urgency to make decisions.

The outlook for the child involved in care proceedings was also raised in relation to the age and timescale of the child:

'if it was a very very young child, baby...local authority would look, could be looking at adoption' (Mary).

This quote encapsulates the implication that the consideration of adoption may be more likely if the child involved is a young baby.

Magistrates also talked about the need to consider whether or not parents could learn new skills or correct concerns regarding their parenting within the child's timescale:

'we would need to get an expert's report on the extent of that disability, the prognosis as to whether it can be treated and whether that again can be within the child's timescale' (Paul). 


\subsubsection{Expert opinion}

All magistrates talked about the regular involvement of experts within care proceedings, although who they considered to be experts varied between participants. The term 'expert' was often used in reference to psychiatrists, psychologists and medical professionals; however, some magistrates considered guardians and social workers to be experts too and Simon said magistrates are being 'encouraged more to regard social workers as experts within their own right'. He explained that this is because social workers have usually known the families for longer and know them better than other professionals who may be called upon in care proceedings. They may therefore be in as good or a better position than other experts to provide information in care proceedings and inform decisions.

Although magistrates talked about the regular involvement of experts in care proceedings, Paul implied that if a parent has a learning disability, it is more likely that experts will be involved:

in cases where there is a learning disability and that has been virtually established, it is almost certain that experts will be called on to give and rely on those experts'.

Participants talked about the various forms of evidence that experts provide in care proceedings, including photographs of the child and/or the family living environment and reports containing information about the welfare of the child and the abilities of the parents to understand and meet the needs of the child. All magistrates explained they rely on evidence provided to them in care proceedings and that expert advice/opinion forms an influential part of their decision-making.

Mary explained that magistrates would 'have to take the expert advice' and Paul stated that 'we can't make decisions without being told from those that should know what the situation is'. These quotes encapsulate the opinions shared by participants that experts are regarded as being in a position where they should be able to report on the circumstances for the child involved in care proceedings and accurately represent what the implications are in terms of their welfare. 
Despite it being common for participants to rely on experts to inform their decision-making, they had mixed opinions regarding the quality and type of information experts had provided in cases they had been involved with. Simon raised a common frustration of his in that the 'right' experts were not always appointed, i.e. they did not always have the necessary level or area of expertise to provide information that would have been helpful in terms of decision-making:

'it was apparent that... whilst she was an expert in learning disability, she had no real knowledge or expertise of people with learning disabilities as parents'.

This quote may suggest that Simon has an expectation that experts should have sufficient knowledge about parenting if they are involved in care proceedings and that they should make reference to parenting in the evidence they provide. It may also imply there is a tendency for experts to focus on the label of 'learning disability' rather than the person as an individual and a parent. An alternative suggestion could be that those appointing the experts do not think to get someone with expertise on parenting.

Similarly, Paul explained that as a result of not having the correct expert, the information received in care proceedings can at times be 'woolly' and not assist the magistrates in their decision-making. Simon and Mary referred to times when information had been provided about the person and the nature of their learning disability, but with no reference to the impact this could have on the person as a parent, what may be helpful to them in terms of support, and the outlook in relation to the welfare of the child.

\subsubsection{Parenting abilities}

All magistrates spoke about the importance of experts in care proceedings providing information regarding the abilities of parents to protect and care for their children. Participants explained that parenting abilities would always be influential in their decision-making. Magistrates referred to the need to determine if the parents were able to provide 'good enough parenting' (Paul), although Mary explained that this is a 'grey area' and 'for each case it is different as to what constitutes "good enough parenting". 
Magistrates highlighted some common features they had become aware of regarding the abilities of parents with learning disabilities to provide 'good enough parenting'. One of which was the ability of parents to understand and meet the child's needs:

'It's understanding the needs of the child and how to meet them...that tends to...come through when learning disabled parents are involved' (Simon).

This was raised by all participants in relation to parenting abilities such as weaning, changing and interacting with their children. Despite this being common in cases involving parents with learning disabilities, participants seemed keen to emphasise that the problems arising as a result of difficulties with parenting were unintentional:

'they may not have wanted to feed it egg and chips, but...certainly they had no idea about how to bring up the child from the point of view of weaning and so on'(Paul).

Although participants were united in these views, they attributed difficulties with parenting to different things. David related difficulties to a 'lack of ability to multitask', a lack of 'confidence' and 'that ability to reflect', whilst Mary related it to difficulties with social skills and 'anticipating the needs of others'.

Magistrates also talked about needing to consider the ability of parents to cope with the stresses and strains that parenting can bring:

'it is their capacity to cope because in stressful times, how are they going to cope?... how do they cope with stress factors?' (Mary).

Mary's quote also reflects the need to look to the future and determine how the parent will cope with challenges both in the short and long term. Although Mary appeared keen to present herself as adopting an individualistic approach when involved with people with learning disabilities, this quote could be seen to reveal 
some uncertainty regarding her expectations of parents with learning disabilities. There appears to be an emphasis on a relationship between learning disability and stress, as if to suggest that a learning disability may make it more difficult for parents to cope with stress. Whilst it is possible that Mary was adopting more universal views about people with learning disabilities and stress, Simon seemed to normalise the need to consider the abilities of parents to cope with stress in all cases, not just those involving parents with learning disabilities:

'particularly as children are getting older and more demanding and...more challenging for any parent to deal with and how their...ability to cope in those sort of situations'.

David talked about the ability of parents to retain and use new information as being influential in his decision-making and implied that an inability to learn new skills was a more common factor in cases involving parents with learning disabilities:

I've found in cases where there are learning disabilities... then it's that inability...to accept and absorb help because you can't keep on saying to somebody that's how you sterilise bottles, you can't keep doing that'.

The above quote also encapsulates an experience shared by Simon and Mary, who noted the ability of parents to learn new skills as being influential in their decision-making. Participants also spoke of the need to consider the scope for change in the future and how assessments and reports by experts can be helpful in guiding their decisions:

'we get reports that say they can change and they have the capacity, we have to go with that' (David).

The abilities of parents to learn new skills and correct issues causing harm or risk of harm to the child were often discussed by participants in the context of the provision of support. 


\subsubsection{Support}

Magistrates spoke about the provision and availability of support as being influential in decision-making in cases involving parents with learning disabilities. Participants suggested that if people with learning disabilities are able to parent adequately with support then there is no reason why they should not be given the opportunity to do so:

'can the parents with help be able to parent the child and if that's the case then there is...no reason why the parents with a learning disability shouldn't be able to parent with assistance' (Paul).

However, magistrates also agreed that some levels of support are unrealistic or unreasonable. This was highlighted by Paul who went on to say:

'but if that assistance should require 24 hour care then logic says (tut), well then no...that's too much'.

David, Paul and Simon made reference to unrealistic levels of support in relation to financial restraints affecting services providing support, such as the local authority. It was suggested that as support is costly, it cannot be available in an endless and timeless supply. Additionally, David and Simon identified that the support required is not always available to parents and there are limits restricting how much support can be provided:

'the help...at some stage will have to be withdrawn just because it will have to and there's a limit to how much you can put in' (David).

It seemed that if the required levels of support were regarded as too high and therefore unrealistic, this would influence the magistrates to be more likely to remove the child from the parents and consider more permanent options such as adoption.

Although there was agreement that some levels of support are unrealistic, what constituted a 'realistic level of support' (Simon) differed between participants. 
Paul considered acceptable levels of support as equivalent to those provided by health visitors in which an 'occasional visit perhaps from a social worker' is offered to the parents to see how they are getting on. In contrast, David and Simon regarded reasonable levels of support to entail teaching and training parents how to learn new skills and visiting the parents to 'keep an eye on what you're doing, who can make sure that you've done the things that you need to do' (David).

As well as considering the support on offer from services when making their decisions, magistrates also talked about the influence of the availability of support from other arenas:

'there's also a factor...of wider family... whether it's their parents or brothers or sisters...and you're looking at... what level of support is available from them... which can also have an influence on whether the parents are able to bring up the child or not' (Simon).

This seemed to be a shared experience for the magistrates who emphasised the importance of determining other means of providing parents with support, especially as these would not entail financial restraints and could be provided long term throughout the child's life. Having such support available from people's families appeared to make magistrates more comfortable in deciding that the child could remain with the parent(s).

This apparent security that support from the extended family gave to magistrates when allowing the child to remain with parents was counterbalanced in situations where they believed that the support needed was not going to be available or would be too difficult to find:

'the temptation is to put it into the 'too difficult' box and say, 'okay, they can't do it' and...you come to the conclusion that the support they need isn't simply going to be there, rightly or wrongly and...you know without that sort they simply can't bring up a child on their own without the support they need' (Simon). 
Simon explained that finding the 'right' support can be a difficult process as it is difficult to determine what that support would be, as well as who could provide it. He also suggested that consequently children may be removed from their parents unnecessarily and, as well as suspecting this may have happened in the past, Simon also implied that had the 'right' support been available, the parents may have been able to care for their child:

you suspect that there are cases where children are taken into care with learning disabled parents that with the right level of support or experts could stay with their parents'.

\subsection{Theme 3: Self characterisation within the system}

This theme encapsulates the way participants appeared to characterise themselves within the care proceedings system. It is divided into three subthemes including how magistrates regarded their level of knowledge about learning disabilities, the roles they adopt within the system and their views about training regarding people with learning disabilities. The ways they characterised themselves within the system appeared to relate to how they viewed people with learning disabilities and how they perceived others to view people with learning disabilities, thus linking in with the themes above.

\subsubsection{Knowledge}

I'm just a lay person and the knowledge I have is just through experience. I've had no formal training in it and I'm not a clinician or anything like that' (Simon).

Simon's quote captures a desire shared by Paul and David to highlight their positions as lay people. They explained that as a result their knowledge about learning disabilities was limited and not 'clinical' (Paul). By drawing attention to their position as lay people, it appeared that these magistrates were emphasising how they characterise themselves within the care proceedings system as not being an expert. These participants may also have wanted to justify or account for any inaccuracies they presented in their accounts about learning disabilities, so as not to be judged negatively. 
Although Simon and Paul seemed to regard their knowledge as limited, David's account did not present him in this way. His experiences of working as a special educational needs teacher meant he had been exposed to a different type of information regarding learning disabilities. This was highlighted when he talked more in detail about the different areas of functioning that may be affected in learning disabilities and his familiarity with Wechsler scores/scales. He also spoke about how this knowledge had affected his role as a magistrate:

I find it a lot easier to break things down into little bits and to use appropriate language'.

David regarded his more in-depth knowledge of learning disabilities as allowing him to adapt his skills to suit the needs of individuals involved in care proceedings and he also saw himself as more confident than some of his colleagues to do this. Although Simon regarded his knowledge of learning disabilities as limited, he also appeared to identify himself as being different to other magistrates:

'the majority of magistrates that sit in family cases don't have...even the experience that I have and so...you have to work on the assumption that magistrates dealing with such cases don't have any knowledge or experience'.

So, even though Simon portrayed himself as having limited knowledge about people with learning disabilities, he implied that it was likely he had more knowledge or experience of people with learning disabilities compared to other magistrates involved in care proceedings. This could be likened to the experiences outlined earlier by Simon, Mary and David through which they have developed awareness of the complexity involved in learning disabilities, whilst they perceive that others fail to appreciate this. 


\subsubsection{Role as a magistrate}

Throughout the interviews, participants' accounts provided an insight into how they viewed their role as a magistrate. However, this appeared to differ between participants and appeared related to the amount of experience they have had with people with learning disabilities.

Simon, David and Mary portrayed themselves as bringing something different to care proceedings when compared to some other magistrates:

I can bring a different perspective to the discussion and raise things that other people may not be aware of and perhaps also draw attention to information that we might need to know particularly...the fact that people with learning disabilities are very individual and we need to know...about their individual learning disability and capabilities rather than adopting a broad brush approach' (Simon).

This quote encapsulates how Simon views himself to be different to other magistrates and he related this to awareness he had developed about the complexity involved in learning disabilities. He implied that other magistrates do not draw attention to the parent as an individual as they view people with learning disabilities together in a non-differentiated group.

As well as considering himself as bringing something different, Simon also drew attention to a more active role that magistrates are now being encouraged to adopt:

in the past, experts were instructed and given a very...general brief as to what courts or people wanted to know, but I think now we're being encouraged to be much more specific and asking more direct, specific questions as to what information we want'.

This experience related to Mary and David's accounts which portrayed them as taking on more active interactions with experts as well as the parents involved in care proceedings. David talked about presenting himself as an 'idiot' to experts to get them to explain their reports without the use of jargon so as to ensure that 
parents had understood what had been said during proceedings. Whilst the use of the term 'idiot' could be viewed as unfortunate as it may suggest that David views people with learning disabilities as idiots, it seemed more likely that he was referring to the need for everyone to have a 'dummies guide' in order to understand the content of expert reports.

As well as being more directive in her role when interacting with experts, Mary spoke about taking on a role in which she could question or challenge experts; for example, when she had not received the information she hoped for from experts or when she thought the parents involved had been disadvantaged due to the views of others. Mary highlighted this through her account of being involved in a case in which the panel thought the family's needs had not been considered thoroughly. As a result of taking on a more active role, Mary felt able to question the information she had received from the experts and the panel decided not to remove the child:

'we actually did not make an order. We were actually taken to appeal; the appeal was eventually dismissed, so the father kept the child; so we felt that actually that was a major triumph'.

In contrast, Paul did not talk about bringing anything different to his colleagues and instead seemed to portray himself as taking on more of a passive role; being told what to do by experts, rather than taking advice from them:

Paul: 'we don't have that expertise; we rely on those people. We can ask them questions. Sometimes the medical practitioners' reports are worse...are not very good and not very helpful, because we're looking for somebody...to be specific and point us in a direction and a woolly report and a 'maybe' type of report is no good. So in essence we rely on the experts that....we're given'

Interviewer: 'so you're influenced by the professional feedback that you receive?'

Paul: 'well yes, it's the evidence we need to look at. We can't make decisions without being told from those that should know what the situation is'. 
It is possible that this more passive role could be related to the lack of knowledge and awareness that Paul had regarding the complexity involved in learning disabilities, as without this he would not be able to identify a need to take on more of an active role.

\subsubsection{Training}

Participants spoke about teaching or training they have received regarding people with learning disabilities through their professions and some spoke about this through their role as magistrates. Discussions highlighted that some elements of training as a magistrate are formal and mandatory, whilst others are like extracurricular activities usually arranged through local areas or by the Magistrates' Association.

Most formal training focused on elements of the law; however, less formal training had focused on areas such as child and brain development and, within this, some information had been provided on how a learning disability may arise. Despite this, it was a shared experience for participants not to have received any mandatory training or to have been directed to any guidance or government initiatives regarding people and parents with learning disabilities:

'we have on odd occasions had bits of training...to try and give us a bit of insight, but it's not part of the formal training; it's just something that we've arranged' (Simon).

Simon's quote reflects the limited amount of training that participants spoke of receiving as magistrates regarding people with learning disabilities. It also captures a shared experience for David and Mary regarding the content of the training, suggesting that what they had received was quite general.

Simon, Mary and David expressed a 'real need for training' (Mary) for magistrates to receive more information on learning disabilities:

'getting people to understand the whole range of learning disability, because it's a spectrum' (David). 
This was raised in relation to the need for magistrates to become aware of the spectrum involved in the area, although participants also acknowledged that providing magistrates with an in-depth understanding of learning disabilities would be unnecessary. David also explained it would be helpful for the magistracy to receive training on being involved with people with learning disabilities:

'what we don't get is training on actually how to talk to people and how to cope with them, in a way that isn't patronising and so that you're assured that they understand what you say'.

David's quote captures views expressed by Simon and Mary, who related the need for more training to the role magistrates could take on within care proceedings. These participants seemed to believe that if magistrates had more training about learning disabilities then they too may adopt a more active role:

I do think there is a need for some sort of training...on broad aspects of learning disabilities...so that they are actually aware of...as...I hope I have become, in terms of trying to ask the right questions when you get an individual case and to look at specific learning disabilities and what experts you need and what questions you need to ask' (Simon).

This quote captures how the knowledge Simon had received about people with learning disabilities had allowed him to take on a more active role when appointing experts and gaining the information needed in order to make decisions. This was also encapsulated in the interview with Mary who referred to the possibility of magistrates gaining different skills following training:

I think it would make magistrates question and challenge...both local authorities and...experts because it comes from a point of view of understanding and knowledge, whereas if you know nothing about a subject you don't challenge'. 
Mary and Simon also seemed united in their opinions that training could be helpful in changing the way people with learning disabilities may be viewed by others. They expressed their hopes that training would allow some of the assumptions about people with learning disabilities to be dispelled:

'there ought to be more training so that...magistrates can actually understand how people with learning difficulties can live independently...but depending on...their disability... how that impacts on their ability to look after others' (Mary).

Although Simon, David and Mary raised a need for more training, Paul did not and in contrast, he appeared to regard there not to be a need for training:

'renowned psychologists and psychiatrists and people with an enormous amount of experience on brain development...tell us how...people's learning disabilities arise, but actually to identify them and work with them because of the way that we deal with cases we haven't had very much'.

Paul appeared to imply there was no need for training in the area of learning disabilities, due to the ways magistrates deal with cases. This may relate to how Paul viewed roles, where the expert holds a more specialist knowledge and position and magistrates are told how to make their decisions.

\section{Discussion}

\subsection{Limitations of the study}

The participants in this study cannot be regarded as representative of the English magistracy; however, IPA does not set out to achieve this (Smith et al., 2009). Instead, IPA aims to adopt an idiographic approach in which a small number of participants' experiences can be explored in-depth (Ibid). Caution must therefore be taken when considering generalising beyond these participants especially as the conclusions drawn have been affected by my role as researcher. Despite this, Smith and Osborn (2003) have suggested that findings from one sample may be relevant to studies that have included similar samples. Smith et al. (2009) also propose that an extension of the findings can be considered through theoretical 
generalisability, in which the findings are assessed in relation to the researcher's or reader's personal and professional experience and knowledge, and claims in the literature. Links with the existing literature will be drawn upon and the findings reflect similarities of the case that I was involved with and some of my field supervisor's experience within this area. Feedback from two participants also suggests that the themes represent their experiences. As such, it is hoped that the findings from this study may contribute to and enrich the understanding of the experiences of magistrates making decisions in care proceedings involving parents with learning disabilities.

One significant caution in this study is that the findings are based on only four volunteers. Whilst a potentially vast number of magistrates were contacted for the purposes of the study, most did not respond. Although there may be various reasons why others did not wish to participate in the study, the response from the Executive Committee reflected some concerns held that generalisations would be made about the magistracy and they would have to defend their position. Whilst efforts were made to reassure the committee that this was not the aim of the research, this could reflect the level of sensitivity this area of interest involves. It is therefore important to consider the issue of social desirability response bias that may be present in this research (Van de Mortel, 2009), in which participants may have presented responses desired to reflect a favourable image of themselves or to gain social approval.

Given the sensitive nature of the area of research, it is possible that those magistrates who participated may have been concerned about needing to present responses that reflected positively on them as individuals and as magistrates. Although this is possible, I do not believe this is entirely true as most participants' accounts in this study included examples of practice which would not reflect especially positively on the magistracy and others involved in care proceedings. With this in mind, it may be that some of those who participated in the study were striving to take on a more evangelical or advocacy role for people with learning disabilities, as their accounts seemed to reflect a sense of injustice that may affect this client group. Indeed, it is perhaps significant that three of the four participants saw themselves as different to the majority of their colleagues; as 
lone voices trying to change a system. At times, it felt like participants were looking to me as a researcher to try and make change for parents with learning disabilities and participants may have had their own expectations about how the findings of the research might be used or what they could do to achieve change. As a result, participants may have been keener to emphasise cases in which they regarded there to be injustice or make wider generalisations about others involved in care proceedings and their views about parents with learning disabilities. This should therefore be taken into account when considering the findings and may give further emphasis to the caution that should be taken when generalising beyond the individual accounts. However, it should be noted that self-selection methods in research recruitment are always said to include an inherent bias (Dallos \& Vetere, 2005).

With these things in mind, future research may consider using more anonymous methods of gaining responses in order to try to account for some of these factors. Now that this initial study and others have been undertaken and tentative commonalities are being discovered, more top-down approaches to data collection may be used.

\subsection{Main findings and links with existing literature}

Whilst keeping the limitations of this study in mind, the main findings and links with existing literature will be outlined in the context of the small and possibly atypical sample of magistrates in this study.

\subsubsection{Learning disability as a continuum}

The results of this study highlighted that most participants conceived of people with learning disabilities as being very individual, noting that any impact on parenting would be dependent on the severity of the learning disability. Most participants appeared to regard the area of learning disabilities as multi-faceted and complex and related this to their experiences with people with learning disabilities. Experiences had allowed them to develop an awareness of the diversity a diagnosis of a learning disability can entail. These findings are in contrast to the literature suggesting that some people within the child protection system may hold stereotypical views about people and parents with learning 
disabilities (Tarleton et al., 2006, Booth \& Booth, 2004a) and may reflect the perhaps atypical nature of the sample of magistrates involved in this study. However, in contrast, Paul reported 'no real' experience with people with learning disabilities, which seemed to affect his perceptions of certain groups of people with learning disabilities (i.e. those with Down syndrome). Participants also described being within a child protection system and society where the views held underestimate the complexity and diversity involved in learning disabilities. These participants also highlighted the impact this has had in cases, in which parents had been 'set up to fail' or put in the 'too difficult box' by not being offered the 'right' support, or any. This is strikingly similar to the findings of McConnell et al, (2002) in Australia in which magistrates reported a tendency to put parents with learning disabilities into the 'too hard basket' and the study by Booth and Booth (2004a) in which it was acknowledged a lack of support could account for parental failure. The findings from this study therefore highlight that universal and stereotypical views may exist within the child protection system and society regarding people with learning disabilities being 'eternal children' and unable to parent (McConnell \& Llewellyn, 2000) and gives support to literature with similar findings. These findings could be explained by the fact that three of the magistrates in this study seemed to regard themselves as somewhat different to others involved in the child protection system and society.

Findings in this first theme may be understood in relation to stereotypes and the contact hypothesis which 'suggests that under certain conditions, direct contact between members of different groups can reduce intergroup stereotyping, prejudice, and discrimination' (Allport, 1954, cited in Smith \& Mackie, 2007, p.176). Therefore, those participants who had more contact with people with learning disabilities may have been subjected to experiences which demonstrated the heterogeneity involved in learning disabilities. In turn, this may have enhanced their knowledge and undermined any tendencies for them to rely on stereotypes about people with learning disabilities and their parenting. This may suggest that these participants might be less likely to make generalisations regarding all individuals who have the label 'learning disability' in their decisionmaking in care proceedings. 


\subsubsection{Determining the best interests of the child}

All participants spoke of the welfare of the child being of 'paramount' importance and a need to prevent delay in care proceedings so as not to negatively affect the welfare of the child. Participants also indicated a greater sense of urgency in cases involving babies and suggested permanent placements outside of the family home are sought more often in such cases. These findings may correspond to The Children Act (1989) which is the main framework guiding magistrates' decisionmaking and places 'paramount' importance on the welfare of the child and the need to prevent delay. They are also similar to the findings of Sheehan (1999) and Booth and Booth (2004a) who found similar factors were influential in decisionmaking. In turn, these findings may add weight to some of the literature regarding higher removal rates of babies involved in care proceedings of parents with learning disabilities and the pressure that professionals are under to seek permanent placements when children are so young.

In the current study, the influence of expert opinion was also described by participants and their involvement was seen as more likely in cases involving parents with learning disabilities. Although participants spoke of relying on experts, there were mixed opinions about how influential expert opinions were and the skills of the experts. Expert opinion was also found to be influential in the studies by Sheehan (1999) and McConnell et al. (2002) with magistrates in Australia. This similarity helps to highlight the important role experts may play in decision-making in care proceedings in England. Having to rely on experts who may be inexperienced or ill-equipped raised in this study also lends support to the suggestion that professionals involved in child protection may not always have the necessary skills or knowledge to assess or support parents with learning disabilities (Tarleton et al., 2006).

The current study found that parenting abilities were described as influential in decision-making. In particular, abilities to understand and meet the needs of the child; abilities to cope with stresses of parenting as the child gets older; capacity to accept support and develop new skills and the need to meet such demands in relation to the timescale of the child. These findings are similar to those of McConnell et al. (2002) in which Australian magistrates spoke of the influence of 
parents to 'lift their game' in their decision-making and the study by Booth and Booth (2004a) in which judges and lawyers suggested that parental abilities to learn new skills and comply with services may influence removal rates of children of parents with learning disabilities. However, the findings from the current study also seem to provide new information about the specific parenting abilities that magistrates in England may focus on when determining the best interests of the child, particularly coping with stresses as children get older.

The provision and availability of support was also described as influential in participants' decision-making in the current study, however, the levels of support deemed appropriate varied between participants. Participants highlighted the need to seek support from other sources outside of the local authority and it seemed that allowing a child to remain with the parent would be better tolerated if support was provided through these channels. Some participants also drew attention to experiences in which the support parents required was deemed to be too complex to identify or provide. As a result there was suspicion that children may have been removed from their parents unnecessarily. These findings are similar to those by McConnell et al. (2002) and Booth and Booth (2004a) in which the provision and availability of support was referred to as being influential in decision-making. The participants in these studies also proposed that if support required was deemed to be too intensive that children may be removed from their parents unnecessarily. However, the need to consider if serious attempts had been made to provide parents with support was not raised in the current study as was done in the study by McConnell et al. (2002).

The findings in this theme indicate that a number of heuristics may be relied upon when determining the best interests of the child, such as: 'delay should be avoided', 'experts should be consulted', 'parents need to show they can understand and meet the needs of their child' and 'parents should be offered support'. However, the specific nature of the heuristics seemed to be different for those participants who had more experiences with people with learning disabilities and Paul who had limited experience. This difference was reflected, for example, in participants' views about what constituted 'reasonable' levels of support. These findings, in turn, suggest that heuristics relied upon in decision- 
making may be more valid i.e. in keeping with current national policy, if magistrates have more contact with people with learning disabilities.

\subsubsection{Self-characterisation within the system}

The effect of contact with people with learning disabilities also appeared to influence how participants characterised themselves within the care proceedings system. Although most participants recognised their knowledge about learning disabilities was not 'clinical' or 'expert', some acknowledged it was likely their knowledge was greater than other magistrates involved in care proceedings. As a result of having developed more knowledge or awareness of people with learning disabilities being individual, this seemed to enable or encourage these participants to take on a different role to other magistrates. This facilitated a more active role in terms of directing or challenging experts; drawing attention to information required about the parent as an individual, rather than allowing others to adopt a 'broad brush' approach, and abilities to interact with the parents themselves. These participants also raised a need for training magistrates about the diversity involved in learning disabilities and how to interact with parents with learning disabilities in care proceedings. It was proposed that more knowledge would provide magistrates with the awareness and skills needed to interact with experts in a more active role; in terms of gaining the information needed to make their decisions. It was also suggested that training might help reduce some of the assumptions that magistrates might make about all people with learning disabilities as parents. Whilst the need for training was raised by participants in the study by Sheehan (1999), the findings in this study appear to be new to this area as they provide information about the impact that training could have on the role of magistrates in England.

The results in this theme may also be understood in relation to stereotypes, as there appear to be a number of ways people can try to overcome the effects of stereotypes. It has been suggested that although stereotypes may be activated, people can make conscious efforts to avoid thinking about them, revise or correct any of their judgements they think could have been influenced by stereotypes, and actively expose themselves to information that is 'counterstereotypic' (Smith \& Mackie, 2007). However, it is reported that it is only in exceptional 
circumstances that those making judgements will adopt 'more strenuous processing of individuating information' and that motivation to expend this effort is required to rely on stereotypes less (Fiedler \& Bless, 2001, p.130). In the current study, it seemed that those participants with more experiences with people with learning disabilities have become aware of the tendency for people to rely on stereotypes about people with learning disabilities as a group, and as such, have become motivated to avoid making stereotypes themselves.

\subsection{Implications for clinical practice and organisations}

\subsubsection{A need for training}

Participants in this study reported valuing training they have received as magistrates; however, an absence of training regarding people with learning disabilities was highlighted. Participants raised a need for more information regarding the diversity involved in learning disabilities and how to interact with parents with learning disabilities in care proceedings. Magistrates may therefore benefit from receiving training about the spectrum involved in learning disabilities, other difficulties commonly experienced such as poverty and social exclusion and the impact such things could have on parenting abilities, and their involvement in care proceedings. Providing such information could help discourage magistrates from grouping all people with learning disabilities together and reduce reliance on stereotypes in their decision-making. Training could also develop magistrates' awareness of the type of information they require about the parents involved to make their decisions and when the information they receive is unhelpful; enabling magistrates to be more directive with experts. This would be of particular importance if magistrates are indeed being expected to take on more of an active role in care proceedings.

A recommendation would be for training to involve people with learning disabilities, as research has shown that contact is now widely used for overturning biased and stereotyped views regarding other groups and their members (Turner et al., 2007). It is important to note, however, that there is the potential for negative consequences to arise as the result of contact e.g. exacerbating prejudice (Brown, 2001). Appropriate conditions are therefore said to be important when trying to use contact as an intervention. These are thought to involve: contact 
with individuals who are seen as typical or representative of their group i.e. not exceptions to the rule, and interaction to be made at an interpersonal rather than at a group level (lbid). It is hoped that under these conditions people will gain more information and knowledge about the diversity within groups, which will then be embedded in their memory and drawn upon when making judgements.

If actual contact is not possible, research has also demonstrated that extended contact (i.e. knowledge that people from one group have friends with people from a different group) or imagined contact (i.e. imagining contact with members of a different group) may be helpful in improving intergroup attitudes and relations ( $b i d)$. Hence, hypothetical scenarios regarding parents with learning disabilities may be beneficial in training or disclosures of more personal experiences with people with learning disabilities.

Training could also include information regarding errors or cognitive biases that can be involved in decision-making as it has been suggested that 'errors can be reduced if people are aware of them and strive consciously to avoid them' (Munro, 1999, p.756).

\subsubsection{Invalvement of 'experts'}

Participants indicated that 'experts' were regularly appointed in cases involving parents with learning disabilities and experts included psychologists. The findings highlight the importance placed on the role of experts in decision-making in care proceedings; in particular their opinions expressed in reports. As such, experts should remain mindful of information included or not included in their reports and how this may be used in the future. This also applies to professionals working in National Health Service (NHS) adult learning disability or children and families teams who may be involved in child protection, as their reports may be requested or drawn upon during care proceedings (BPS, 2007a).

The findings also suggest that experts should not assume that magistrates know anything about learning disabilities or have had contact with this client group before. It may therefore be helpful for experts to provide as much information as possible in their reports, particularly regarding the specific nature of the learning 
disability and the individual being reported on, even if this has not been specifically requested. This may help to indirectly educate magistrates and increase awareness of learning disabilities, whilst trying to ensure that the individual's needs are being recognised. A further recommendation would be for psychologists to refer to the BPS (2007b) Psychologists as expert witnesses: guidelines and procedure for England and Wales if they are requested to produce reports for care proceedings.

\subsubsection{Parenting assessments and interventions}

In relation to the need to prevent delay in care proceedings, it would be essential for professionals completing assessments and interventions to keep this in mind. This may be particularly important in cases where the parent has already had a child removed; as it has been found that young babies may be removed permanently from parents if there have been child protection concerns with previous children (Booth \& Booth, 2004a). The completion of earlier assessments and training with parents with learning disabilities has been recommended by Ward and Tarleton (2007) who note the extra time people with learning disabilities may need to learn new skills and generalise them to less familiar settings. As has been recommended, parenting assessments and support should also be adapted to suit the needs of the parent (e.g. given more time and avoiding out-of-home placements) (McGaw \& Newman, 2005). A recommendation would be for professionals to refer to good practice guidance on working with parents with learning disabilities (DfES \& DH, 2007).

\subsubsection{Finding the 'right' support}

With regard to the influence of support in decision-making, it is essential that steps are taken to identify the support needs of parents with learning disabilities and where the most appropriate providers of this support might be. This is especially important as the number of people with learning disabilities becoming parents is likely to increase in the future and the need to offer the 'right' support has been emphasised in recent UK studies, government initiatives and legal frameworks, which state that the need for support should not impede the person's right to parent. Tarleton and Ward (2007) suggest that for assessments to be most useful in identifying the parents' support needs they should 'be based 
upon competency (rather than IQ)', 'to take account of parents' existing skills' and 'be holistic and pay attention to the family's wider social context' (p.26). The authors also report that staff supporting parents with learning disabilities should start one-to-one work with parents in the $16^{\text {th }}$ week of pregnancy.

\subsubsection{Parents with learning disabilities}

Although the results of this study do not have any direct implications for parents with learning disabilities, there may be some indirect implications. The findings of this research may have an impact on the participants and how they act in care proceedings and when making decisions. It is hoped they continue to make decisions in the best interests of the child, whilst considering how best the parents' needs can be assessed and supported. It is also expected that if some of the implications are addressed, especially the provision of training for magistrates regarding learning disabilities, this may too have an impact on parents with learning disabilities involved in care proceedings.

\subsection{Implications for future research}

Although this study aimed to recruit a relatively homogeneous sample, anyone between the ages of 18 and 70 can become a magistrate and applications are encouraged regardless of gender, ethnicity, religion or sexual orientation (Judiciary of England and Wales, n.d.). Additionally, magistrate panels aim to include a mix of age, gender and ethnicity to 'bring a broad experience of life to the bench' (Ibid), so it may be worth exploring a more diverse sample in future research.

The focus of this study explored the experience of decision-making by magistrates in care proceedings involving parents with learning disabilities. A further study could therefore examine the contrast with non-learning disability cases. In this study participants were also not required to provide detailed information about parents' learning disabilities or specify if they were referring to cases involving single-parents or two parent families, so further exploration with such factors in mind could be considered. 
Decisions in care proceedings by magistrates are always made within the context of a panel and ultimately the decision is shared equally. Further studies could therefore involve magistrates in groups or panels as it may be that decisionmaking in such groups differs to decisions that individuals would make alone. Indeed evidence from social psychology would support this (e.g. groupthink and group polarization) (Smith \& Mackie, 2007). Such findings could potentially be more representative of how things happen in the real world.

Although a need for training to be given to magistrates regarding learning disabilities was raised, along with suggestions for the content of future training, it may be helpful to explore this with larger samples of magistrates. It may be of use to determine the level of knowledge that magistrates have about learning disabilities and some of their views or perceptions so training may suit their needs. This could help ensure that training offered is as helpful as possible to magistrates, particularly if they are to take more of an active role in care proceedings. Further research could also explore the impact that education about learning disabilities might have on magistrates' views about people with learning disabilities as parents and their decision-making.

\subsection{Final reflections}

Throughout this process I have made efforts to remain mindful that my passion for this area of research arose following an experience in which I felt a mother with learning disabilities had been treated unfairly and discriminated against, but that this experience was not representative of all parents with learning disabilities involved in care proceedings. I was aware I may have taken on an advocacy type role for parents with learning disabilities and wanted to facilitate change through research I completed if there was any way I could achieve this. I was also wary that the passion I had developed could make me biased during the research, in terms of the literature I drew upon and rejected, and the interpretations I made about the participants' experiences. As a result I strove to ensure that steps were taken to assess and enhance the validity of the research. These included keeping a reflective journal, having regular meetings with my academic supervisor, discussing literature and the findings with my field supervisor and sharing my thoughts and feelings with the qualitative group at university. 
These strategies were particularly useful following the first interview with Paul, when 1 experienced frustration and anger about some of the views and experiences he had shared as I was concerned about the consequences these might have had for parents with learning disabilities (i.e. they may have been discriminated against). This feeling was followed by relief and hope during subsequent interviews in which the participants appeared to regard parents with learning disabilities somewhat differently and adopt a different approach during care proceedings. Although these feelings were present, | believe the strategies | adopted helped to ensure that I remained balanced in my role in the research. I also remember my feelings towards Paul changing during the analysis when I focused on a quote by Simon who said 'it's just they've got no reason to know any different' and I realised this was actually very true and that my feelings of anger were particularly unnecessary as Paul was not to blame; he had just not had the experiences or knowledge that may have altered his views.

\subsection{Conclusions}

This research has explored the views and perceptions of family court magistrates regarding people and parents with learning disabilities. It has also investigated factors that are or have been influential in their decision-making in care proceedings involving parents with learning disabilities. As such, it has started to address an area of research that has so far been lacking in England. The influence of stereotypes and the contact hypothesis (Smith \& Mackie, 2007) have been particularly helpful in thinking about the views that people have about parents with learning disabilities and how this may affect them in their role as a family court magistrate and their decision-making. Finally, some implications have been made as a result of the findings and some suggestions for future research, especially in relation to the suggestion that family court magistrates may benefit from training regarding learning disabilities, and specifically, parenting in this context. 


\section{References}

Allport, G. W. (1954). The historical background of modern social psychology. In G. Lindzey (Ed.) The handbook of social psychology: Vol. 1 (pp.3-56). Cambridge, MA: Addison-Wesley.

Aunos, M. \& Feldman, M.A. (2002). Attitudes towards sexuality, sterilization and parenting rights of persons with intellectual disabilities. [Electronic version]. Journal of Applied Research in intellectual Disabilities, 15, 285-296.

Booth, T. \& Booth, W. (1993). Parenting with learning difficulties: lessons for practitioners. [Electronic version]. British Journal of Social Work, 23, 459-480.

Booth, T. \& Booth, W. (2004a). Parents with learning difficulties, child protection and the courts. A report to The Nuffield Foundation. Retrieved May 2010 from http://www.supportedparenting.com/projects/NuffieldReport.pdf

Booth, W. \& Booth, T. (2004b). A family at risk: Multiple perspectives on parenting and child protection. [Electronic version]. British Journal of Learning Disabilities, 32, 9-15.

Booth, T., Booth, W. \& McConnell, D. (2005). The prevalence and outcomes of care proceedings involving parents with learning difficulties in the family courts. [Electronic version]. Journal of Applied Research in Intellectual Disabilities, 18, 7-17.

British Institute of Learning Disabilities (BILD). (2007). Factsheet: Learning disabilities. $\quad$ Retrieved May 2010 from http://www.bild.org.uk/docs/05fags/Factsheet\%20Learning\%20Disabilities.pdf

British Psychological Society. (2001). Learning disability: definitions and contexts. [Electronic version]. Leicester: Author.

British Psychological Society. (2007a). Child protection: Position paper. Leicester: Author. 
British Psychological Society (2007b). Psychologists as expert witnesses: guidelines and procedure for England and Wales. Leicester: Author.

Brown, R. (2001). Intergroup relations. In M. Hewstone \& W. Stroebe (Eds.) Introduction to social psychology ( $3^{\text {rd }}$ edn., pp.479-515). Oxford: Blackwell.

Carradice, A., Shankland, M. C. \& Beail, N. (2002). A qualitative study of the theoretical models used by UK mental health nurses to guide their assessments with family caregivers of people with dementia. [Electronic version]. International Journal of Nursing Studies, 39, 17-26.

Cleaver, H. \& Nicholson, D. (2008). Parental learning disability and children's needs: Family experiences and effective practice. Executive summary. [Electronic version]. Department for children, schools and families: HMSO.

Dallos, R. \& Vetere, A. (2005). Researching psychotherapy and counselling. London: Open University Press.

Department for Education and Skills \& Department of Health. (2007). Good practice guidance on working with parents with a learning disability. [Electronic version]. London: The Stationery Office.

Department of Health. (2001). Valuing People: A new strategy for learning disability for the $21^{\text {st }}$ century. [Electronic version]. London: The Stationery Office.

Department of Health. (2009). Valuing People Now: A new three year strategy for people with learning disabilities. [Electronic version]. London: $\mathrm{DH}$.

Elliot, R., Fischer, C. T. \& Rennie, D. L. (1999). Evolving guidelines for publication of qualitative research studies in psychology and related fields. British Journal of Clinical Psychology, 38, 215-229.

Emerson, E. \& Hatton, C. (2004). Estimating future need/demand for supports for adults with learning disabilities in England. Institute for health research, 
Lancaster University: UK. Retrieved May 2010 from http://www.lancs.ac.uk/shm/dhr/research/learning/downloaci, estimatingfutureneed.pdf

Emerson, E., Malam, S., Davies, I. \& Spencer, K. (2005). Adults with learning difficulties in England 2003/4. [Electronic version]. London: National statistics \& Health and Social Care Information Centre.

Fiedler, K. \& Bless, H. (2001). Social cognition. In M. Hewstone \& W. Stroebe (Eds.) Introduction to social psychology ( $3^{\text {rd }}$ edn., pp.115-149). Oxford: Blackwell.

Försterling, F. (2001). Attribution: An introduction to theories, research, and applications. Hove: Psychology Press Ltd.

Golsworthy, R. \& Coyle, A. (2001). Practitioners' accounts of religious and spiritual dimensions in bereavement therapy. [Electronic version]. Counselling Psychology Quarterly, 14(3), 183-202.

Goodinge, S. (2000). A jigsaw of services: Inspection of services to support disabled adults in their parenting role. [Electronic version]. Social Services Inspectorate/Department of Health: HMSO.

Her Majesty's Courts Service (n.d.). Magistrates and Magistrates' Courts. Retrieved May 2010 from

http://www.hmcourts-service.gov.uk/infoabout/magistrates/index.htm

Hogg, M. A. \& Abrams, D. (Ed.) (2001). Intergroup relations: Essential readings. Hove: Psychology Press.

Judiciary of England and Wales (n.d.). Family Justice. Retrieved May 2010 from http://www.judiciary.gov.uk/about judiciary/roles types jurisdiction/ family justice/index.htm\#4 
Llewellyn, G., Mayes, R. \& McConnell, D. (2008). Editorial: Towards acceptance and inclusion of people with intellectual disability as parents. [Electronic version]. Journal of Applied Research in intellectual Disabilities, 21, 293-295.

Lyons, E. (2007). Doing qualitative research: Initial questions. In E. Lyons \& A. Coyle (Ed.) Analysing qualitative data in psychology (pp.3-8). London: Sage Publications.

McConnell, D. \& Llewellyn, G. (2000). Disability and discrimination in statutory child protection proceedings. [Electronic version]. Disability \& Society, 15(6), 883-895.

McConnell, D., Llewellyn, G. \& Ferronato, L. (2002). Disability and decisionmaking in Australian care proceedings. [Electronic version]. International Journal of Law, Policy and the Family, 16, 270-299.

McGaw, S. \& Newman, T. (2005). What works for parents with learning disabilities? - Summary. Ilford: Banardo's. Retrieved May 2010 from www.banardos.org.uk/resources

Munro, E. (1999). Common errors of reasoning in child protection work. [Electronic version]. Child Abuse \& Neglect, 23(8), 745-758.

Pettigrew, T. F. (2001). The ultimate attribution error: Extending Allport's cognitive analysis of prejudice. In M.A. Hogg \& D. Abrams (Eds.) Intergroup relations: Essential readings (pp.162-173). Hove: Psychology Press. (Original work published 1979).

Ponterotto, J. G. (2005). Qualitative research in counseling psychology: A primer on research paradigms and philosophy of science. Journal of Counseling Psychology, 52(2), 126-136. 
Ross, L. (1977). The intuitive psychologist and his shortcomings. In L. Berkowitz (Ed.) Advances in experimental social psychology (Vol. 10, pp.174-220). New York: Basic Books.

Sheehan, R. (1999). The children's court and child protection: The primacy of the socio-legal response to child abuse. [Electronic version]. Australian Social Work, $52(4), 5-10$.

Smith, J. A. \& Eatough, V. (2007). Interpretative Phenomenological Analysis. In E. Lyons \& A. Coyle (Ed.) Analysing qualitative data in psychology (pp.35-50). London: Sage Publications.

Smith, E. R. \& Mackie, D. M. (2007). Social psychology (3 ${ }^{\text {rd }}$ edn.). Hove: Psychology Press.

Smith, J. A. \& Osborn, M. (2003). Interpretative Phenomenological Analysis. In J.A. Smith (Ed.) Qualitative psychology: A practical guide to research methods (pp.51-79). London: Sage Publications.

Smith, J. A. \& Osborn, M. (2008). Interpretative Phenomenological Analysis. In J.A. Smith (Ed.) Qualitative psychology: A practical guide to research methods ( $2^{\text {nd }}$ edn., pp.53-80). London: Sage Publications.

Smith, J. A., Flowers, P. \& Larkin, M. (2009). Interpretative Phenomenological Analysis: Theory, method and research. London: Sage Publications.

Tarleton, B. (2007). Specialist advocacy services for parents with learning disabilities involved in child protection proceedings. [Electronic version]. British Journal of Learning Disabilities, 36, 134-139.

Tarleton, B., Ward, L. \& Howarth, J. (2006). Finding the right support. A review of issues and positive practice in supporting parents with learning difficulties and their children. London: Baring Foundation. Retrieved May 2010 from http://www.baringfoundation.org.uk/Findingrightsupport.odf 
The Adoption and Children Act. (2002). London: Stationery Office. Retrieved May 2010 from http://www.opsi.gov.uk/acts/acts2002/ukpga 20020038 en 1

The Children Act. (1989). London: Stationery Office. Retrieved May 2010 from http://www.opsi.gov.uk/acts/acts1989/ukpga 19890041 en 1

The Children and Young Persons' Act. (1989). Victoria, Australia: Victorian Government Printer.

The Disability Discrimination Act. (1995). London: Stationary Office. Retrieved May 2010 from http://www.opsi.gov.uk/acts/acts1995/ukpga 19950050 en 1

The Human Rights Act. (1998). London: Stationery Office. Retrieved May 2010 from http://www.opsi.gov.uk/acts/acts1998/ukpga 19980042 en 1

Turner, R. N., Crisp, R. J. \& Lambert, E. (2007). Imagining intergroup contact can improve intergroup attitudes. Group Process \& Intergroup Relations, 10(4), 427441.

Van de Mortel, T. F. (2009). Faking it: Social desirability response bias in selfreport research. Australian Journal of Advanced Nursing, 25(4), 40-48.

Ward, L. \& Tarleton, B. (2007). Sinking or swimming? Supporting parents with learning disabilities and their children. [Electronic version]. Learning Disability Review, 12(2), 22-32.

Yardley, L. (2008). Demonstrating validity in qualitative psychology. In J.A. Smith (Ed.), Qualitative psychology: A practical guide to methods ( $2^{\text {nd }}$ edn., pp.235-251). London: Sage Publications.

Zimbardo, P. G. \& Weber, A. L. (1997). Psychology ( $2^{\text {nd }}$ edn). Harlow, England: Longman. 


\section{Major Research Project}

\section{Appendices}




\section{Appendix 1: Welfare checklist}

\section{from Children Act (1989)}


Welfare checklist from The Children Act (1989)

- (a) the ascertainable wishes and feelings of the child concerned (considered in the light of his (sic) age and understanding);

- (b) his (sic) physical, emotional and educational needs;

- (c) the likely effect on him (sic) of any change in his circumstances;

- (d) his (sic) age, sex, background and any characteristics of his which the court considers relevant;

- (e) any harm which he (sic) has suffered or is at risk of suffering;

- (f) how capable each of his (sic) parents, and any other person in relation to whom the court considers the question to be relevant, is of meeting his (sic) needs;

- (g) the range of powers available to the court under this Act in the proceedings in question' $\left(1(3)^{2}\right.$, Children Act, 1989).

\footnotetext{
${ }^{2}$ Numbers in brackets indicate section number and part of the Act.
} 


\title{
Appendix 2: Detailed
}

\section{information on Section 8 \\ orders of the Children Act}

\author{
(1989)
}


Detailed information on the Section 8 orders of The Children Act (1989)

- "'a contact order" - requiring the person with whom a child lives, or is to live, to allow the child to visit or stay with the person named in the order, or for that person and the child otherwise to have contact with each other;

- "a prohibited steps order" - that no step which could be taken by a parent in meeting his parental responsibility for a child, and which is of a kind specified in the order, shall be taken by any person without the consent of the court;

- "a residence order" - settling the arrangements to be made as to the person with whom a child is to live; and

- "a specific issue order" - giving directions for the purpose of determining a specific question which has arisen, or which may arise, in connection with any aspect of parental responsibility for a child' (8(1) Children Act 1989). 


\title{
Appendix 3: Further
}

\section{explanatory notes regarding}

\author{
recruitment
}


Explanatory notes regarding recruitment

- The Magistrates' Association is a membership body covering England and Wales. It is not compulsory for magistrates to be members of the association, however, $73 \%$ of all 28,000 magistrates in England and Wales are currently members. It has not been possible to determine how many of these members act as magistrates in family proceedings courts.

- Contact was initially made with the Magistrates' Association in order to discuss requirements for ethical approval. After no responses were received via the courts that had been sent information about the research by post, the Magistrates' Association offered to circulate information about the research by email. Information was circulated by the Magistrates' Association to all 13 members of the Family Courts Committee (who have been selected to take charge of family court matters within the association), with the request that the information then be passed on to other family court magistrates in their constituencies. Unfortunately it has not been possible to determine how many people this information was circulated to as this was done through intermediaries (as was advised by the University of Surrey Faculty of Arts and Human Sciences Ethics Committee).

- Following the very small response rate during the research (i.e. only four), magistrates who had already participated in the research were asked to circulate information about the research to other magistrates in their constituency. Whilst three participants circulated the information by email to other family court magistrates in their constituencies, one participant decided to do this via the Executive Committee in their constituency. This was done by the participant to determine if the committee approved of the information being circulated to other family court magistrates (even though the Magistrates' Association did not deem this to be necessary). As this happened during a very late stage during the research process and as the other participants had circulated the information about the research, contact was not made with other 
Executive Committees representing the courts that the other participants were involved with.

- A number of Executive Committees exist within Her Majesty's Court Service and have been set up to oversee and provide guidance in relation to matters within courts. Every court has a connection with an Executive Committee but may not have one located within the court.

- 80 copies of information about the research were sent by post to four family proceedings courts within Surrey and Greater London as it is estimated that approximately this number of magistrates act within these courts. However, it is not known how many magistrates received information about the research as information sent by post was also circulated via intermediaries.

It has not been possible to determine the ratio of male to female family court magistrates in England and Wales. However, the Magistrates' Association did not think that the ratio involved in this research i.e. 3 males: 1 female, was representative of that in England and Wales. When considering the representativeness of ratios, attention should be paid to the fact that magistrate panels aim to have a balance of gender. 


\section{Appendix 4: Email}

\section{correspondence with Executive}

\section{Committee}


Response received from the executive committee following a request made for their assistance in recruiting participants. This request was made by a participant from the study during an executive committee meeting they attended at the court.

Dear Ms Kollinsky,

I write further to the executive committee meeting on the $28^{\text {th }}$ January at which your request for assistance was discussed. The Committee felt that they did not have sufficient information to make a decision as to whether or not to participate in your project. They would like much fuller information than your brief synopsis provided. It was not clear what sort of information they would be expected to provide. They were very unhappy with the concept of being asked questions about cases without being prepared and having notes to refer to, which would necessitate advance notice that the interviews were to take place, and there would have to be a long lead up time to ensure that they had actually dealt with cases in the category in which you are interested. In addition it is not clear how the information is to be presented and for what purpose and concern that the numbers of magistrates you were proposing to speak to is so small that they cannot fairly be said to be representative of the Magistracy as a whole nor a forensic examination of their (meaning the Magistracy as a whole) thoughts about the process in order to draw any meaningful conclusions.

They were willing to invite you to address them at their next meeting, but I accept that is probably too late for you as the next one is not until the $12^{\text {th }}$ may. If you do want to come and address them I can try to arrange an earlier meeting for you with as many of the Executive as I can get together. If you do not wish to do so they felt that they would not be recommending to the bench that they participate in this project.

If I can be of any further assistance please let me know.

Yours faithfully,

Response provided to the executive committee, composed by me and my university supervisor.

Dear Ms X,

Thank you for your response in relation to the executive committee meeting on the 28th January. I am writing to provide a fuller response to the concerns that were raised in the meeting and hope that the information provided will be sufficient to answer any queries or concerns. Please see below:

Firstly I would like to explain that my research project forms part of my doctorate in clinical psychology at the University of Surrey. All individuals who train to become a clinical psychologist are required to devise and complete a research project during the second and third year of their training. It is important to choose an area that is relevant to psychology and to design a research project that can contribute to a growing evidence base. As psychologists are regularly 
called upon to provide evidence or reports for care proceedings this was an area that I became interested in. With previous experience of working with a parent with a learning disability who was involved in care proceedings, after completing an extensive literature search I became aware of the limited research involved in this area, particularly involving magistrates. More research has been completed to date involving social workers than any other professionals. Although the research project is required as part of the doctoral training, it is relatively small scale compared to some other projects as we also work on placements and have other assignments to complete. Once the project is completed it will be written up in a maximum of 20,000 words and submitted for marking by internal and external examiners at the University of Surrey. After it has been marked, the research will be written up and submitted to a research journal or magazine in order to disseminate the findings. No participant will be identifiable in any publications. Additionally, feedback will be provided to all those who participated in the research. A copy of the research project will also be held in the University of Surrey library.

As the topic for my research is a new area, the aim of my project is to be exploratory and it is recommended that a qualitative approach and analysis is used in the project. This is due to the fact that little is known about this topic, so imposing a specific framework such as when one uses questionnaires would be inappropriate. This means that small numbers of people are interviewed so that their experiences can be heard and understood in more detail. The interviews are then transcribed (i.e. written up word for word) and this is a lengthy process. The interviews are then analysed to extract the important and meaningful themes that arise. These can then be explored by interviewing further participants. In this way a conceptual framework can be developed based on what participants say. Any findings from the interviews will be related to the participants that are involved in the study and will not under any circumstances be generalised as representing whole groups of people such as the Magistracy as a whole. Instead, the conceptual framework that has been developed with a smaller number of participants can then be used to develop further research questions that can be explored with larger groups of people in follow up studies.

Although the Committee did not feel that they had enough information to make a decision, I would like to reassure the Committee that the synopsis provided was produced specifically for the project and it was passed by an ethics committee. Unfortunately it is not possible to provide vast amounts of information regarding the project as this may interfere with the responses that participants may provide during the interviews. However, these are the broad areas that the questions focus on:

- Understanding of a learning disability

- Experience of working on child care proceedings involving a parent with a learning disability (no specific case details are required)

- Experience of training about parents with a learning disability

- Experience of what magistrates perceive their training needs are regarding working on cases involving parents with a learning disability

The main aim of the study is to be exploratory as, to my knowledge, no research has been done involving magistrates in the UK and their experiences of working on care proceedings involving parents who have a learning disability. The 
interview schedule has been designed to incorporate open questions that will enable discussions to take place about what it has been like for magistrates to be involved in cases with parents with learning disabilities.

One of the most important aspects of the research is that the responses provided during the interviews accurately reflect magistrates' views and experiences at the time and it would therefore be deliberately discouraged that participants are provided with information on the content of the interview questions in advance. The questions in the interview will not require participants to provide specific details about individual cases they have worked on but more general information about cases that have involved parents with a learning disability. The only criteria for participants is that they have been involved with at least one care proceedings case in which a parent had a learning disability and the hope was that people would volunteer to participate who knew that they had already had this experience.

I would like to reassure the committee that this research has no intention of blaming people for anything or being critical of individuals but is rather an exploratory study to gain a greater understanding of magistrates' experiences of working on cases involving parents with learning disabilities, with the hope of making a meaningful, although small contribution to the limited research base in this area which currently exists. One way in which the findings might have important implications is in the areas of information and training and ways in which psychologists might be usefully involved in this.

So far I have interviewed four magistrates; however, I am hoping to recruit more magistrates to interview for the research project. I am required to submit the write up of the project by the middle of July so ideally $\mid$ will need to have completed any interviews by early June.

I hope I have answered any queries or concerns that were raised in the initial meeting and I hope that the Executive can reconsider supporting my research project. If there are any further questions then please feel free to contact me, or you can contact my supervisor Dr Laura Simonds whilst I am away from the $18^{\text {th }}$ March $-5^{\text {th }}$ April. We would also be very happy to attend a meeting to discuss the project in any more detail if this is required.

I also enclose with this response the participant information sheets.

I look forward to hearing from you.

Yours sincerely,

Laura Kollinsky

Trainee Clinical Psychologist 
Final response received by the executive committee.

Dear Ms Kollinsky

Thank you for providing further information in respect of your research project, which I forwarded to the members of the Executive Committee for their views.

After very careful consideration of all the available information the Committee still feel that they are unable to recommend to the bench that they participate in this particular project. In reaching their decision members of the Committee expressed the following -

"My view is that we have no particular expertise about most of the problems that come before us. We use Cafcass reports and reports from experts, such as psychologists, to inform our practical and, hopefully, sensible decisions. Our remit is to weigh the evidence before us - not to have particular views about certain groups of people"

"If a parent or parents have learning disabilities, this may well be part of the reasons that lead a local authority to be concerned about their capacity to care adequately for a child. Our role would be to decide to what extent those disabilities are so great as to justify, along with any other relevant facts, placing the child in the care of the local authority. In this we would be guided by the reports of the Guardian and or any experts."

"The sample is going to be so small that any meaningful conclusions will be difficult to sustain."

"Ms Kollinsky does go into some detail to explain her methodology but would appear to only want to interview, or take evidence from, a small group of magistrates and to ask them about their direct experience in this area. This would, almost inevitably, be specific to certain cases, and might be open to the challenge of being anecdotal. Yet she seems to want them to extrapolate these individual accounts into statistical evidence. This could end up with a misleading outcome."

"My view is that I do not think we are necessarily qualified to respond in the way that Ms Kollinsky wants us to, and therefore I am concerned that we might be forced to "defend" any decisions we make, which, in actual fact, are really based on the reports we receive rather than our own knowledge of the problems presented to us."

I am sorry that we are unable to assist you on this occasion but would like to take this opportunity to wish you every success for the future.

Kind regards 


\section{Appendix 5: Interview schedule}


Views and experiences of family court magistrates who have been involved in care proceedings cases involving parents who have a learning disability

\section{Interview schedule - topic guides}

Please feel free to ask me any questions at any point throughout the interview today.

1. Can we start by you telling me why/how you got into working as a family court magistrate?

PROMPTS - did you work as a different type of magistrate before? What drew you to becoming a family court magistrate?

2. Can you tell me about your experiences and understanding of the term 'learning disability'?

3. Can you tell me about any experiences you've had working with a person with a learning disability?

4. Have you had any other experiences of working/being with people who have a learning disability?

5. What do you understand by the term learning/intellectual disability?

PROMPTS - do you have any ideas about how learning disabilities are caused or develop?

6. Can you tell me about any training you have received regarding people who have a learning disability, through role as a magistrate or other?

PROMPTS - what was the nature of this training? What did you get out of it?

7. I want you to think about care proceedings cases that you have been involved in where a parent(s) had a learning disability. Can you tell me about these experiences?

PROMPTS - why was the referral made? What were the main concerns of other professionals involved? What was the outcome? What were the similarities and differences in the cases you have worked on involving a parent(s) with a learning disability?

8. What factors of the case influenced your decision?

PROMPTS - why were these factors influential to you? 
9. What factors were most influential in your decision-making involving cases with parents with learning disabilities?

10. Are there any particular guidelines/policies that you can refer to when working on care proceedings cases involving parents who have a learning disability?

PROMPTS - why do you work in the way that you do? Who do you turn to/listen to for advice about work?

11. What impact, if any, do you think a learning disability has on parenting ability?

PROMPTS - how does this differ to parents who do not have a learning disability? How do you view the outlook for children of parents who have a learning disability?

12. Can you tell me if anything in particular has influenced your views about the impact that a learning disability may have on parenting ability?

PROMPTS - Have you had a particular experience or read something that has influenced your views?

13. Can you tell me about any similarities and differences that there might be regarding the process in which parents go through in care proceedings if they do or do not have a learning disability?

14. Do you think the process or experience is different for a parent if they have a learning disability?

PROMPTS - Can you tell me about any support measures which may be in place?

15. Is there anything you feel that I haven't asked you today that you think I should have done or is there anything else that you would like to say? 


\section{Appendix 6: Participant}

\section{information sheet}


Views and experiences of family court magistrates who have been involved in care proceedings cases involving parents who have a learning disability

\section{Participant Information Sheet}

My name is Laura Kollinsky and I am a trainee clinical psychologist from the University of Surrey. I would like to invite you to take part in a research study investigating family court magistrates' experiences of being involved in care proceedings involving parents with learning disabilities, in particular their understanding of a learning disability and the impact that this may have on parenting. Before you decide you need to understand why the research is being done and what it would involve for you. Please take your time to read the following information carefully and feel free to talk to others about the study if you wish.

Please ask if there is anything that is not clear or if you would like more information. Take time to decide whether or not you wish to take part.

\section{Thank you for reading this.}

\section{What is the purpose of the study?}

Research is being conducted to explore family court magistrates' experiences of being involved in care proceedings involving parents with learning disabilities i.e., the type of cases they have been involved with and the factors which may have influenced their decisions. The research is focused on care proceedings involving parents with learning disabilities and the knowledge about learning disabilities that family court magistrates may have and the factors which influence the decisions that they make. Research has shown that parents with a learning disability have been found to be disproportionately represented in care proceedings (Booth et al., 2005) and so it is important to investigate what family magistrates think about cases which involve parents with learning disabilities.

\section{Who is conducting and supervising the research?}

Laura Kollinsky, Trainee Clinical Psychologist, University of Surrey

\section{Supervisors}

Dr Laura Simonds, Academic supervisor, University of Surrey

Dr. Julie Nixon, Consultant Clinical Psychologist, South West London and St Georges' NHS Trust

\section{Why have I been invited?}

Family court magistrates who have been involved in care proceedings involving parents with learning disabilities are needed to participate in the study in order to explore their experience of being involved with individuals with learning disabilities. It is expected that 6-8 participants will be needed to take part in this study. 


\section{Do I have to take part?}

It is up to you to decide. Participation is entirely voluntary. The purpose of this sheet is to explain what the study involves. If you agree to participate, we will then ask you to sign a consent form to show you have agreed to take part. However, you are free to withdraw, without giving a reason, even if you have signed a consent form.

\section{What will happen if I take part?}

If you decide to take part you will be asked to attend a meeting with me which will last about one hour. During this meeting you will be asked questions about the work that you do, some of the cases you have been involved in (without the need to identify those involved in the cases) and the factors which may have influenced the decisions that you have made. The meeting will take place in a confidential setting in the court in which you work or another convenient location. The meeting will be recorded and the information recorded will be confidential. I will arrange this meeting at a time and date which is convenient for you. You will also be asked to complete a demographic information questionnaire i.e. asking you about your age, work and qualifications etc.

\section{Will my participation in the study be confidential?}

All information collected during the study is confidential. If you decide to take part only I will have access to your name and contact details. The recorded interviews and transcripts of your interview will be stored securely and only accessible to me and my supervisors. All recordings and transcripts will remain anonymous. The recordings will be destroyed after the study has been completed and the anonymised transcripts will be kept for the required 10 year period before being destroyed.

\section{What are the possible disadvantages and risks of taking part?}

It is possible that participants may have questions or feel the need to discuss their working practice in more detail after taking part in this research. Completing the interview may have an emotional impact on participants as they reflect on their work. I will be available after the interview if participants wish to discuss any issues that may cause distress.

\section{What are the possible benefits of taking part?}

I cannot promise that the study will help you, although you may find it valuable to have time to discuss your experiences of working with parents with learning disabilities. It is also hoped that the information we get from this study will help improve the experiences of parents with learning disabilities involved in care proceedings.

\section{What will happen if I don't want to carry on with the study?}

You can choose to withdraw from the study if you change your mind. Even if you have agreed to participate in the Interview, you do not have to continue with it. You do not have to give a reason for withdrawing from the study. If you choose to withdraw from the study, your data (i.e. from the interview) will be destroyed and no longer included in the study. You can withdraw your data from the study within one month of the interview taking place. 


\section{What if there is a problem?}

If you have a concern about any aspect of this study, you should ask to speak to my academic supervisor who will do her best to answer your questions (contact details at bottom of page). If you remain unhappy and wish to complain formally, you can do this through the University of Surrey Ethics Complaints Procedure. Details can be obtained from the University of Surrey's faculty of arts and human sciences committee website http://www.fahs.surrey.ac.uk/ethics/

\section{What will happen to the results?}

A report of the results will be written for the University of Surrey and will also be written up for publication in a scientific journal. Participants will not be identified in the report; however, direct quotes from the interviews will be used, although these would remain anonymous. A brief summary of the results will be made available to you upon request.

\section{Who has reviewed this study?}

All research done under the University of Surrey is looked at by an independent group of people, called a Research Ethics Committee to protect your safety, rights, wellbeing and dignity. This study has been reviewed and given a favourable opinion by the University of Surrey Research Ethics Committee.

\section{Who should I contact for further information?}

If you have any questions about the study, would like to participate, or wish to request a summary of results please do not hesitate to contact Laura Kollinsky at kollinskv@surrey.ac.uk or on 01483 689441. If you have a complaint or concern, please contact Dr Laura Simonds at l.simonds@surrey.ac.uk or on 01483689441. 


\section{Appendix 7: Demographic}

\section{sheet}


Views and experiences of family court magistrates who have been involved in care proceedings cases involving parents who have a learning disability

\section{Participant Demographic Sheet}

The following questions ask you some personal details about yourself.

You do not have to answer these questions if you do not wish to. Any responses that you do give will be kept strictly confidential. Completed questionnaires will only be seen by the researchers involved in the study.

Thank you for reading this.

1. Are you

Male

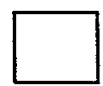

Female

2. How old are you?

3. Please state your professional status and your current role

4. How long have you worked as a magistrate?

5. How long have you worked in family courts as a magistrate?

6. Did you have any experience of being involved with people with learning disabilities prior to working in family courts, either professional or personal? Please give details

7. How many care proceedings cases involving a parent with a learning disability have you been involved with? 


\section{Do you have another occupation?}

9. Are you a parent?

10. What is your highest level of qualification obtained or currently working towards? (please tick which apply)

No qualifications
GCSE or O'levels (A-C grade)
NVQs

Please give details

A' levels, GNVQ or Equivalent
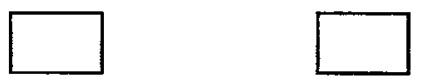

Higher Education
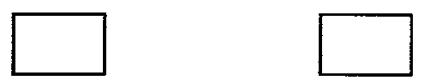

Degree or equivalent
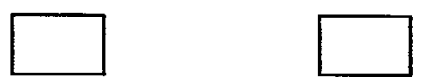

Higher degree or postgraduate

Qualification
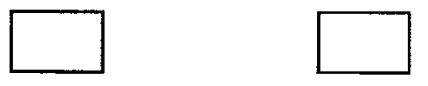


\section{What ethnic group do you belong to?}

White:

White

White British

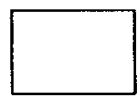

White Irish

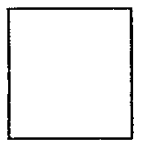

White Scottish

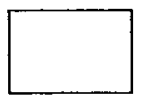

Irish Traveller

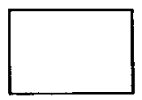

Any other White background

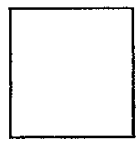

\section{Mixed:}

Mixed - White and Black Caribbean

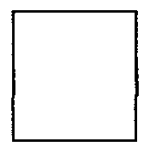

Mixed - White and Black African

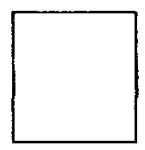

Mixed - White and Asian

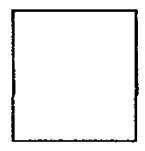

Any other Black background

\section{Black or Black British:}

Black or Black British - Caribbean

Black or Black British - African

\section{Asian or Asian British:}

Asian or Asian British - Indian

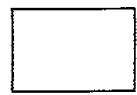

Asian or Asian British - Pakistani

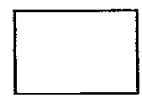

Asian or Asian British -

Bangladeshi

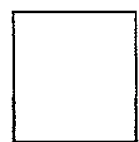

Chinese

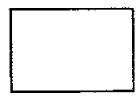

Any other Asian background

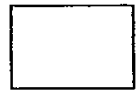

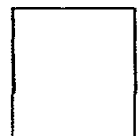

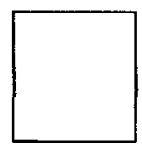

Any other Mixed background
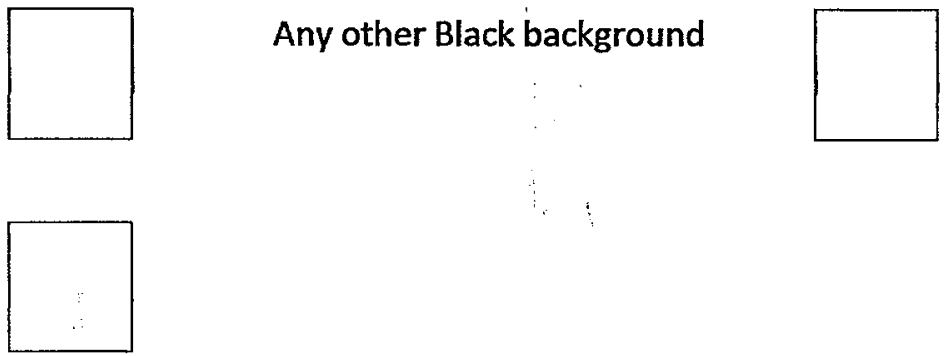


\section{Other Responses}

Not Known

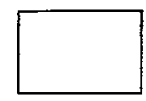

Not Known

Refuse to Comment

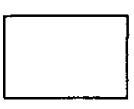




\section{Appendix 8: Consent form}


Views and experiences of family court magistrates who have been involved in care proceedings cases involving parents who have a learning disability

\section{Consent Form for Research Participants}

Participant Identification Number for this research:

Name of Researcher: Laura Kollinsky

Please initial box

I have read and understand the participant information sheet. I have had the opportunity to consider the information and ask questions. My questions have been answered satisfactorily.

I understand that my participation is voluntary and that I am free to withdraw. I do not have to give any reason for withdrawing from the study. There will be no negative consequences for me if I decide to withdraw.

I understand that data collected as part of this research project will be treated confidentially. I understand that the results will be published and that direct quotes from interviews will be used, but these will remain anonymous and I will not be identifiable.

I consent to participate in the above study.

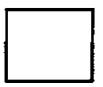

I consent to being recorded during the interview
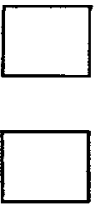

I understand that the recordings will be transcribed and destroyed at the end of the study and that the analysed data will be kept in a secure place for a period of 10 years. 


\section{Appendix 9: Ethical approval from University of Surrey Faculty of Arts and Human Sciences Ethics Committee}


Dr Adrian Coyle

Chair: Faculty of Arts and Human Sciences Ethics

Committee

University of Surrey

Laura Kollinsky

Trainee Clinical Psychologist

Department of Psychology

University of Surrey

$11^{\text {th }}$ June 2009

Dear Laura

Reference: 334-PSY-09

Title of Project: Views and experiences of family court magistrates who have been involved in care proceedings cases involving parents who have a learning disability

Thank you for your submission of the above proposal.

The Faculty of Arts and Human Sciences Ethics Committee has given favourable ethical opinion.

If there are any significant changes to this proposal you may need to consider requesting scrutiny by the Faculty Ethics Committee.

Yours sincerely

Dr Adrian Coyle 


\section{Appendix 10: Example of annotated transcript}

illustrating process of analysis 


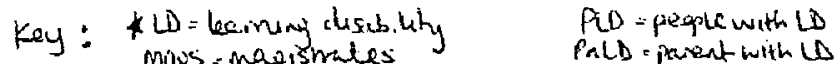

$$
\begin{aligned}
& \text { Mus - masismales } \\
& 1 \text { i: So feel free to stop me at any point and ask questions throughout } \\
& 3 \text { how you became a family court magistrate. } \\
& 4 \text { P: Um, I began as a magistrate initially through contacts; I was Nit smathung he get }
\end{aligned}
$$

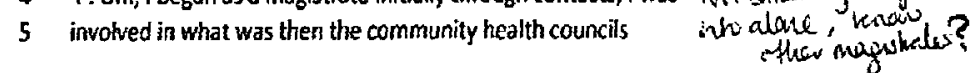

$$
\begin{aligned}
& 6 \mathrm{l}: \mathrm{mm}
\end{aligned}
$$

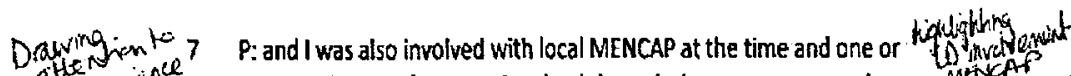

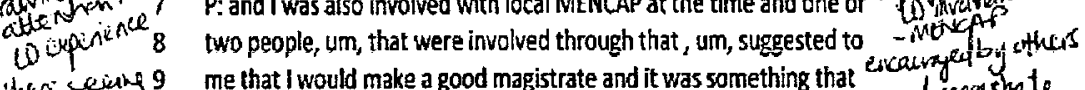

$$
\begin{aligned}
& \text { Others seines } 9 \text { me that I would make a good magistrate and it was something that excauryed a gry }
\end{aligned}
$$

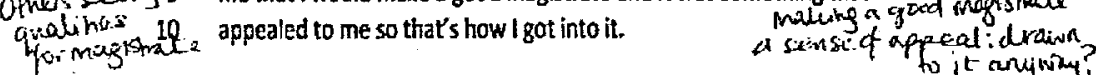

$$
\begin{aligned}
& \text { Something } 11 \mathrm{l}: \mathrm{mm} \\
& 12 \text { P: Um, once you go through the selection process to be a magistrate, hydhighing haing } \\
& 13 \text { you start off just doing adult criminal courts sctected, neteling } \\
& 14 \mathrm{l}: \mathrm{mm}
\end{aligned}
$$

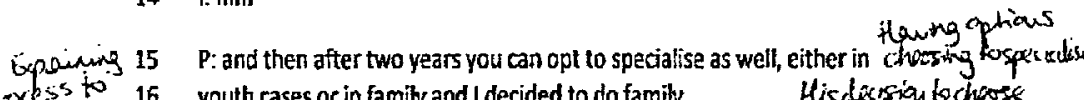

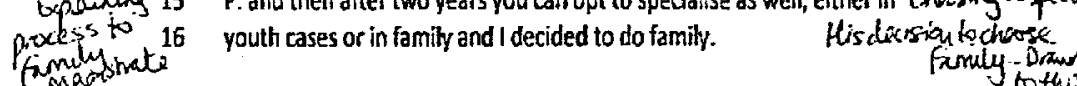

$$
\begin{aligned}
& \text { 1: And so for how long were you a magistrate in the other courts? } \\
& \text { finuly tothis. }
\end{aligned}
$$

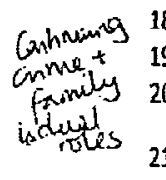

$$
\begin{aligned}
& \text { P: Well, I mean I still do the adult criminal type of work and l've been by lasugy can } \\
& \text { Cunnuing } 19 \text { a magistrate altogether for } 17 \text { years and l've been doing family for caultwe with } \\
& \text { about } 14 \text { years } \\
& \text { I: right, great, thank vou. Um, in relation to that I wondered what } \\
& \text { drew you to becoming a magistrate; what was appealing? } \\
& \text { inin kenandede. of role }
\end{aligned}
$$

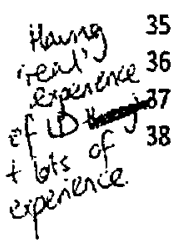

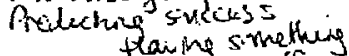

$$
\begin{aligned}
& \text { plaing simetweng }
\end{aligned}
$$


Ii right

Knowiste 40 lentryng 42 inmoly Nribereté 43

Coentains 44 impotiments

45

Loul 46 prower 47

of 1548 - whos know onge $125 ;$ Krou 49

\section{0}

51

Dfiullites 52 Redinfing 53 dis undist 54

\section{5}

Shigma 56

$+1057$

58

Pexplenth59

(1) net in 60 inainal 61 wemple

62

Inwilvimentos with LD 64

Pegul with 65 Uleogntas 66

A thine 67 in. Nimint 68

lends to 69

of haw is

Auraens 73 of hatheres 74 for 200

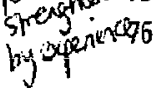

P: so it covers um, a whole variety of disabilities; difficulties with Mianeruss of

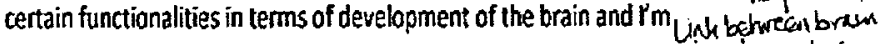
not a clinician so I don't know the clinical details

\section{l: $\mathrm{mm}$} D.aving my with ic

P: that sort of impair their ability ta learn in an educational sense ingact of a lD attenticy to hon chiniculiodoe $1: \mathrm{mm}$ Acuaingy/Apoginingfor? P: and also to um, functioning socially and to interact with other iwiareness f imponct. people which is something which is often overlooked and the way haring a dffeed bouleghe that they respond to other people

l: yep, okay and can you talk about some of the experiences you've

ingerares of to others othis uprestings fria? had working with people who have a learning disability; it doesn't have to be in the court system, it can be outside of that?

P: um, I think it's one of those areas where, you know, there may well ijat always knawing have been people with leaming disabilities that l've worked with, but leople it's not something that people generally um, are up front about iD pot a ways's l: yeah Maybe thal pesplo want io P: because of the stigma that's often attached, as separately it is with accounting for lack mentaliliness

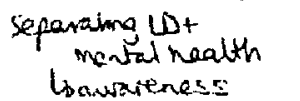
mighlighting shigna in saikely aromed $0_{\text {th }}$ Similanties in ith alt l: $m m$ P: so, um, consciously, l've not been aware that I've worked particularly in a nomal working envinonment with paople with Nof wathed will paple with 10 ; wiles he learning disabilities, although I may well have unknowingly whs vinawione drawng atterliar to paple 1: (laughs) yeah with LS not waluing in

P: but obviously l'm aware of it through working with MENCAP and The sise of doviais' the roles that we try and get them to play in the organisation terms ing highting that of participating in the way that it's run

$$
\begin{aligned}
& \text { certanny?- peoplewinh } 40 \text { wand } \\
& \text { is } 10 \text { association. } \\
& \text { feype corth iD as alleagines }
\end{aligned}
$$

l: $\mathrm{mm}$

$P$ : and also our involvement in employment schemes to try to get Difining rolo in Mix AP people with learning disabilities into work, so l'm aware of some of 's hawing 'achveress' the aspects of difficulties and challenges that they foce in interviews What hi's lcourt and things

l: $\mathrm{mm}$, and 1 was wondering when you first, kind of 1 guess became aware of what a learning disability involved?

P. Erm, again probably through the work with the local health Becomuing awart of councils back in the 1980s and then with MENCAP and through the Wover time. special school that I am chair of governors of, it hits home very much - L she of entexing awencedess. the challenges that people face

$$
\begin{aligned}
& \text { Affechng ing pavefut curveress } \\
& \text { persenally of "hit hane.. }
\end{aligned}
$$




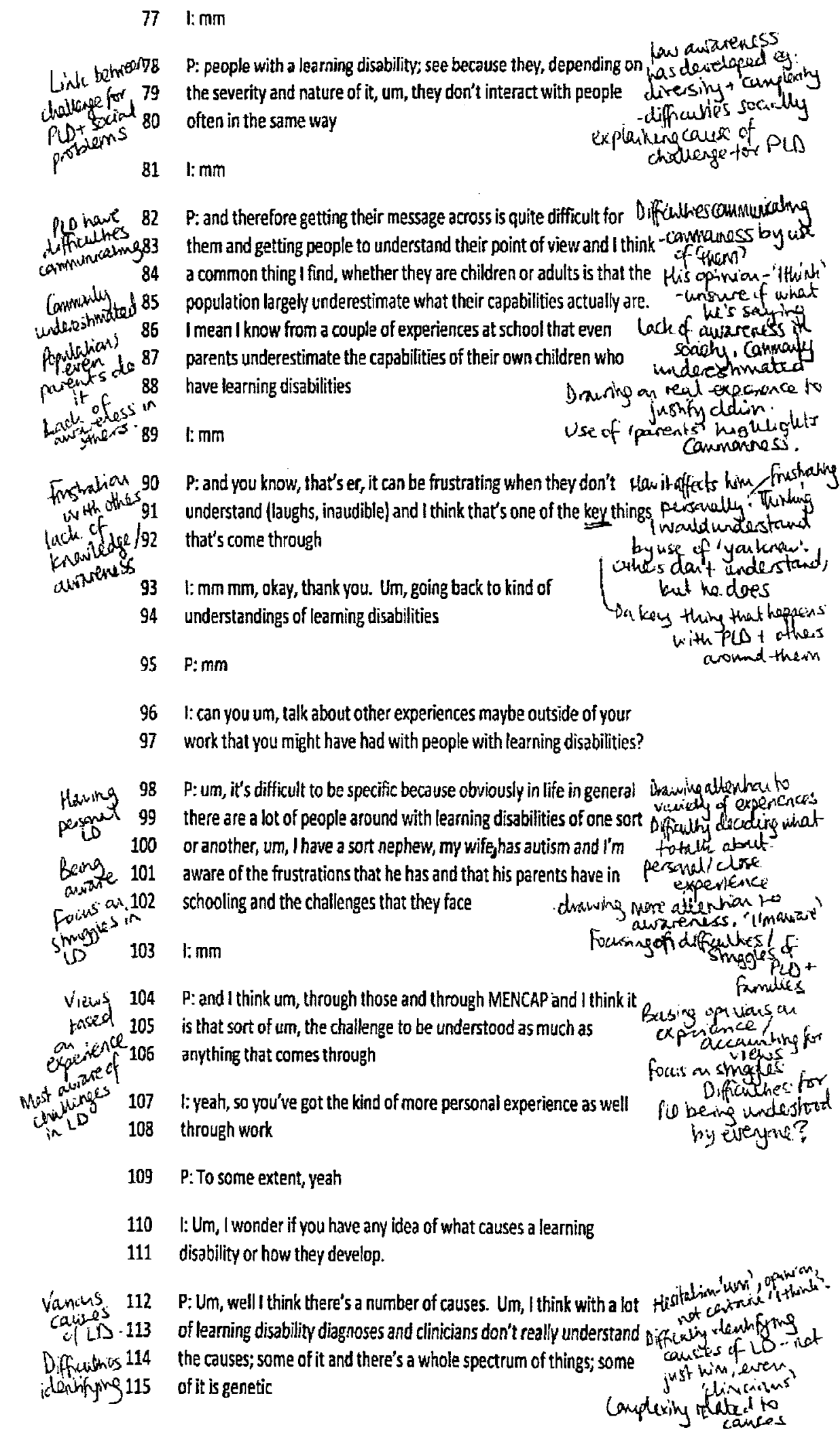


$116 \mathrm{l}: \mathrm{mm}$

Dentushimaling 117 p: um Kanvede +118

a naturet 118 nimure in 119 P: um, some of it is er believed to be caused through chemical 'beciused'.

Woghighting wocerrainty

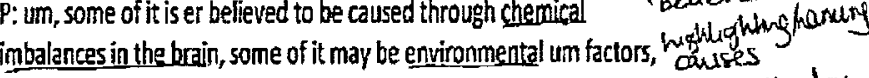

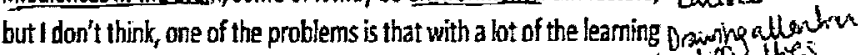
disabilities there is no definitive cause

121 I: $\mathrm{mm}$

knawivgsh 122 P: for a lot of these conditions and also again I know through some of Different caud has penence 123 the children at school that some of them will have multiple 124 disabilities so actually trying to identify one from another and what

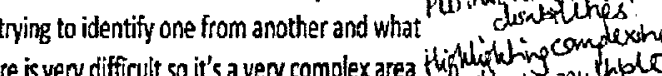

$126 \mathrm{l}: \mathrm{mm}$, yep that makes a lot of sense hearing what you're saying

$127 \quad \mathrm{P}: \mathrm{mm}$

128 I: um, I wonder if you have had any training to work with people with

129 learning disabilities, through magistrates work or outside of thak.

Senves 130

$\mathrm{P}:$ Um, I mean mainly through MENCAP um and involvement there Thuning terot in that respect so I'm not trained specifically to deal with learning

$134 \quad$ l: $\mathrm{mm}$

Formed 135 P: but obviously in the course of that you're involved in various disabilities

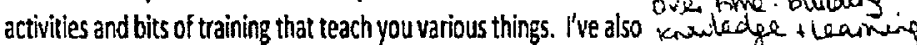
had, um, I mean it's not part of the formal training with magistrates

Wighliahthig142 P: um, and so to try and give us a bit of insight, but it's not part of the Aims ef framuig to

145 I: right, so that's something that you've arranged vourself

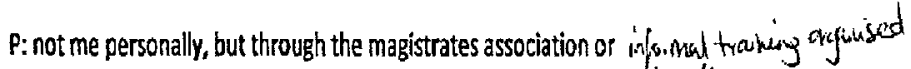

147 through the court

148 liright

Tratring 149 aums to 150 greveright 151

152

P: to bring people in with that sort of background and obviously in involuing people with other aspects as well, to try and give a little bit of understanding and better hrawhed these insight

l. and can you remember what sorts of professionals have come in to mave "Expent" Thos" to

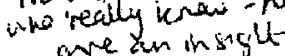
do training with you? 


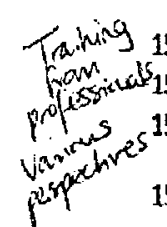

158

159

160

cakent of 161

frasing 162

Trainh 163 conthits of 165 benes

166

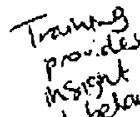
$5 \times$ we we is 10 .

\section{7} 168 469

170 prutie of fD being 17 divecther 174 cont tonge sterent 17

\section{7}

178

179

180

18

182

183

184

185

Eepinderce
of paid
in lawt sing $2+2$

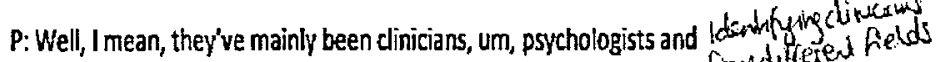
erm, psychiatrists as well. Um, some specialise in adult and some in frevr cufferen heces paediatrics varicus pesp<smiles>C1CCCCC1</smiles>

$\mathrm{l}: \mathrm{mm}$

P: so um,

I: and can you talk a little bit about maybe some of the themes of What the training involved?

P: um, it was mainty, again talking about um some of the clinical Focw ru more chini cal aspects of how for example children develop and where it goes dereheparant, canses wrong in tems of erm, when they have leaming disabilities. Again,

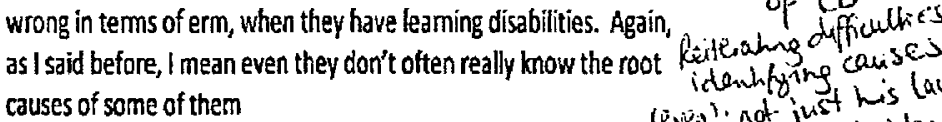
intying lach (iviz)': not just herinty l:mm

P: I mean they can identify what's happened but not why it's showing what he's loarnt. happened and again to try and provide that sort of insight as to why heing sbe to idach their behaviour may be in the way that it is

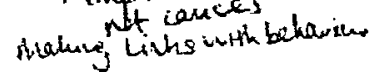

l: mm

P: and also um, where there sort of limits of functionality may be, but Lempen ibants It think the thing that comes through all the time is that it's impossible the main mes iage to generalise and that you have to treat every person as an indid he recired i it's and everson as an individual the seceated in troutury and that you can't compartmentalise people with a particular diagnosis

I: $\mathrm{mm}$, okay, so it sounds like it's been um, kind of helpful in helping

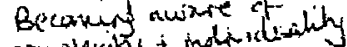
you understand vitet fo gencalise cr siesedrype bruagliagnoss

Piyes

I: the impact of having a learning dissbility

P: mm, yep

I: okay, thank you that's great. I wonder if you could think about care proceedings that you've been involved with and where a parent had a learning disability

\section{P:yep}

l: and um, either pick a case or talk generally about your experiences of these cases

187 P: Um, we do get, I have dealt with care cases where either one or Hig Whighthy ape asence 188 both parents has had a learning disability I: $\mathrm{mm}$

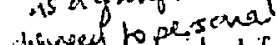
exivgen to persenentidenting 


$$
\begin{aligned}
& \text { One that stands out in }
\end{aligned}
$$

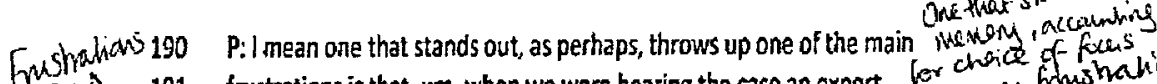

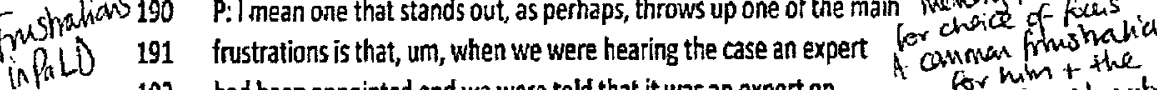

$$
\begin{aligned}
& \text { cusses } 192 \text { had been appointed and we were told that it was an expert on for him t the } \\
& \text { learning disability Experts appainted by a thews } \\
& \text { I: } \mathrm{mm}
\end{aligned}
$$

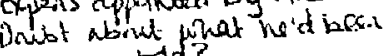

$$
\begin{aligned}
& \text { No? } \\
& \begin{array}{l}
\text { Appioving } 195 \\
\text { to be w } \\
\text { expest } 197
\end{array}
\end{aligned}
$$

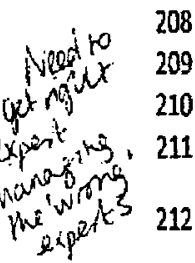

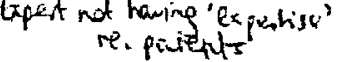

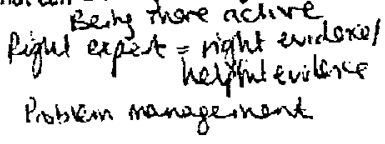

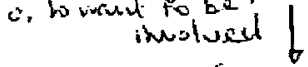

$$
\begin{aligned}
& \text { feringer }
\end{aligned}
$$

\section{P: no that's right}


230

231

lopact of 232

Winte 234

wenting 235

this for

in $\sin ^{2} \cos y^{2} 236$

$\operatorname{lin}_{2} x^{2}\left(x^{3}\right) 237$

Inthens 238

diecision 239

Gudors 240

cassider

241

sough 242

247

248

Arvare of 240 inigyeres

251

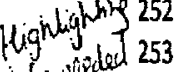

info, weles 253

from 2 exits 254

impout of 255

lom aride

257

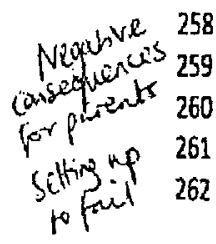

263 Problens 264

265

267
P: having two learning disabled carers - Focus on other scencemas

- different for cinild with two

P: and how that might affect them and how they would deal with it, chidd's veice, inclung

disabilities, but in other areas, where the child becomes the carer in pous a c child ns

effect and that encloses a whole new range of isssues carer - nd- anily in

limm, vep

$$
\text { impact on cluld ling vant }
$$

$P$ : and so those sort of aspects is something that we would look for defineng hachors that

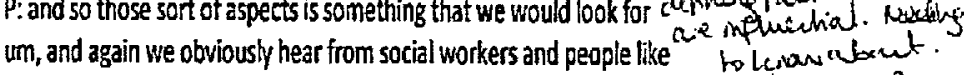
that, some of which, some of whom have had some training in those'brsinstly'. shaving areas

ithes have input 1: $\mathrm{mm}$

\section{P: but again, it's obviously much more general and not maybe social werveers inly specific, but also if the parents have a very specific leaming disability net speusust} you would need to know about that

thplyong thing avily paxide

I: mm, yeah

Neseding te know at somet

P: um

sparsice is - heywlighth

krowlietge of

I: um, could you give an example maybe of or a specific learning

disability?

P: well, you know if a parent is er autistic for example and that is 'yan knew'! obvicus he

their particular problem

Auhishic: speuficico.

l: $\mathrm{mm}$ shawing innowiedye

P: and then you need to know how that may affect their ability to what ha'd newed to hrews to relate to children and also other agencies, you know schools that malke it parest children may be involved with and the wider community and what, to Diffeest areas that child to be supported Haw is affects cieas

l:mm

$$
\begin{aligned}
& \text { reoding to } 4 \text { chulat's uife. } \\
& \text { idendfy supp it rouds to } \\
& \text { hatp pescin pirent died }
\end{aligned}
$$

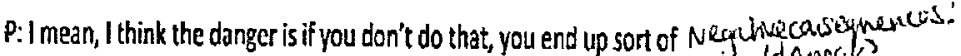
setting up the parents to fail and I think I'm always very conscious of For parents - settins to that and it is frustrating when, basically what you're trying to do is fiul = not thew frealt

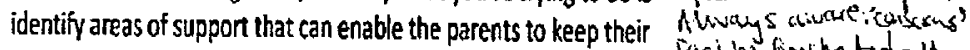
child Feeing fimshated-it

I: yeah

Tinging to help doesn't d iderinfying what

P: but it's not always easy to identify what that support actually is Haxi to identify the and then to identify when it; whose going to provide it

l: mm, so it sounds like more than just general information you'd like more specific information

$$
\begin{aligned}
& \text { 'nght snpp-d t } \\
& \text { who to gue it } \\
& \text { 'nd ensy'- } \\
& \text { couplex process, } \\
& \text { a shuggue? }
\end{aligned}
$$




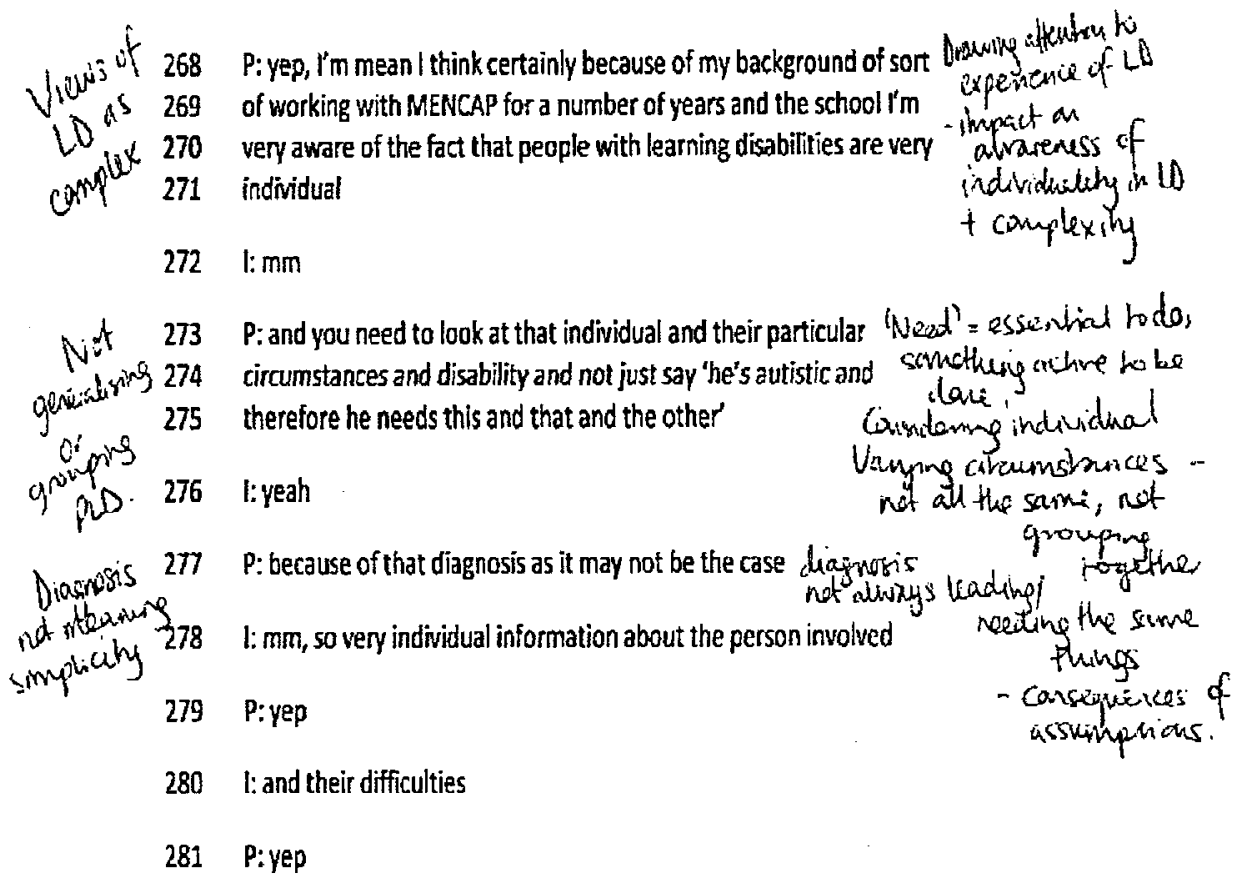<smiles></smiles>

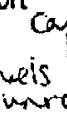

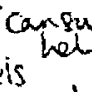

P: with a sort of realisticlevel of support supprat

idemifymy concerns of inofessionses with pll parents with learning disabisities is not, doesn't relate to abuse or wh telahig to abuise anything like that, I don't think there is, as far as i'm aware, there's Nisit awdore that 10 nathing that indicates that leaming disabled parents are any more or morejoss u lasly to less likely to abuse children than anyone else

caccoms as diferent with pais. l: $m m$

P: I think the main concern tends to be around, sort of neglect, again roflect mire canma Ple liberases

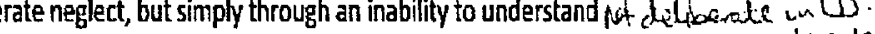
the needs of a child that's growing up. I mean not only basic, pefect a ining $\alpha$ we. sometimes basic things such as feeding. hid's ned d - me there. l: $\mathrm{mm}$ topading: sikepic essumbin? leaming disabled parents and they have tried to feed a young baby with solid food, which is obviously not appropriate and whether you can sort of educate and work with those parents to understand the needs of a child growing up, and again that comes back to the fact that it will depend on the indivicual parents and their abilities to understand and put those sort of principles into action

Neviling to havar arents simappropiste Expermence - hightght vikws based ow cancimsifeeder xhids thighlighing ulack of purents by seyply icbriensing

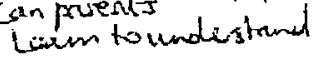
livery indivishanal 


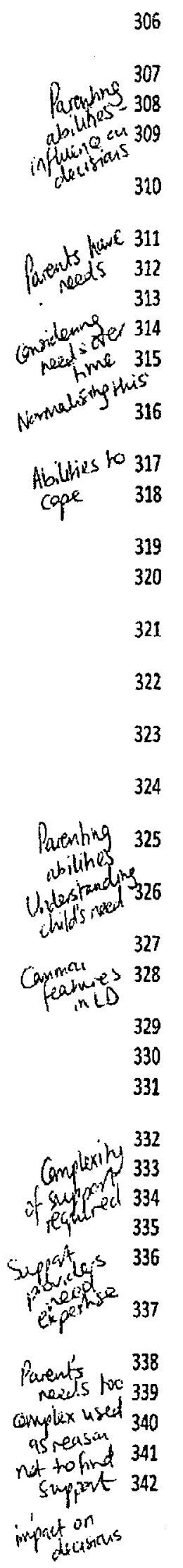

I. $\mathrm{mm}$

P: It's so soot of finaudible) in understanding and also when you've got, apart from meeting the physical needs of the child, there's also the emotional needs

1: $\mathrm{mm}$

neading to cansider

bithies to nost

phyricat tounchal. needs of chuld

P. Um and sametimes with the parent, the learning disabled parents identhrying pares's who are needy of themselves as well in terms of support and iveds fo supp particularly as children are getting older and more demanding and Mere grededs ing to gets more difficult for any parent; more challenging for any parent to deal more demaund hing with sometimes

l:yeah Parenting difficult over hime for all
pouents

P: and how their sort of, ability to cope with those sort of situations Cousidengng coping as well

I: yeah, so it sounds like maybe a simüarity across some of the cases

influence on deasions

it's about not purposeful

P: no

I: neglect or harm to the child

P: no

1: but differences linaudible)

P: It's understanding the needs of the child and how to meet them reteating fous an

I: $\mathrm{mm}$

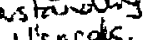

chuld'sncols.

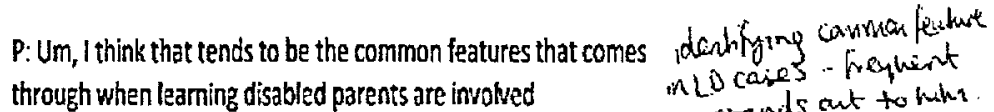
- stands out to hing.

I: $m m$, okay, thank you. Um, and I wonder if you can tell me anymore about kind of the outcome of cases that you've been involved with. 1

know that's quite hard to focus on one case

$\mathrm{P}:$ I mean I think, um, the wory is that because of the, often it, it's A coucen of his ; oc rums the fact that because the needs of learning disabled parents in any iffects him pescurally one individual in being able to support them to bring up children is to supp-t pewrent is often quite sort of complex and needs an understanding of the camplex then to people providing that support, whether it's social workers

I:yep

suppost them io

is. Compux $\therefore$ requerstise

P: or whoever, it's sort of, the temptation is to put it inte the 'too easy cphicu seuring difficult' box and say' 'okay, they can't do it' and ithink that's the logiving ine, says is that I've done, un, you come to the conclusion that the support they need isn't simply going to be there

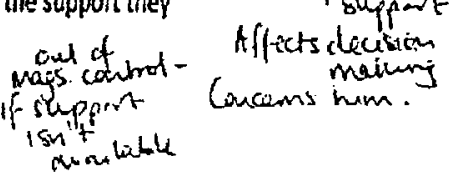




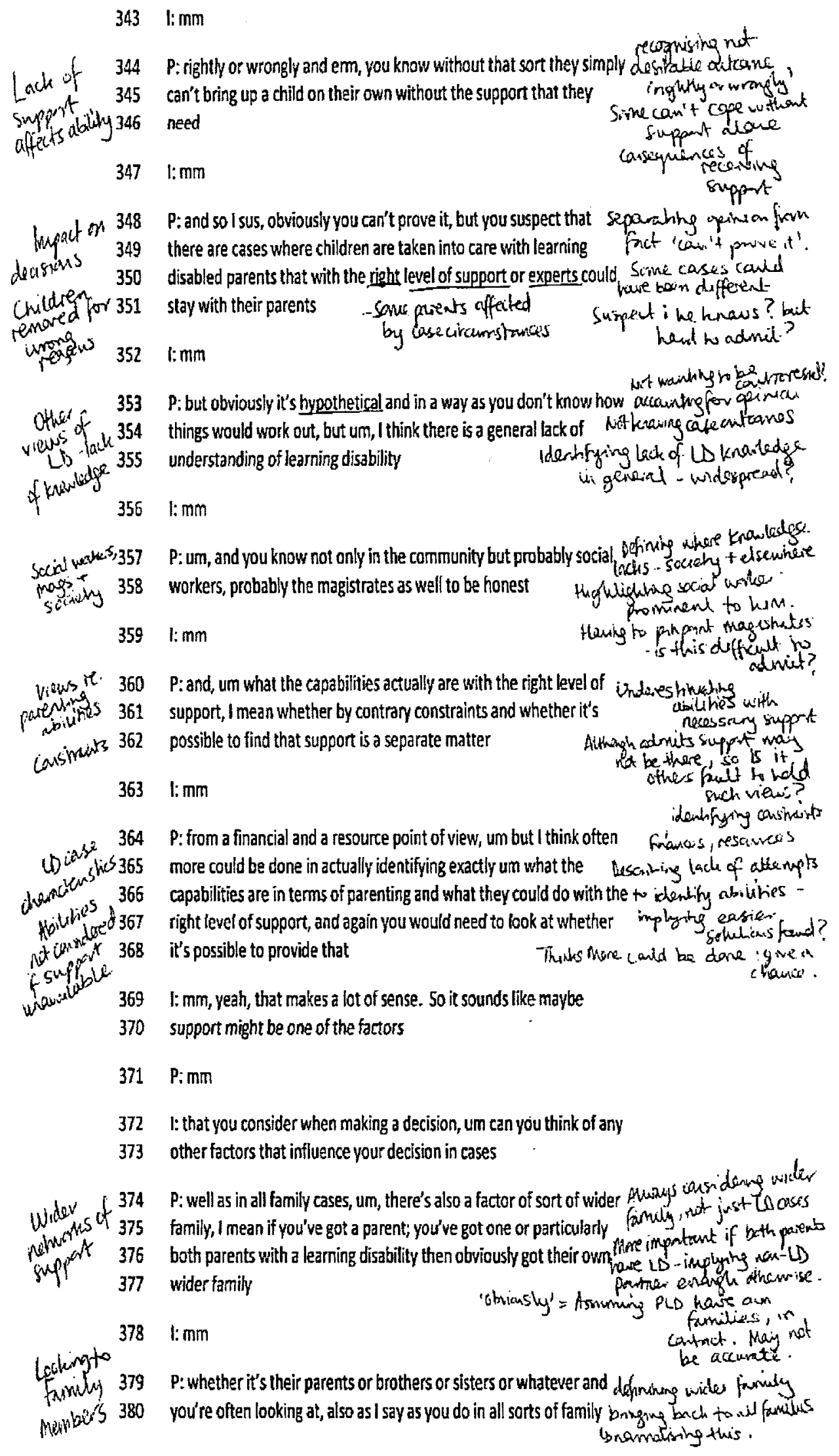




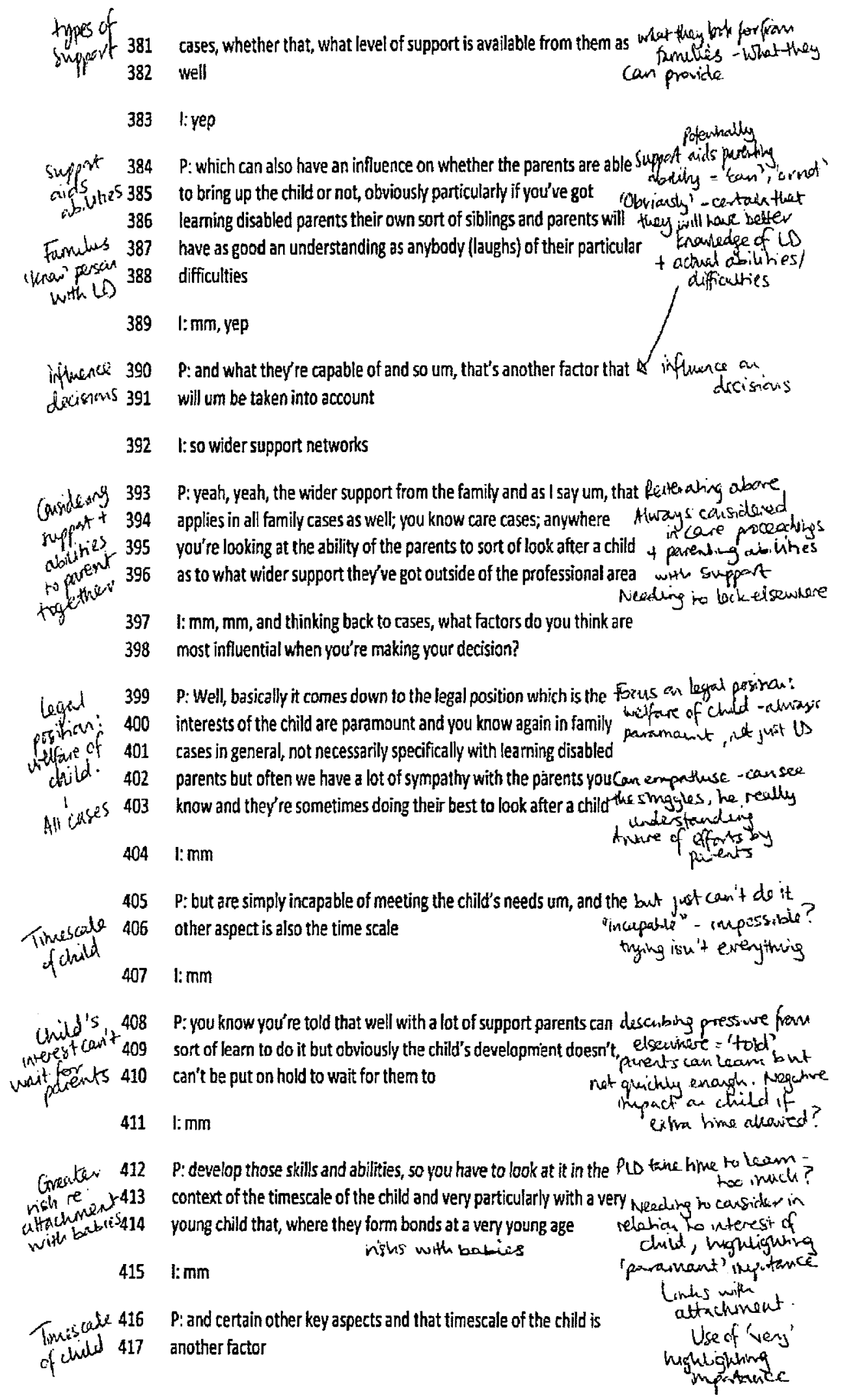


$418 \mathrm{I}: \mathrm{mm}$, okay, just in relation to that, I wonder do you have training on

419 child development and the effect of

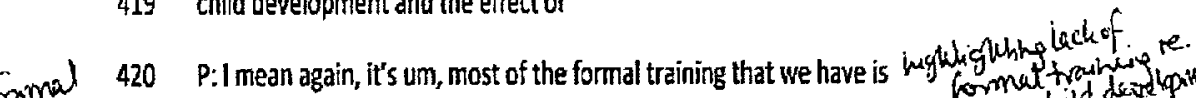

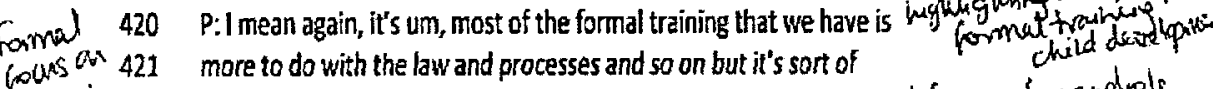
rovi

22 mixed in with that

Formul fous an lan and role

$423 \mathrm{l}: \mathrm{mm}$

424

$P$ : and sort of extra-curricular training if you like (laughs)
Net muidatory-av'exha'
not everyase racives

425 l:yep

Trainingt $426 \quad P$ : we do have to get training whether it's from social workers or Jse of 'have' - is it aidabry?

particular experts on child development; on things like, we've had Pruveles of tre-ining

training on attachment theory for example

429 l:mm, yep

demansminting

awdences's of issus

Linles with ineacet an bowds with whisien

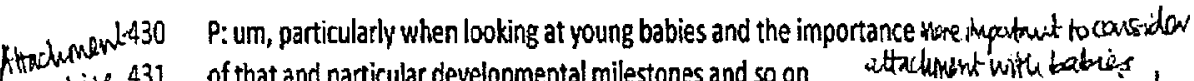

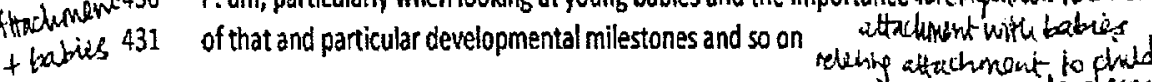

432 li:mm, okay

$433 P$ : but it, you know as I say it is a bit sort of hit and miss that it's not a

434 formal part of the training

435 l:mm, so it's not mandatory?

436 P: no, no

net maudatory

437 l: not everybody has to?

438 P: no

439 l: okay, and so are there any particular guidelines or policies that you

440 can refer to when working on a case involving a parent with learning

441 disabilities?

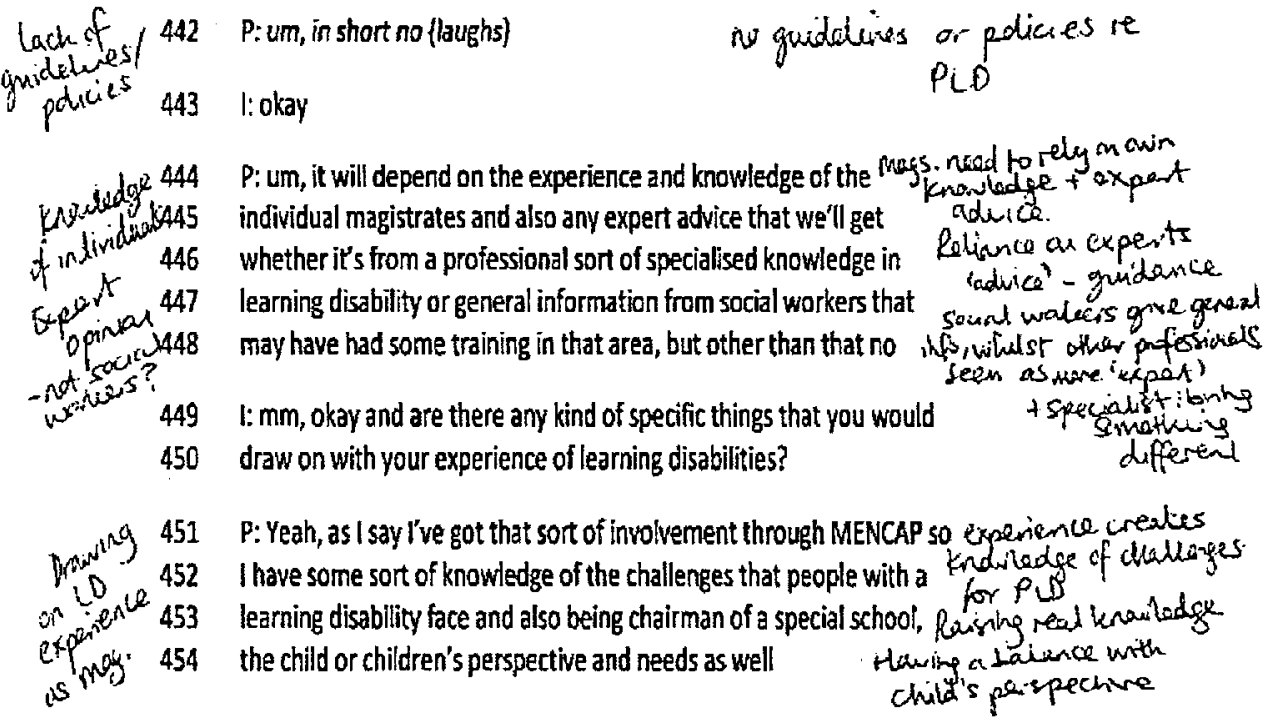




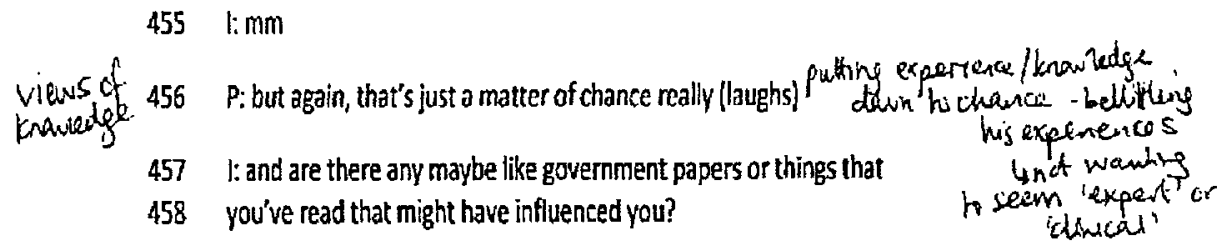

tean of 459 P: um, no Idon't think so, I wouldn't say there is specifically, I mean it not ar arere giv. papeus

1i) 460 is, as I mentioned at the beginning, it is an area that really doesn't seeing L D a rea os wided

have much; it doesn't seemed to have had much work put into it or

research and er 50 ? think there is a need for more information on it souing (D) as an 'area'

adifferent to is on. LD,

463 l: Okay and do you think in your experience that you work any

464 differently to magistrates who don't have the leaming disability

needing 3 mething

inere to do

5 experience that you do? case inelu i. LD?

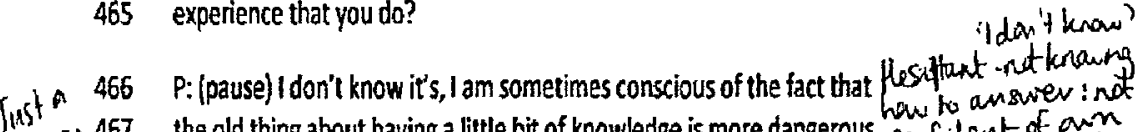

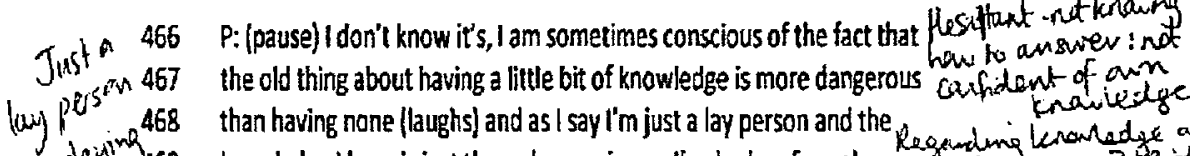
Daunploying k69 knowledge I have is just through experience; I've had no formal unhelp find to him? TRishy?

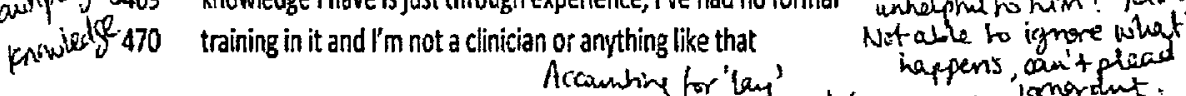

471 l: $\mathrm{mm}$

A ware 472 P: and so l'm always conscious of the limitations of trying to pretend I Aware of his timits $\begin{array}{ll}\text { of Wimils } & 473 \text { know things (laughs) when lactually don't } \\ & \text { be acts as a may? }\end{array}$ 474 I: yeah

Masp: navion

475

of $i D$

477

479

480

481

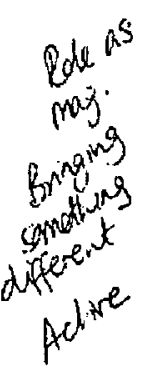
483

484

485

486

487

488

489

490

Not 491

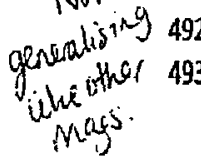

viewing lenarladfe "s:

P: so it's helpful, bet, er, the majority of magistrates that sit in family helphin. Genewalising cases don't have any, even the experience that I have and so um, abuct othe nogs, hyt

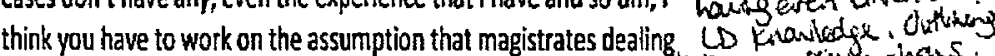
with such cases don't have any knowledes or experience "his num asswh phaces. Telling me: 'you' - aboume

I: $\mathrm{mm}$, yep and do you think you kind of view cases differently or go no knaviedigel into them differently to other magistrates? exponen they din't knai:

P: I can sometimes, not in the sense of having any preconceived ideas Net always " 'smchincs'. or, as to what the outcome might be but I'm mean sometimes, seahy cases differently. certainly sometimes I can bring that sort of, a different side, a claci not io inalu different perspective to there that I would say doesn't have a big we hai him as effect on the decision making, but I can bring a different perspective just? Bing-ring to the discussion and raise things that other people may not be aware of and perhaps also draw attention to information that we might need to know particularty again as I talked about earlier the fact that people with learning disabilities are very individual

l: $\mathrm{mm}$ preventing ithes
Sterechyping inferent side" - battle 'Other side' - bathe. Takity sides? Dow laying impact an Raising

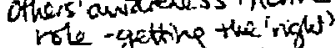
informerion.

P: and we need to know in terms of the parents about their individual dhreching the foras learning disability and capabilities rather than just adopting a broad in decision. making brush approach

$$
\begin{gathered}
\text { chenging approach- } \\
\text { preventing rssiumphows/ } \\
\text { challe.ying inacs. }
\end{gathered}
$$


494

Others 508 attindos 509 rel

510

Chessuct ioblants

Heloing then 512 mags. Giving 514 comething helphin 515

I: $m m$, okay and you don't have to answer this, but could you tell me what sort of perspective you might bring to discussions that might be a bit different or

P: um, I mean il's difficult to be specific hanst to ligighight what he does l: $\mathrm{mm}$

P: but I think again, it's just as I said before that um, we get cases that reminding intensenver,

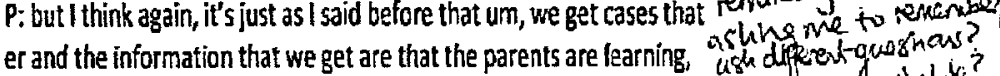
have a learning disability and my immediate reaction is 'yeah' (laughs) you krow 'yes and?' He seas bayond the whed 20 -not maluing ossubiuphous - a different liveah reachion to others.

P: you know; what learning disability, what level of functioning do Thay hht processes they have, what, whereas other people don't necessarily immediately when nececing in cases. think to go down that road

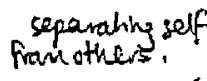

separaling self isad' Ghaing choping spontes.

others not lenavith. about consingexing Holding somplishe

$P$ : and they just have an attitude of they have a learning disability and other moss. that's it

l: $\mathrm{mm}$

generatise. Ore atsimde for all $C D$.

P: without, you know, not through any, it's just they've got no reason Not blanking mags. to know any different and so I'll tend to sort of be able raise questions that perhaps might otherwise not be asked / think is the most relevant things

l: yeah, no that's really helpful

P: yeah

inferingivel. the thishs is holpoint to raise gueshous Noreagon - paver as hose to know ajout W. They don't knaw what they dan't hears.

\section{I: it sounds like your guiding a more, a less generalised focus of} learning disabilities

P: yeah that's right

1: but being more specilic

P:yeah

l: and it sounds like you might encourage experts to be more specific, is that right?

P: yeah and I think that's what I try to do and as I say try and raise wre direchive with questions to get more information that might not otherwise in the case

l: okay, that's really helpful, thank you. Um, who do you tum to for advice or listen to for your work involving parents with learning disabilities, if anybody? 


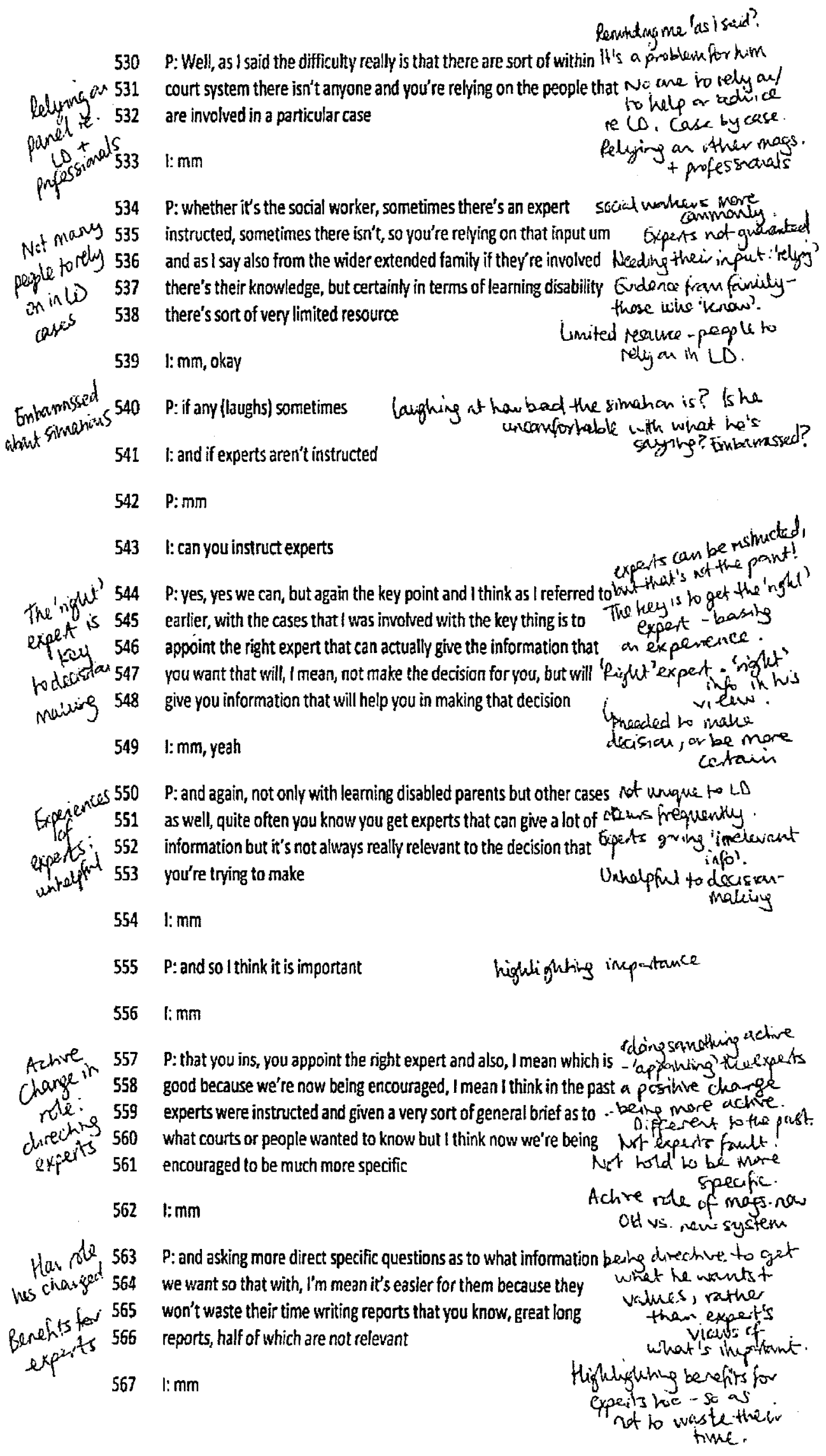


Boneftsfo' 568 mas. mp 560 ondecisis

Aclively 571 inciaranget 573

574 changeas 576 pornive 577

578

Pequesingy 581

583

Aroverping 584 rexpents.

infunces 586 on a to get 588 wre tof 588

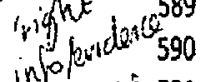
(an't aivary' 591 (andeber) 592

conitysinge 593 exhans 594

pecos on 596 based whot's jed

povid 597

Not 598

ideat 599

600

601

Parenting 602

jesy 604

indrivat 605

complex 606 l:mm
P: and also it's better for us because you know they're hopefully better system/ more answering the questions that we want

l: okay what mass. wirut. Mor caund

P: so I think we're certainly being encouraged to do more of that, I Adxinite change in rote. mean partly it's to save money but I mean it's good because rencoung ged 't 'Co, ianhly'. otherwise you're wasting people's time

Nered to di mare. frousan as money - effictent.

I: mm, yep

P: um, and um, to provide better information so I think that's a good hesitant, repehtive, thing that's happening generally and again it's not just for where whuhis to emphas sese

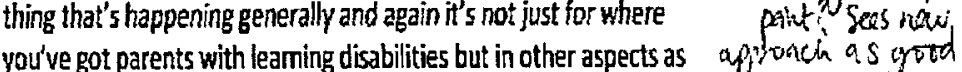

l: and if you te not given the information you need from experts can you request to have more information or is that it?

P. yes, er no we can ask for more inf if we think we don't have able ho ash for more info-ditechne rean information and try and identify where that information can best san decisia. come from

Can be directive in tioms of saines of A rete ideuhinging the 'inghl expert

P: obviously in the legal process and in the interests of the child Time reshaints clus to another aspect that we have to think about is the delay that all this child's timercale causes because in the meantime the child is sort of growing up and Musmit dolay dured all the attrchment aspects and everything, so you know we're also hot in thesi hte est. told constantly, which is quite right that we can't delay things Mare info = delay : regaive indefinitely

l: $\mathrm{mm}$ Riskinded reoustantly'. Nit Mass. Foult , but he agrees net to delay, but hishlights

P: to get every little last bit of information that we might want so at can't be (indefinitely. some point you have to say well you know realistically within the exhoushive, howe. to timescale we've got as much information as we're gonna get and accept thu 5 . Risili hes that's what we'll have to base ourdecision on of cases + eurdence they recese. Not idsal. Basingenesisias an whlet l:mm have vathe than what P: so sometimes it's not ideal but you're making a compromise in the Tush fying net deleying interest of the child in that respect deic rocliber's weifore

I: $\mathrm{mm}$, brilliant, thank you. Um, what impact, if any, do you think a learning disability has on parenting ability?

P: um, again 1 go back to my earlier responses; it really depends on Danwihg an Ear heer the individual. Um, some learning disabled parents are perfectly viows aborticitity. capable of bringing up children um, no better or worse than anybody else is

Net all PaLD urrable to pasent, not all different to P non-lis pourents lisenting spertmon. Not genowising 


$$
\text { - impact of (D) ar parening }
$$

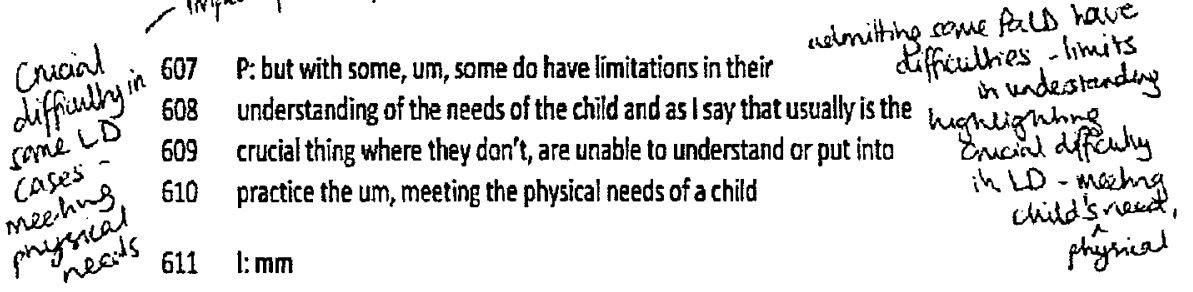

Parenting 612 P: whether it's feeding or whatever, so it basically comes back to difficullies feeduig,

prodens 613 looking at the parent as an individual and what they're able to da in but misin't gensendsing.

Pouent as 614 the interests of the child as you just can't generalise in terms of implying nocess a individucil 615 learning disability

basic approach

$616 \mathrm{~V}: \mathrm{mm}, \mathrm{okay}$, that's great and do you think this is different to parents

ie. Serith lo as individuat

617 who don't have a learning disability?

Seeing person as ubal

Lo custs 618 P: um, in some ways, um because the vast majority of cases we have, Lts of cases +

We5 619 of care cases are parents with no, or apparently with no learning expentence - rucust'

in procealings

Co.s. $\operatorname{Nan}-623$

(1) parents. 624

P: but still for whattevet reason, whether it's througher (pause) sort Cthew reassars

cesesentionsuan?

Dificuthes 625

infugung 626

of drug or alcohol problems or other reasons they are incapable of probs, not just its.

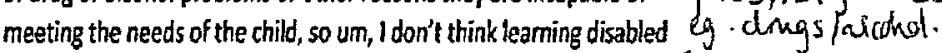

parents are any different in that respect

Save impact ey

7 I: okay, thank you and how do you view the outlook for children of meehne celld's neced

628 parents with a leaming disabbility?

$$
\begin{aligned}
& 10 \text { parents ne } \\
& r \text { : impact ar }
\end{aligned}
$$

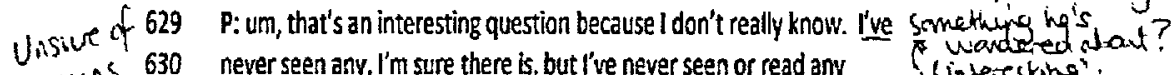
awtepincs 630 never seen any, I'm sure there bs, but t've never seen or read any "l interesting'.

for 631

Deesn't hrain what

hoidiven 632

esearth as to what those outcomes are um, because, I'm sure,

possibly more so now that there probably are more children being

Finture hodds.

brought up by

mare chuldrem

Just because hasn't

with pa 10

seen, doesn't mean

doen't exist.

$634 \mathrm{l}: \mathrm{mm}$

Thinhis must hase

(1) prets 635
mare
connow.
rant.

$P$ : in families with one or both parents or a fone parent with a mere cumman for $P Q D$ is leaming disability so I will guess that there is some research going on ho poure ws, in somewhere flaughs) mogmbarmassud not knaing? l: $\mathrm{mm}$

P: or being produced into what the outcomes are, but to be honest 1 would like to know don't know and it would be interesting to find out

I: to try and find out flaughs, okay. Um, can you tell me if anything in particular has influenced your views about the impact that a learning disablilty may have on parenting, outside of what you've told me already

P: (laughs) um, no I don't think so, I mean I think it's very tempting I think for people that have got no sort of experience or just to have ingeret an childien

\footnotetext{
Thorning now to nod experience are tempted different to him
} 


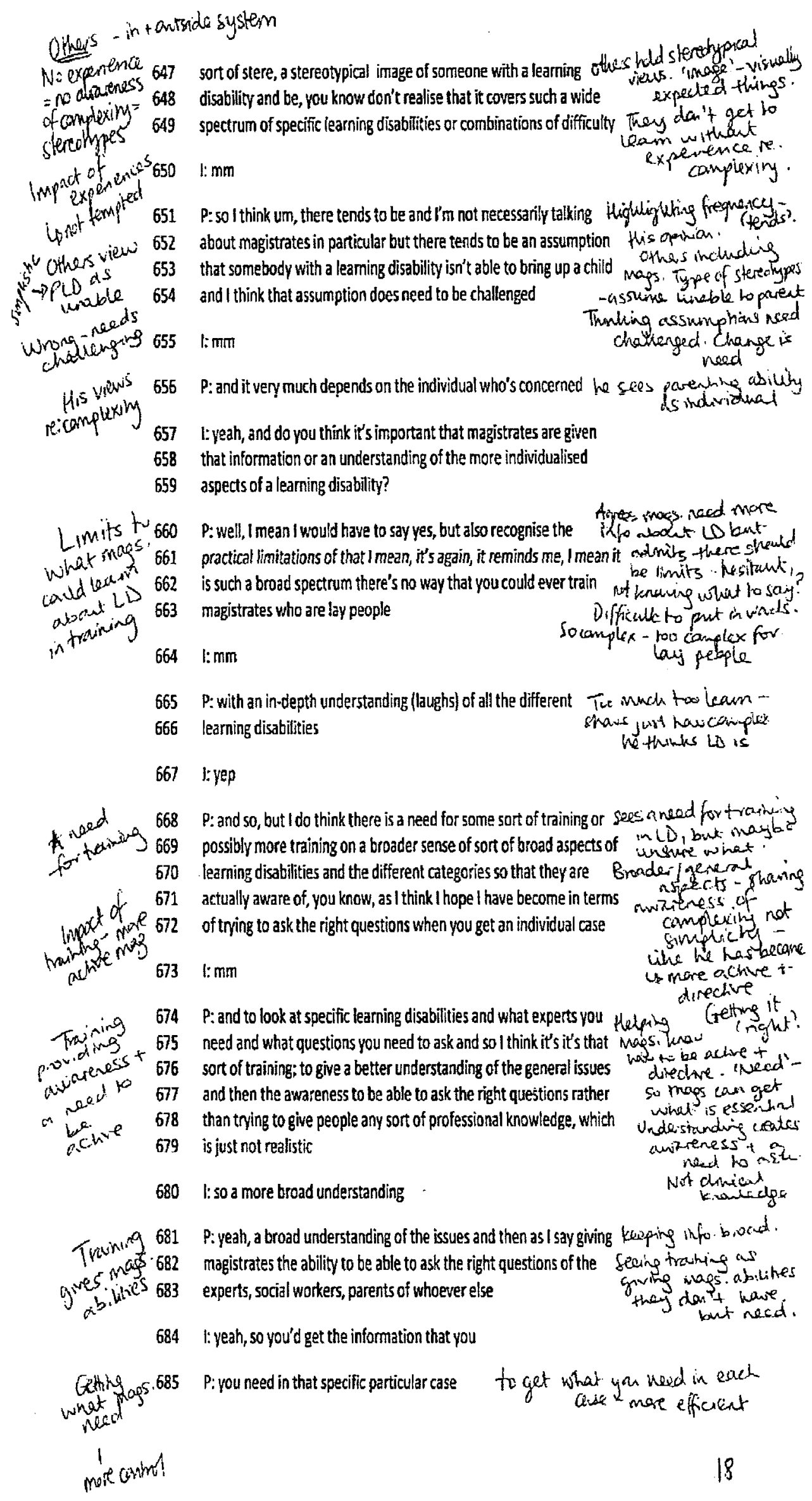


by

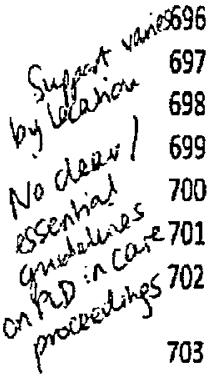
in cout 723 probablym 725 l: $\mathrm{mm}$ l:mm

I: $\mathrm{mm}$

P:yeah

$\mathrm{mm}$
I: mm, okay, thank you. Um, talking about the process that people go through in care proceedings; what parents go through, do you think you could talk about any similarities and differences that there might be if a parent has a learning disability compared to other pasents?

P: I think largely it depends on what sort of support $u$ m and resource expeninvec for PLC there is um in the local authority generally in terms of the social work on supos $A$ f what's resource; the leaming disability teams for example, what, whether they've got members that have a particular knowledge of learning disabled people as parents available-utralliy. from scuicis servicts seeine cach case os individurat too. Not alurays centam Not all to sirats have parentirgs

P: um, I think it, I suspect it varies quite a lot from authority to Uncoutain - 'Suspect'. authority and the individuals that they've got and the resources and Net deax acauss incal sol suspect that there are some areas where there is quite good um ourtrontios. Depende t

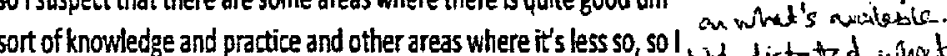
sort of knowledge and pratice and other areas where it's less 50 , so I Nit dictoted winet think it, the um aspect of learning disabled people as parents is something that isn't a prionity as far as I know (laughs) and so it will depend on whether they've got individuals there $P L$ shovida keanining forthisd(f) not essential $=$ net wor tiventain of what ke's as prianity. Pegde get lickin?

P: social workers that have that interest or knowledge singth ont specinily traned: Heici
aun interest. Upho Straff to whent to loom?

1: to the people that come in

P: Yes, I think so. I mean I think for the most part they don't do and also I mean again it's, I think as with a lot of things, the danger is that it falls between the stalls, you know is it a children's issue or is it an adult's issue<smiles>[V]=[AsH2][AsH2]</smiles><smiles>C1C[Se]CC[As]1</smiles>
lis experience-most, donth save supe ant of $p$ battle belwean carces bathe boibility : carises matey tiang? a risk. Not knawivg unosic responsible

P: You know if you've got (inaudible) as to who, what area the social worker comes into.

I: and do you think it's any different if a parent a drug or alcohol problem compared to someone who has a learning disability; the process that they go through?

P: umm, well it shouldn't be; the process shouldn't be any different Process shenidn't be and obviously you're talking about lots of different areas; problems and different areas of expertise and certainly from my experience in the court doing family cases and care cases; the problems of parents with drug or alcohol problems are far more prevalent and there's probably more knowledge of that in terms of parenting children and

$$
\text { chesents, but }
$$
of pous .h caut impuning uncataining Professionals with diffeent expelise ist erengutere

Mure expelise in ding t akshal due to more. previchence in scaely iseinces

Seoing LD as izire. underesensecheot for? 


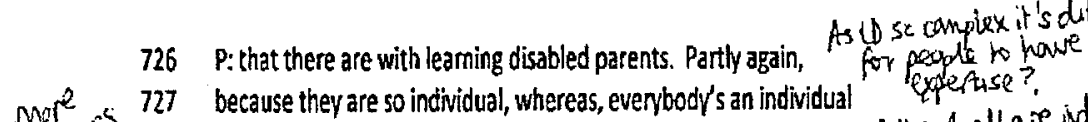

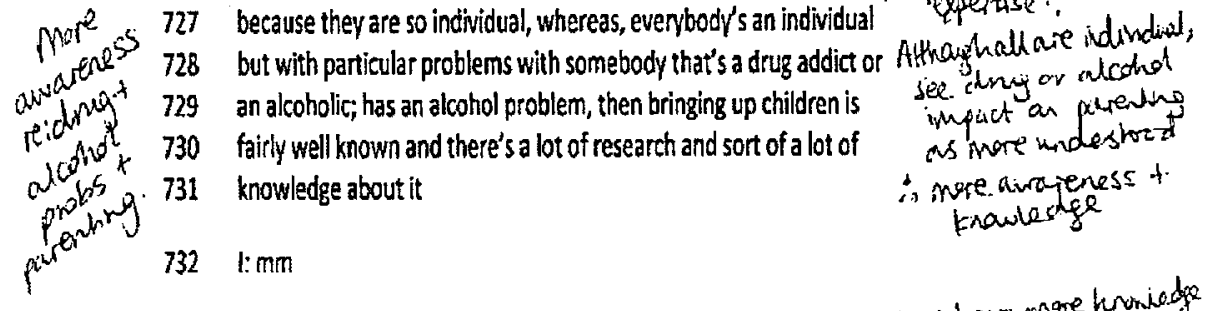

733 P: that you can apply and adapt to an individual case but I think in

learning disability that that's not generally the case

mags. howe mere turowiady

roapply to othercasts ahdous inere act 10 .

I: $\mathrm{mm}$, okay and how about maybe like how long people are given in

the cour room and things like that, is that standard for all cases?

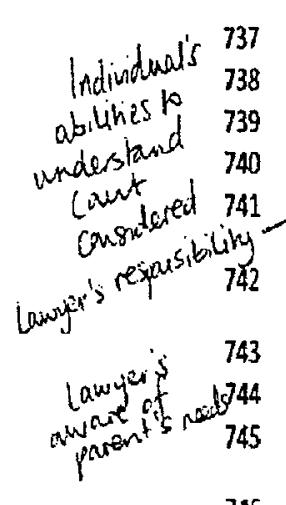

746

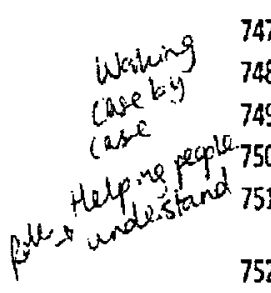

752

Al $\operatorname{mag} 5.753$

$\begin{array}{ll}\text { ast } & 755 \\ \text { ouft } & 756\end{array}$

757

758

Matis to 759

trainesith 760

wath with 761

divtising 762

maspiane
sume
suils

P: um, prob, in general yes, but obviously when you're actually sitting No speciel guidence

in court doing cases, I mean obviously you have to take account of But do cousinder's

the individuals concerned and their level of what's going on. I mean parents neseds

in care cases most, if not all parents, but most will be represented by that's a giveren? 'c istly'

a lawper

limm

Ahilines io ind cant

process impiyingert

mags respisitivy

P: who hopefully (laughst, will have some understanding of the 'hapefully' + laught - he has particular problems and aware of their needs and I don't think that's always the case but they should be

daubt, but

thinhs lacingers

should laf andatet

of parend's used

Gepares ining his dabt, lasert

$$
\text { clawighs } 5 \text { de the post partent }
$$

P: able to put their case strongly, but also if you're asking the learning disabled parents to actually give evidence in court then as with all Nist all pagpe gree again thensibiting

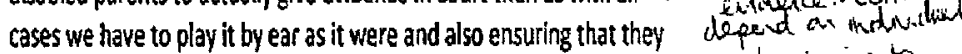
understand what is being asked and what the issues are that are Achive rote = hying to involved

I: mm and do you think other magistrates do think you're

$$
\text { lenswe parents }
$$

$P$ : er, no I think generally they do, because I mean, whether its in the

Assurithe knows ing

criminal couts or the family courts; you get a whole variety of people Net just somethe

Net quish saucticing

appearing, whether it's defendants, witnesses or parties in family

cases from a whole variety of backgrounds

$$
\begin{aligned}
& \text { inplying it's due to } \\
& \text { essemnal peepile } \\
& \text { wresing ct pert. }
\end{aligned}
$$

P: and with a whole variety of particular, I mean I wouldn't say

problems, but aspects, whether it's language; a language issue or caryoliving of issues

ability to understand or whatever so I think part of our general

training where we're used to being able to deal with and treat

different people fairly

763 I: $\mathrm{mm}$

$764 \quad P$ : and in terms of that aspect

$$
\begin{aligned}
& \text { com } \\
& \text { deateng wing in } \\
& \text { beano fair - not wrantly } \\
& \text { athor mags ho sein } \\
& \text { unfour. } \\
& \text { Defensive? } \\
& \text { Thintuing ive Misindesskad? }
\end{aligned}
$$


765 l: okay, that's very helpful, thank you. Um, just finally, can you tell

766 me about any support measures which might be in place if a parent

767 has a learning disability and they come into care proceedings?

P: um, again apart from outside of the sort of social work profession, obviaus that sociaj, but diver in say haw obviously they would be involved, I mean there are organisations such as MENCAP that are involved and will provide support generally for them or point them in the right direction to where that support is

Hiduiguts othere chid or 0 .

2 I: $\mathrm{mm}$ sumbs of suppolis he knaws they do thes. Provides

773 P: as far as court proceedings themselves are concerned; generally no guedence

774 l: okay Nit specific suppint achailly in

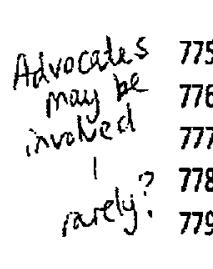

780

P: um, I mean

No exponence lumself of involving parents with leaming disabilities, they've had any specific ases with iexh support other than extended family members, well actually that's not Reainses is lintme quite right because l've had one cr two cases where one or other of thichliguts inw heinsert the parents or both of them have had an advocate of alvecates for Rue if ouby 102 ? bolse if not dear

ot usnal in molvenent

781 i: right P: but I mean, not usually but certainly that has happened once or not us wal involvenin
twice um or their own social worker frown 10 secial wovler,

783 I: yep
Si usueily ilied scied Whatei inutived?

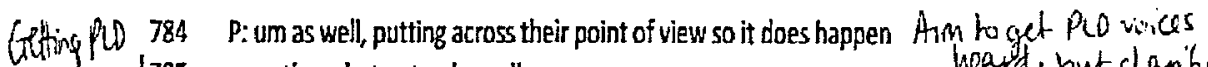
vice heand 785 sometimes but not universally.

hoard, but clanfios not coumon essential.

786 I: mm, okay. That's all my questions. I wondered if there's anything

787 you feel that I haven't asked you today or wanted to say?

Aulians 789

$788 \quad P$ P: er, no I mean you have covered a lot of the ground I think um and-Dees this imply he loud ind 790 obviously something you touched on but whether it's part of your research I don't know, is actually the um (pause) sort of knowledge and expertise of social workers when they're dealing with parenting issues and what their perspective is on it in terms of care proceedings, but I guess you're talking to social workers as welf

794 l:well

aims of what he say to ishited?

wandeng abant researich aums. Uhisit wethe to out'? wald ille to knavatiant sezial wahters

poes he infly thas wout workers often; most of them have a very good understanding and knowledge of child development issues and general issues of parenting but I think it's a bit hit and miss when it comes to learning disability

800 l: $: \mathrm{mm}$ noosts dang'.

801 P: um, so I think that's an area that could do with sort of more, um

802 l: more research?

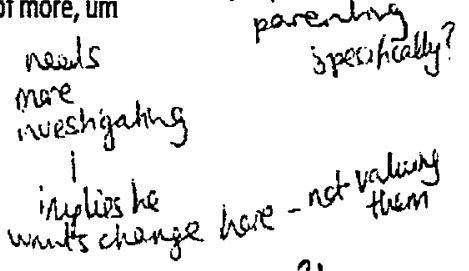


805 P: inaudible

805 I: sorry, you carry on peseanch 808

810

811

812

813

814

Sociad as 815
waters as 816
uxpeds 817

Scaid as 819

alternatre 821

rexpers 822

exp

\section{3}

824

Neding 825

jorerest 826

so input 828

. to 829

CD p 830

consons

Fivere 831

incistent 832

Inconis

$\sin \alpha^{6}$

wins 834

835

837

838

P: more research

I: $\mathrm{mm}$ in that aspect

$\mathrm{l}: \mathrm{mm}$ l:yes

workers

37 P:yes

$P$ : no, I was saying, it's always the case that whatever sort of area of umits of experenence

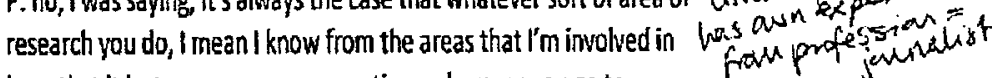

here that it just opens up more questions wherever you go to

1: yeah, there's always something else that you could be looking at. I

think that's really interesting that you bring that up and I think

research is developing with social workers, but 1 just wondered how

much social workers might influence magistrate's decision or

whether it's more expert roles that are drawn on.

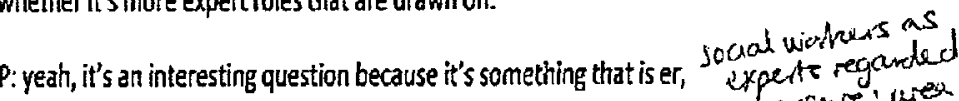
sort of talked about. I think we're generally now being encouraged os unswre: wies. more to regard social workers as experts in their own right

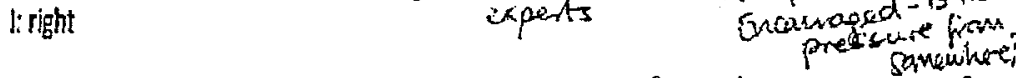
sccial warleers as jeen a changed as! Pi rather than, you know, rather than trying to call in sort of Pusked to axvid lise of independent experts or clinicians or whoever and that where experts - lised as ah possible you know, we should use the social workers as experts, even workisus alone in though their sort of maybe on one side care proceedings. Expentence of them
being biased?
sides.

P: but they are professionals and should adopt an objective Achnaulacyus shach du the approach, but obviously when it comes to ven; you know a lot of cases I think that's fine and that works but where it comes to very trying to cover if specific areas of expertise such as learning disability or mental health socel waid? or others then i think their expertise is more limited unless you happen to have one that does have a specific knowledge or training Socuat wahes as ases, bint 00 too complex for thes

P: which again as I say is a bit hit and miss

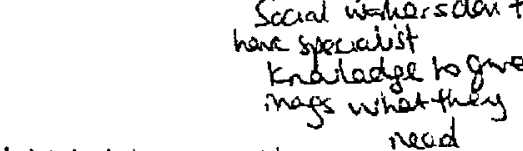

P: um, so it is in those areas where we tend to get a more expert view

I: okay, so maybe if you're not given the information from the social

I: then you'll call on an expert

will call an othes

savries if sociel werkes don't

have-shils 


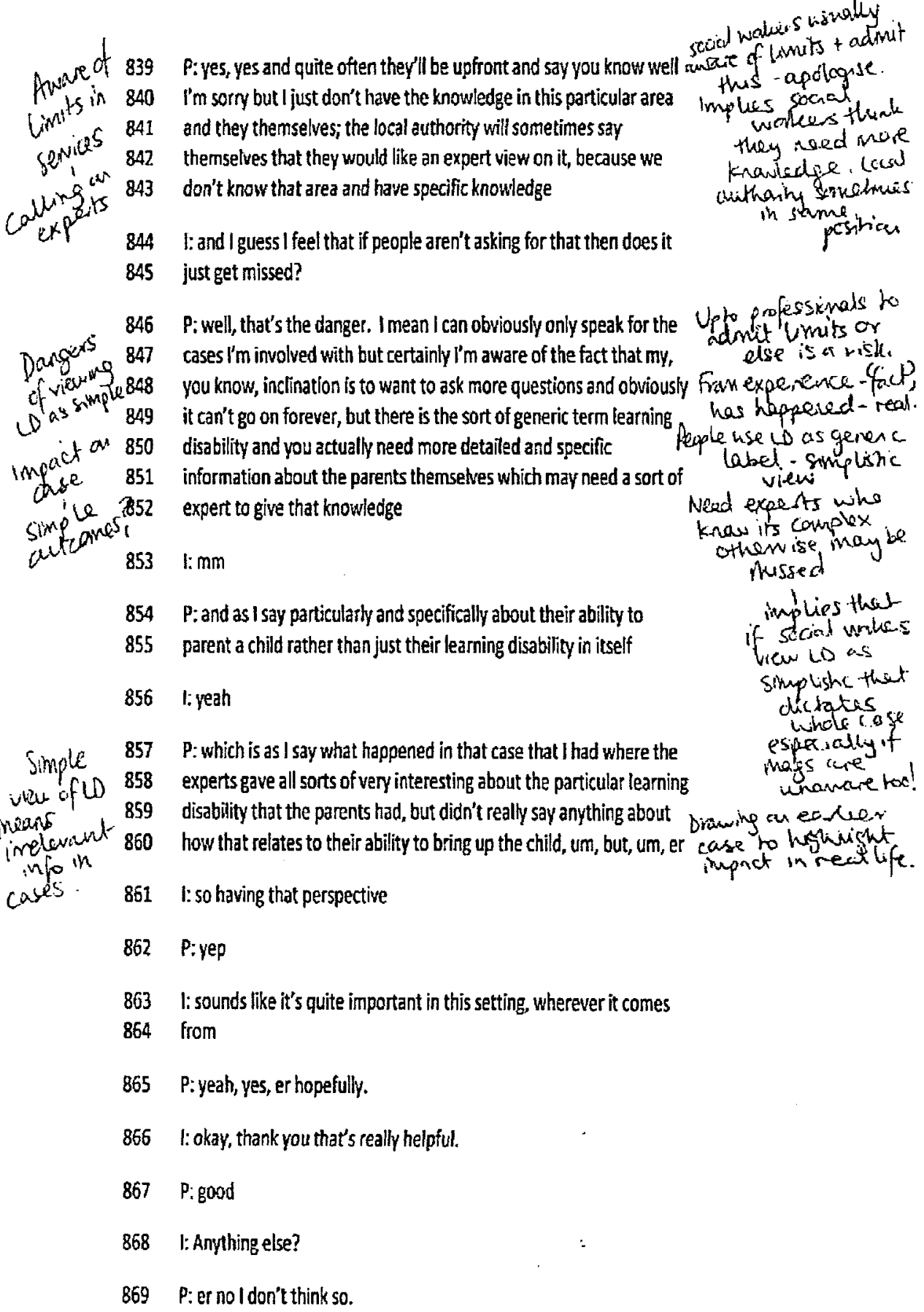




\title{
Appendix 11: Feedback
}

\author{
questionnaire
}




\section{SURREY}

Experiences of magistrates making decisions in care proceedings involving parents with learning disabilities

\section{Participant Feedback Sheet}

Late last year or earlier this year, you kindly participated in a research study investigating magistrates' experiences of making decisions in care proceedings involving parents with learning disabilities, in particular your understanding and experiences of the term 'learning disability', factors that may be influential in your decision-making and any training or guidelines that may inform your practice when being involved in such cases. I am writing to thank you again for your participation in the research and to also ask you for some feedback on the initial findings.

Four magistrates participated in the study and after I had completed interviews, I transcribed the interviews and analysed all the information to look for themes which captured what participants had spoken about. I did this using a process which involved reading and re-reading the interviews and identifying main themes to capture participants' experiences.

Enclosed with this letter is a list of these themes and I would be really grateful if you could provide any feedback about your views on these. If you would prefer for your feedback to be anonymous then please let me know and I will send you a paper copy and stamped addressed envelope so that you can return them to me. If providing feedback via email, it would be much appreciated if you could respond by $21^{\text {st }}$ June 2010 .

If you have any questions or wish to speak to me about the research or this feedback I can be contacted at:

1.kollinsky@surrey.ac.uk or 01483689441

Or you can contact Dr Laura Simonds at:

L.Simonds@surrey.ac.uk or 01483689441

Thank you again for your time

Laura Kollinsky

Trainee Clinical Psychologist 


\section{SURREY}

\section{Feedback Questionnaire}

This is a list of the themes participants talked about in relation to their experiences of making decisions in care proceedings involving parents with learning disabilities

\section{What do I need to do?}

Please read the descriptions of each theme and comment on:

i) the points you feel are a true description of your experiences

ii) the points that you do not agree with or do not represent your experiences

Then return your feedback via email or in the stamped addressed envelope once it has been sent to you.

\section{Theme 1: Positioning of people with learning disabilities as parents}

This theme relates to participants' experiences of people with learning disabilities and how they viewed them as parents i.e., their understanding of a learning disability and how this may impact on parenting. It also included participants' experiences of how they perceive other people to regard people with learning disabilities as parents. This theme included:

\section{Positioning by self:}

- Participants viewed the term 'learning disability' as covering a wide spectrum of disabilities and difficulties.

- On the whole, participants viewed people with learning disabilities as very individual and thought that they should not be compartmentalised based on a diagnosis e.g. autism. However, others thought that some groups of people with a learning disability may be similar to each other if they had the same diagnosis i.e., people with Down syndrome struggle to live independently.

- Participants regarded the impact of a learning disability on parenting to be dependent on its severity.

\section{Perceived positioning by others in the care proceedings system:}

- On the whole, participants regarded other people in the care proceedings system as being unaware that the term 'learning disability' covers a wide spectrum of disabilities and difficulties.

- On the whole, participants thought that there was a tendency for people to make generalisations about people with learning disabilities and group them together as all being the same.

- On the whole participants thought that due to a lack of understanding regarding learning disability, people in the care proceedings system may assume that people with learning disabilities are unable to parent and make generalisations about them as parents. 
- On the whole, participants thought that as a consequence, parents with learning disabilities may be 'set up to fail'. This was also related to the perceived difficulties that people in the care proceedings system had in relation to providing parents with learning disabilities with appropriate support, which had lead to some parents with learning disabilities being put in the 'too difficult' box.

\section{Perceived positioning by others:}

- On the whole participants thought that people in the community and society were unaware of the spectrum of disabilities and difficulties involved in learning disabilities.

- On the whole, participants thought that people generally had difficulty distinguishing between a learning disability and mental health issues.

- Some participants thought that people in society underestimate the abilities of people with learning disabilities and assume that they are unable to parent.

Do these themes capture your experiences and the discussions we had in our interview?

\section{Theme 2: Influences on decision-making}

This theme relates to the factors that are or have been influential in determining the welfare of the child and their decision-making in care proceedings cases involving parents with learning disabilities. Four main areas were discussed:

\section{Timescale and age of the child:}

- The need to prevent delay was influential in care proceedings and decision-making and delay was regarded as negative as this could affect the attachment/bonds that the child formed.

- Some participants thought that delay was better tolerated if the child was older as the important time frame regarding attachments/bonds had passed.

- Some participants thought that different outlooks for the child were dependent on the age of the child i.e., adoption considered sooner and more often with young babies.

- Some participants talked about the need to consider whether or not the parents could learn new skills or correct concerns within the timescale of the child.

\section{Expert opinion:}

- Experts discussed included: psychiatrists, psychologists, medical professionals, children's guardians and social workers.

- Participants explained that experts were regularly involved in care proceedings and some suggested that this was more likely if the parent 
had a learning disability as issues surrounding learning disability were viewed as more complex.

- Participants said that evidence provided by experts was influential in their decision-making and this included photographs and reports.

- Participants said that what they were told or advised by experts was influential in their decision-making.

- Participants viewed experts as being in a position to report on the circumstances for the child and the implications for their welfare.

- Some thought that the 'right' experts were not always appointed and that the most helpful information regarding decision-making was not always provided i.e., information about the learning disability but not how this related to parenting.

\section{Parenting abilities:}

- The expert opinions regarding the abilities of parents to protect and care for their children were influential in decision-making.

- Participants spoke about the need to determine if parents were able to provide 'good enough' parenting, which was regarded by some as a 'grey area' and very case specific.

- The abilities of the parent to understand and meet the child's needs were influential in decision-making.

- The abilities of parents to cope in times of stress, particularly as children got older were influential.

- Some participants talked about the need to consider the parent's abilities to learn and retain new skills in relation to their parenting.

\section{Support:}

- Participants spoke about the provision and availability of support as being influential in their decision-making.

- Some participants regarded certain levels of support required by the parents as being unrealistic or unreasonable i.e., 24 hour support. This was related by some to financial constraints that providers of support experience (such as in the local authority).

- Levels of support that were regarded as reasonable varied between participants. Some thought the occasional visit was appropriate, whilst others thought that more regular and intensive support, including teaching parents new skills was reasonable.

- Some participants explained that the necessary support was not always available to parents with learning disabilities, so efforts to look to the wider family and even others in society were often made.

- Some participants thought that there were cases that they had been involved with, where if the 'right' support had been available the child could have remained with their parents.

Do these themes capture your experiences and the discussions we had in our interview? 


\section{Theme 3: Self-characterisation within the system}

This theme relates to the way that the participants appeared to characterise themselves within the care proceedings system. It included how magistrates viewed their level of knowledge and understanding regarding learning disabilities, the various roles that they adopt within the system and their views about training regarding people with learning disabilities. This theme included:

\section{Knowledge}

- On the whole participants presented themselves as lay people with no clinical knowledge regarding learning disabilities.

- Most participants acknowledged how much they thought they did not know about learning disabilities due to the wide spectrum of difficulties they regarded the term to cover.

- Although some participants regarded their knowledge as being limited, others did not present themselves this way and seemed to have a more in-depth knowledge, due to their background of working with people with special educational needs.

- Those participants with more experience of people with learning disabilities acknowledged that it was likely that they had more knowledge and experience about learning disabilities than most other magistrates they have been involved with.

\section{Role as a magistrate}

- Those magistrates with more experience of learning disabilities seemed to regard themselves as being able to bring something different to care proceedings as a result of their experience i.e., drawing attention to information that may be missing from experts, especially regarding the individual nature of learning disabilities and how this affects the person as a parent.

- These participants also seemed to regard themselves as adopting a more active role in care proceedings; directing experts more in terms of the information they require and questioning the information they bring.

- Some participants did not highlight this active role and seemed to suggest that they take on a more passive role; taking advice from experts.

Training

- Participants acknowledged that they do not receive any mandatory training regarding people or parents with learning disabilities.

- On the whole, participants thought that there was a need for training in this area, especially regarding the spectrum of difficulties involved in learning disabilities and how to be involved with people with learning disabilities in care proceedings.

- These participants thought that training would help magistrates to position people with learning disabilities differently i.e., not seeing them as all the same and help them to be involved with experts in a more active way. 
- Some participants did not seem to think that there was a need for training as it is the expert's role to have specialist knowledge and not the magistrates.

Do these themes capture your experiences and the discussions we had in our interview?

\section{Overall Comments:}

Do you have any overall comments on the themes identified in the research study?

Was there anything that surprised you, or are the results as you expected?

\section{Thank you again for taking part in this study}




\section{Research Log}




\begin{tabular}{|c|c|}
\hline Research Log & \\
\hline 1. Formulating and testing hypotheses and research questions & $\overline{\mathbf{V}}$ \\
\hline $\begin{array}{l}\text { 2. Carrying out structured literature search and literature search } \\
\text { tools }\end{array}$ & $\mathbf{V}$ \\
\hline $\begin{array}{l}\text { 3. Critically reviewing relevant literature and evaluating research } \\
\text { methods }\end{array}$ & $\sqrt{ }$ \\
\hline 4. Formulating specific research questions & $\mathbf{v}$ \\
\hline 5. Writing brief research proposals & $\mathbf{v}$ \\
\hline 6. Writing detailed research proposals/protocols & $\sqrt{ }$ \\
\hline $\begin{array}{l}\text { 7. Considering issues relating to ethical practice in research, } \\
\text { including issues of diversity and structuring plans accordingly }\end{array}$ & $\mathbf{v}$ \\
\hline 8. Obtaining approval from a research ethics committee & $\sqrt{ }$ \\
\hline 9. Obtaining appropriate supervision for research & $\mathbf{v}$ \\
\hline 10. Obtaining appropriate collaboration for research & $\mathbf{v}$ \\
\hline 11. Collecting data from research participants & $\mathbf{v}$ \\
\hline 12. Choosing appropriate design for research questions & $\sqrt{ }$ \\
\hline 13. Writing patient information and consent forms & $\mathbf{v}$ \\
\hline 14. Devising and administering questionnaires & $\sqrt{ }$ \\
\hline 15. Negotiating access to study participants in applied NHS settings & $\sqrt{ }$ \\
\hline 16. Setting up a data file & $\mathbf{V}$ \\
\hline 17. Conducting statistical data analysis using SPSS & $\mathbf{v}$ \\
\hline 18. Choosing appropriate statistical analysis & $\boldsymbol{v}$ \\
\hline 19. Preparing quantitative data for analysis & $\sqrt{ }$ \\
\hline 20. Choosing appropriate quantitative data analysis & $\sqrt{\mathbf{V}}$ \\
\hline 21. Summarizing results in figures and tables & $\sqrt{ }$ \\
\hline 22. Conducting semi-structured interviews & $\sqrt{ }$ \\
\hline $\begin{array}{l}\text { 23. Transcribing and analysing interview data using qualitative } \\
\text { methods }\end{array}$ & $\sqrt{ }$ \\
\hline 24. Choosing appropriate qualitative analysis & $\sqrt{ }$ \\
\hline 25. Interpreting results from quantitative and qualitative data & $\sqrt{ }$ \\
\hline
\end{tabular}




\begin{tabular}{|l|l|}
\hline analysis & \\
\hline 26. Presenting research findings in a variety of contexts & $\mathrm{V}$ \\
\hline 27. Producing a written report on a research project & $\mathrm{V}$ \\
\hline 28. Defending own research decisions and analysis & $\mathrm{V}$ \\
\hline $\begin{array}{l}\text { 29. Submitting research reports for publication in peer-reviewed } \\
\text { journals or edited book }\end{array}$ & \\
\hline 30. Applying research findings to clinical practice & $\mathrm{V}$ \\
\hline
\end{tabular}

